This document was prepared in conjunction with work accomplished under Contract No. DE-AC09-96SR18500 with the U. S. Department of Energy.

\title{
DISCLAIMER
}

This report was prepared as an account of work sponsored by an agency of the United States Government. Neither the United States Government nor any agency thereof, nor any of their employees, nor any of their contractors, subcontractors or their employees, makes any warranty, express or implied, or assumes any legal liability or responsibility for the accuracy, completeness, or any third party's use or the results of such use of any information, apparatus, product, or process disclosed, or represents that its use would not infringe privately owned rights. Reference herein to any specific commercial product, process, or service by trade name, trademark, manufacturer, or otherwise, does not necessarily constitute or imply its endorsement, recommendation, or favoring by the United States Government or any agency thereof or its contractors or subcontractors. The views and opinions of authors expressed herein do not necessarily state or reflect those of the United States Government or any agency thereof. 


\section{DWPF FLOWSHEET STUDIES WITH SIMULANTS TO DETERMINE MODULAR CAUSTIC SIDE SOLVENT EXTRACTION UNIT SOLVENT PARTITIONING AND VERIFY ACTINIDE REMOVAL PROCESS INCORPORATION STRATEGY}

C.C. Herman

M.F. Williams

S.L. Crump
A.R. Marinik
T.L. White
D.R. Best
E.K. Hansen

March 2006

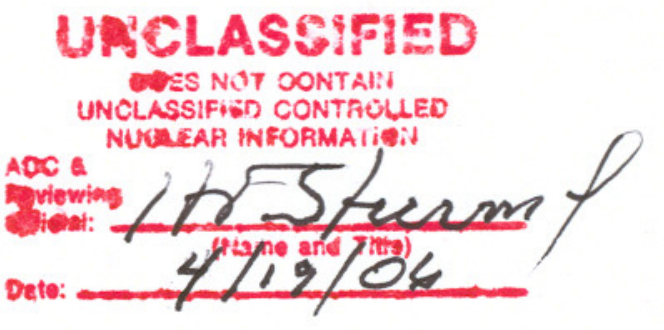

Process Science \& Engineering Section Savannah River National Laboratory Aiken, SC 29808 


\section{DISCLAIMER}

This report was prepared by Washington Savannah River Company (WSRC) for the United States Department of Energy under Contract No. DE-AC0996SR18500 and is an account of work performed under that contract. Neither the United States Department of Energy, nor WSRC, nor any of their employees makes any warranty, expressed or implied, or assumes any legal liability or responsibility for the accuracy, completeness, or usefulness, of any information, apparatus, or product or process disclosed herein or represents that its use will not infringe privately owned rights. Reference herein to any specific commercial product, process, or service by trademark, name, manufacturer, or otherwise does not necessarily constitute or imply endorsement, recommendation, or favoring of same by WSRC or by the United States Government or any agency thereof. The views and opinions of the authors expressed herein do not necessarily state or reflect those of the United States Government or any agency thereof.

\section{Printed in the United States of America \\ Prepared For U.S. Department of Energy}


Key Words: Sludge, ARP, MCU, Salt, DWPF, Solvent

Retention: Permanent

\section{DWPF FLOWSHEET STUDIES WITH SIMULANTS TO DETERMINE MODULAR CAUSTIC SIDE SOLVENT EXTRACTION UNIT SOLVENT PARTITIONING AND VERIFY ACTINIDE REMOVAL PROCESS INCORPORATION STRATEGY}

C.C. Herman

M.F. Williams

S.L. Crump

A.R. Marinik

T.L. White

D.R. Best

E.K. Hansen

March 2006 


\section{REVIEWS AND APPROVALS}

\section{AUTHORS:}

comme ctouman

C.C. Herman, Process Science \& Engineering Section

Mal 7. Willians

M.F. Williams, Process Science \& Engineering Section

$$
\sum L
$$

S.L. Crump, Analytical Development

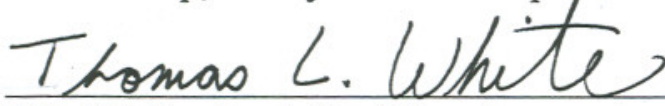

T.L. White, Analytical Development

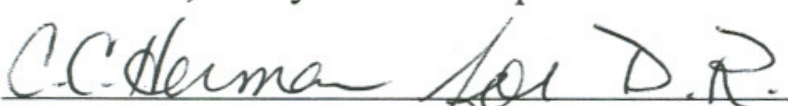

D.R. Best, Process Science \& Engineering Section

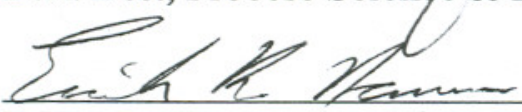

E.K. Hansen, Process Science \& Engineering Section

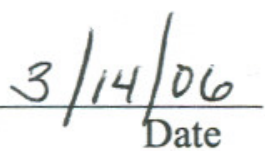

$3 / 14 / 06$

Date
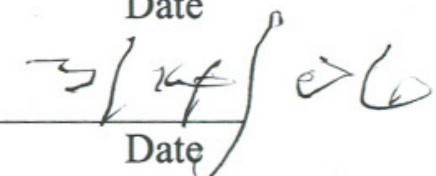

\section{TECHNICAL REVIEWER:}

\section{MQA AL}

M.E. Stone, Process Science \& Engineering Section L Lnana

S.L. Marra, Manager, Remote Specialty Equipment Section
$3 / 14 / 06$

Date

$3 / 14 / 06$

Date

\section{APPROVERS:}

Ricinds

R.E. Edwards, Manager, Process Science \& Engineering Section

$\frac{3 / 14 / 06}{\text { Date }}$

J.E. Occhipinti, Manager, Process Cognizant Engineering

Waste Solidification Engineering 


\section{EXECUTIVE SUMMARY}

The Actinide Removal Process (ARP) facility and the Modular Caustic Side Solvent Extraction Unit (MCU) are scheduled to begin processing salt waste in fiscal year 2007. A portion of the streams generated in the salt processing facilities will be transferred to the Defense Waste Processing Facility (DWPF) to be incorporated in the glass matrix. Before the streams are introduced, a combination of impact analyses and research and development studies must be performed to quantify the impacts on DWPF processing. The Process Science \& Engineering (PS\&E) section of the Savannah River National Laboratory (SRNL) was requested via Technical Task Request (TTR) HLW/DWPF/TTR-2004-0031 ${ }^{1}$ to evaluate the impacts on DWPF processing.

Simulant Chemical Process Cell (CPC) flowsheet studies have been performed using previous composition and projected volume estimates for the ARP sludge/monosodium titanate (MST) stream. ${ }^{2,3}$ Due to changes in the flammability control strategy for DWPF for salt processing, the incorporation strategy for ARP has changed and additional ARP flowsheet tests were necessary to validate the new processing strategy. The last round of ARP testing included the incorporation of the MCU stream and identified potential processing issues with the MCU solvent. ${ }^{3}$ The identified issues included the potential carry-over and accumulation of the MCU solvent components in the CPC condensers and in the recycle stream to the Tank Farm. Therefore, DWPF requested SRNL to perform additional MCU flowsheet studies to better quantify the organic distribution in the CPC vessels.

The previous MCU testing used a Sludge Batch 4 (SB4) simulant since it was anticipated that both of these facilities would begin salt processing during SB4 processing. The same sludge simulant recipe was used in this round of ARP and MCU testing to minimize the number of changes between the two phases of testing so a better comparison could be made. ARP and MCU stream simulants were made for this phase of testing. The ARP stream represented the sludge/MST stream from Appendix E of the material balance provided by Subosits ${ }^{7}$. The MCU stream represented the "Maximum Volume" case from the material balances provided by Campbell ${ }^{6}$. The latest DWPF processing plan involves adding the ARP stream to the sludge at boiling in the Sludge Receipt and Adjustment Tank (SRAT). This would be accomplished before the SRAT receipt sample is taken and SRAT processing is initiated. The MCU stream will be added at boiling during the normal reflux phase of the SRAT cycle. The SRAT cycle will be considered complete once the MCU stream has been added. SRNL replicated this processing strategy in this testing.

A total of five 4-liter SRAT runs were performed to meet the objectives of the testing. The first two tests specifically evaluated the ARP processing strategy, while all five runs attempted to determine the organic material balance. The first three runs targeted a solvent concentration of $239 \mathrm{ppm}$, which represented the DWPF estimated maximum concentration of Isopar ${ }^{\circledR} \mathrm{L}$ that could be processed, and the last two targeted a solvent concentration of $50 \mathrm{ppm}$ which is close to the nominal concentration anticipated in the effluent from the Salt Waste Processing Facility (SWPF). For the first SRAT run of this series, the organic solvent used in the testing was the same as that used in earlier testing and contained the four organic components $(0.007 \mathrm{M}$ BOBCalixC6, $0.75 M$ Cs-7SB modifier, $0.003 M$ tri-n-octylamine (TOA), and the diluent Isopar ${ }^{\circledR} \mathrm{L}$ ). For the other four tests, a solvent fabricated by the Chemical Science \& Technology section was used ${ }^{8}$. BOBCalixC6 was not added to this solvent due to the high cost and limited availability. All runs targeted $150 \%$ acid stoichiometry and $1 \mathrm{wt} \% \mathrm{Hg}$ in the sludge slurry dried solids after the incorporation of ARP. One of the runs had a higher acid stoichiometry due to operator error in programming the acid addition pump, which had minimal impact on the processing and testing objectives. In the previous MCU testing, only the condensates, SRAT product, and rinses of the SRAT equipment were monitored for organics. The assumption was that the remaining organic was emitted as vapor after passing trough the Formic Acid Vent 
Condenser (FAVC). To help close the material balance in this set of runs, carbon tubes were installed at the SRAT offgas exit to collect any organics emitted.

The significant findings of the lab-scale experiments related to the revised ARP processing strategy were as follows:

- Neither nitrite destruction nor mercury reduction was impacted by ARP incorporation compared to SB4 only processing and earlier ARP/MCU runs.

- The $\mathrm{pH}$ profiles during SRAT processing were not impacted. The $\mathrm{pH}$ remained relatively high (between 9-10) during ARP incorporation.

- The carbon dioxide, nitrous oxide, and nitric oxide generation rates were comparable to previous testing, with none of the gases generated during ARP addition.

- Based on the simulants (sludge, ARP, and MCU) used and the ARP and MCU addition amounts tested, no foaming or processing issues such as air entrainment were identified. Some problems with ARP solids settling was experienced during the lab-scale testing in the transfer line. Although the feed rate was scaled to the DWPF addition rate, the pumping system used was not necessarily prototypic of the DWPF addition system. Small scale pumping systems, such as those related to the CPC, are not very representative of the larger scale DWPF system. The settling of the ARP solids may be an issue that needs to be addressed by DWPF engineering.

The organic analyses and material balances suggest the following:

- The highest concentration of Isopar ${ }^{\circledR} \mathrm{L}$ was found at the offgas exit as indicated by analysis of the carbon tubes from the runs. The recovery on the carbon tubes ranged from 33 to $92 \%$ with higher recoveries found in later runs as changes were made in processing and rinsing to enhance capture of the solvent and in the analytical protocol.

- $\quad$ Isopar ${ }^{\circledR} \mathrm{L}$ was found to collect in both the Mercury Water Wash Tank (MWWT) and the FAVC to a very small extent (i.e., $<1 \%$ of the total Isopar ${ }^{\circledR} \mathrm{L}$ in each case). Of this small quantity, appreciably more Isopar ${ }^{\circledR} \mathrm{L}$ was found in the vessel rinses versus the actual condensate samples. The starting solvent concentration did not appear to have a direct impact on the amount condensed in the SRAT system at the levels tested.

- While complete Isopar ${ }^{\circledR} \mathrm{L}$ recovery did not occur in every test, the low concentration results were repeatable from run to run and suggest that the amount of Isopar ${ }^{\circledR} \mathrm{L}$ condensed by the SRAT and vent condensers should be low during SRAT processing (i.e., $<1 \%$ of the total Isopar ${ }^{\circledR} \mathrm{L}$ ).

- Modifier was found in the MWWT, the SRAT condenser rinse, and in the SMECT condensate. Roughly half of the added modifier remained in the SRAT product or in the SRAT kettle. From a flammability perspective, Isopar ${ }^{\circledR} \mathrm{L}$ represents more of a concern than the modifier to DWPF due to the differences in the lower explosive limits. However, the amount of modifier remaining in the SRAT product must be taken into account when considering the redox control strategy and potential melter flammability issues.

- The material balance closure for modifier was much better in this series of testing compared to previous testing after adjustments were made to the SRAT equipment and analytical protocol. The recovery ranged from $\sim 81$ to $100 \%$. This closure was considered acceptable due to the uncertainty in the small masses and analytical methods.

Based on the results of the testing, additional MCU lab-scale runs to measure the accumulation over time are recommended. In the earlier MCU runs, the concentration of organic solvent retained in the condensers changed over time; thus, these continuous runs might be a better indication for the amount of material expected to accumulate with DWPF processing. Once the final concentration of MCU solvent to DWPF is defined, SRNL will complete an assessment of the impact on redox, which must be finished before DWPF begins processing with MCU. An evaluation of the ARP/MST feed system should be performed by DWPF, 
WSRC-TR-2006-00063

Revision 0

if not already completed, to ensure that the prototypical feed rate will not result in solids settling in the ARP feed line. 


\section{TABLE OF CONTENTS}

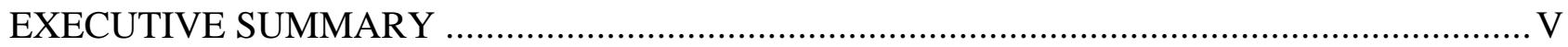

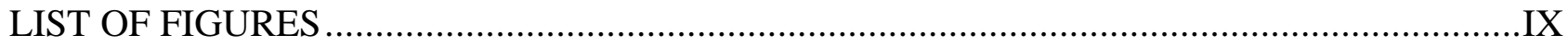

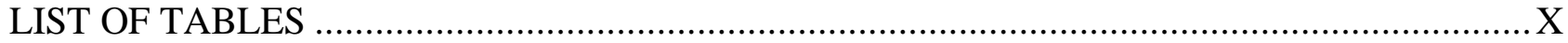

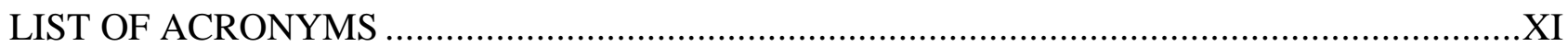

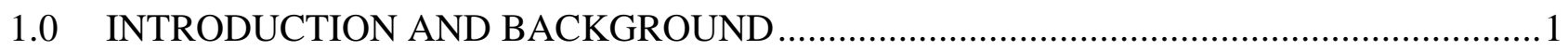

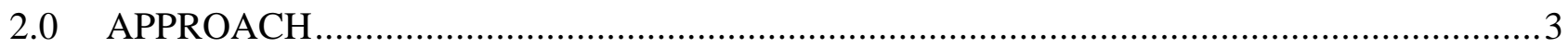

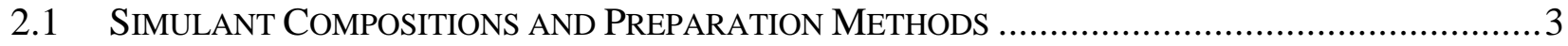

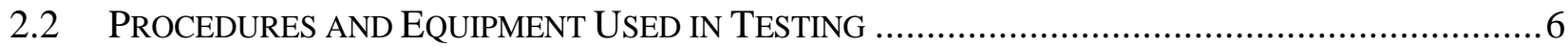

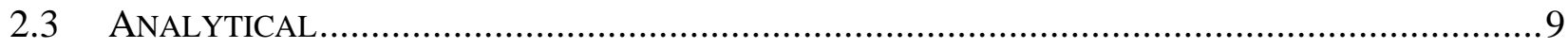

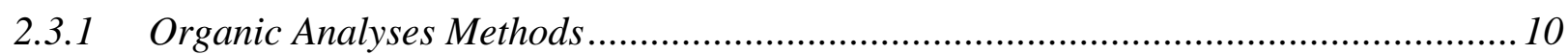

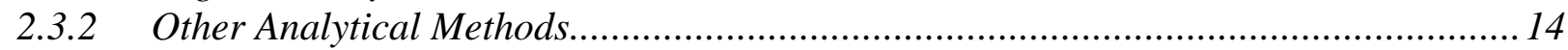

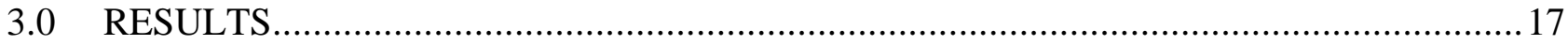

3.1 SLUDGE SiMULANT, ARP SIMULANT, AND SRAT RECEIPT CHARACTERIZATION..................17

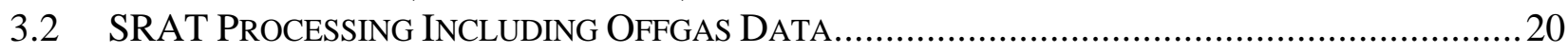

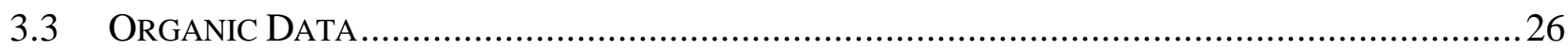

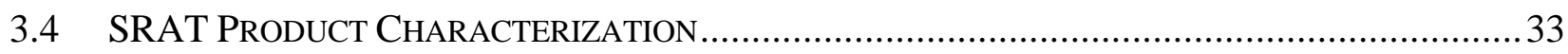

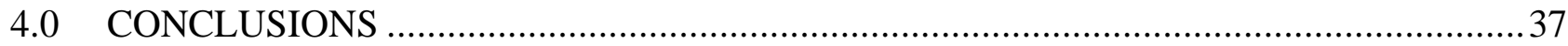

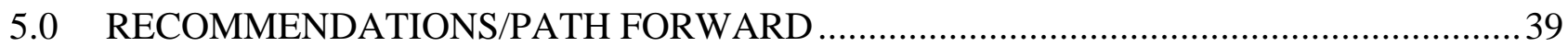

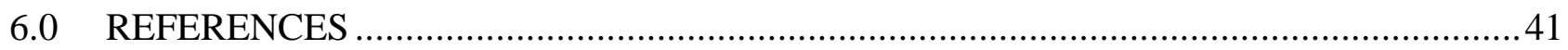

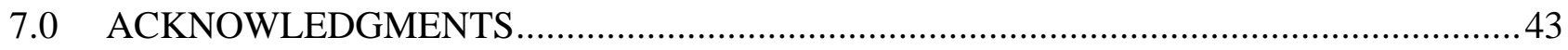

ATTACHMENT A. SRAT RUN PARAMETERS, RHEOLOGY DATA, GC, AND CARBON

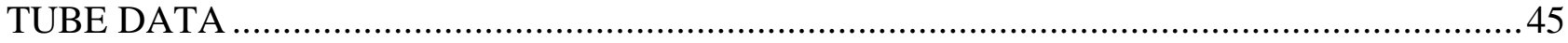




\section{LIST OF FIGURES}

Figure 2-1: Schematic of SRAT Equipment Set-Up ……......................................................

Figure 2-2: 4-L SRAT Vessel Set-up with ARP Addition ........................................................ 8

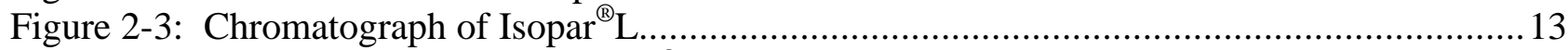

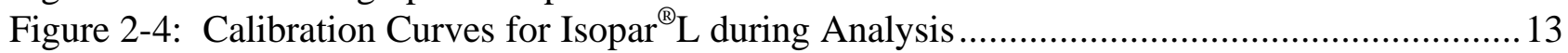

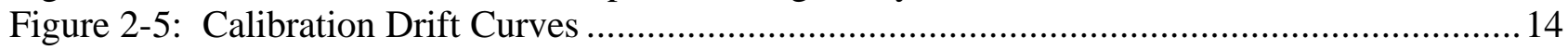

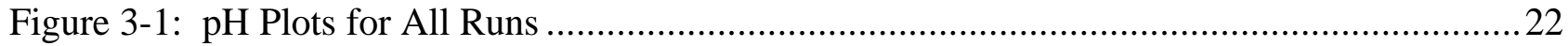

Figure 3-2: pH Plot of Current MCU Run, Previous MCU Run, and Sludge Only Run ..................22

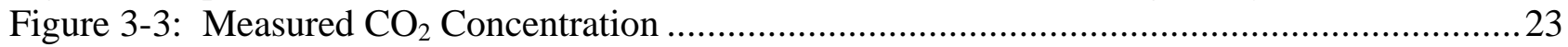

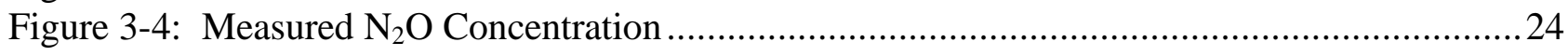

Figure 3-5: Measured NO Concentration .................................................................................. 24

Figure A - 1: Rheology of SB4 Simulant - Sludge Only ........................................................

Figure A - 2: Rheology for SB4-18 SRAT Receipt Samples .....................................................48

Figure A - 3: Rheology from Previous Testing -Concentrated ARP Added to Sludge Simulant.....49

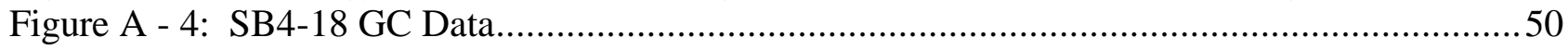

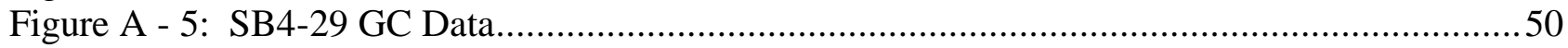

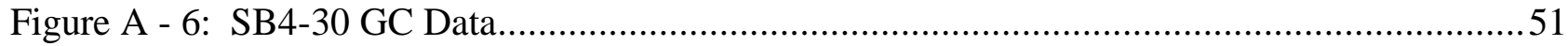

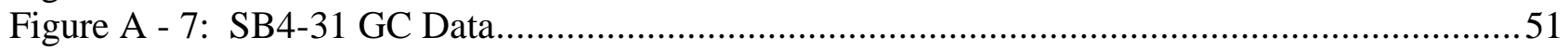

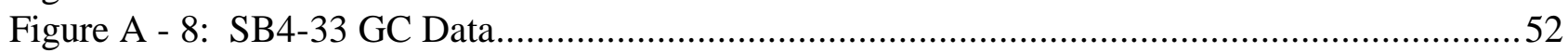

Figure A - 9: Carbon Tube Data from Run SB4-18 ……..................................................52

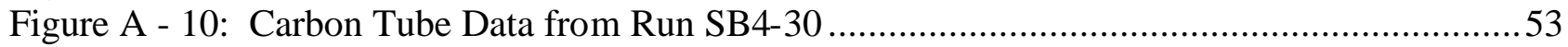

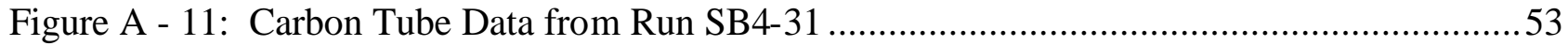

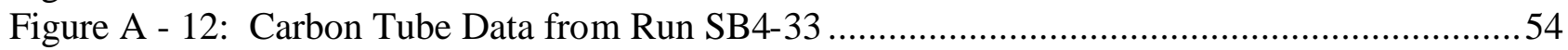

Figure A - 13: Rheology of SB4-18 SRAT Product with ARP and MCU ……….........................55

Figure A - 14: Rheology from Previous Testing - SB4-13 SRAT Product ......................................56

Figure A - 15: Rheology for Sludge Only SRAT Product........................................................57 


\section{LIST OF TABLES}

Table 2-1: Target Composition for SB4 Simulant 4

Table 2-2: Target Supernate Chemistry and Solids Concentration.................................................

Table 2-3: Nominal Appendix E ARP Components for DWPF Stream .........................................5

Table 2-4: MCU Aqueous Fraction Mass Balance Values for the Maximum Case ………………....5

Table 2-5: Target Levels of Noble Metals Used in Testing..........................................................

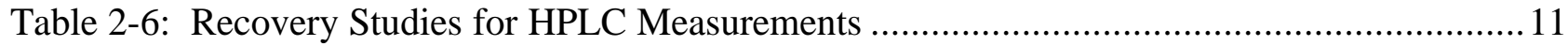

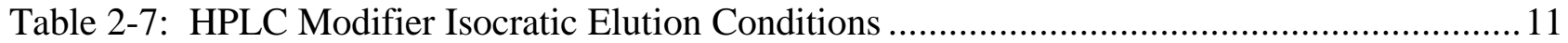

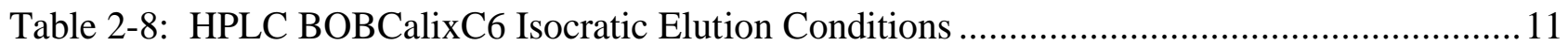

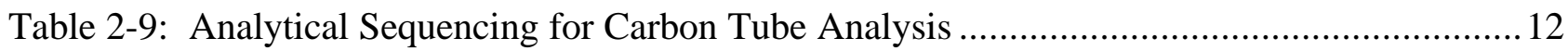

Table 3-1: Sludge Simulant, ARP Simulant, and SRAT Receipt Compositions .............................18

Table 3-2: SRAT Receipt Measured Inputs, Assumptions for Acid Calculation, and Target Acid

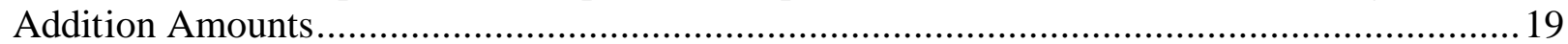

Table 3-3: Rheology Data for Sludge Simulant and SRAT Receipt for Run SB4-18 …..................20

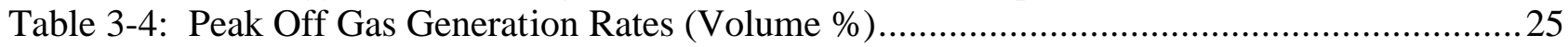

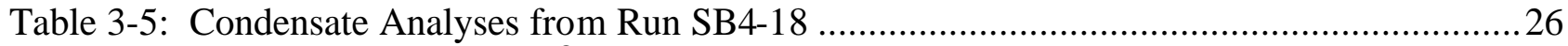

Table 3-6: Concentration of Isopar ${ }^{\circledR} \mathrm{L}$ as Measured by SVOC ……............................................2

Table 3-7: Concentration of Modifier as Measured by HPLC.......................................................2

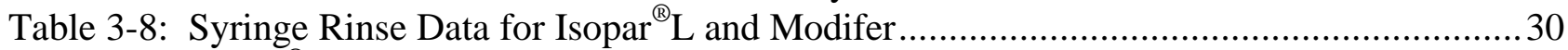

Table 3-9: Isopar $^{\circledR} \mathrm{L}$ Data from Carbon Tubes ..........................................................................

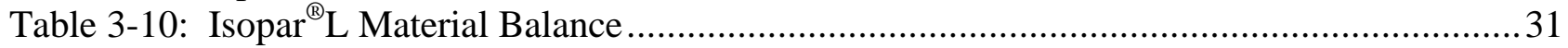

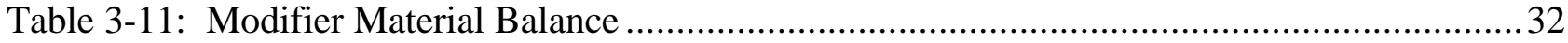

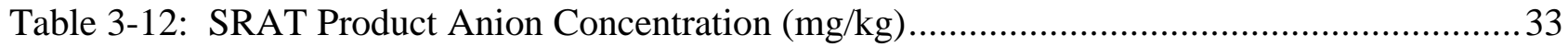

Table 3-13: SRAT Nitrite to Nitrate Conversions and Formate Destructions...................................33

Table 3-14: SB4-18 SRAT Product Elemental Data - Calcined Solids Wt \% ..................................34

Table 3-15: Physical Property Data for SRAT Products ................................................................34

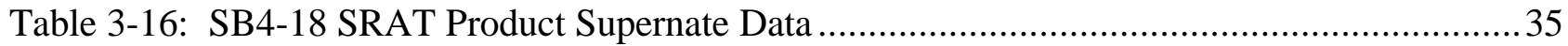

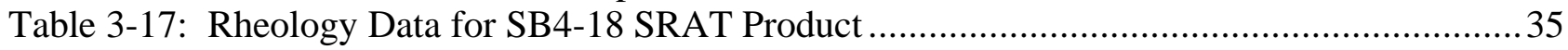

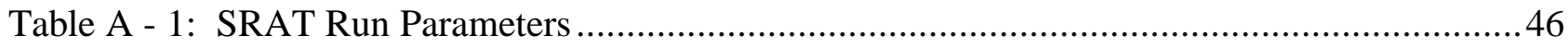




\section{LIST OF ACRONYMS}

$\begin{array}{ll}\text { ACTL } & \text { Aiken County Technology Laboratory } \\ \text { AD } & \text { Analytical Development } \\ \text { ARP } & \text { Actinide Removal Process } \\ \text { ASP } & \text { Analytical Study Plan } \\ \text { CPC } & \text { Chemical Process Cell } \\ \text { CSSX } & \text { Caustic Side Solvent Extraction } \\ \text { DWPF } & \text { Defense Waste Processing Facility } \\ \text { FAVC } & \text { Formic Acid Vent Condenser } \\ \text { GC } & \text { Gas Chromatograph } \\ \text { GC/MS } & \text { Gas Chromatography/Mass Spectrometry } \\ \text { HPLC } & \text { High Pressure Liquid Chromatography } \\ \text { HLW } & \text { High Level Waste } \\ \text { IC } & \text { Ion Chromatograph } \\ \text { ICP-AES } & \text { Inductively Coupled Plasma - Atomic Emission Spectroscopy } \\ \text { MCU } & \text { Modular Caustic Side Solvent Extraction Unit } \\ \text { MST } & \text { Monosodium Titanate } \\ \text { MWWT } & \text { Mercury Water Wash Tank } \\ \text { NIOSH } & \text { National Institute of Occupational Safety and Health } \\ \text { PSAL } & \text { Process Science Analytical Laboratory } \\ \text { PS\&E } & \text { Process Science \& Engineering } \\ \text { SB3 } & \text { Sludge Batch 3 } \\ \text { SB4 } & \text { Sludge Batch 4 } \\ \text { SEFT } & \text { Strip Effluent Feed Tank } \\ \text { SMECT } & \text { Slurry Mix Evaporator Condensate Tank } \\ \text { SRAT } & \text { Sludge Receipt and Adjustment Tank } \\ \text { SRNL } & \text { Savannah River National Laboratory } \\ \text { SVOC } & \text { Semi-Volatile Organic Compound } \\ \text { TIC } & \text { Total Inorganic Carbon } \\ \text { TOA } & \text { Tri-N-OctylAmine } \\ \text { TTR } & \text { Technical Task Request } \\ \text { UV } & \text { Ultra Violet } \\ \text { WAC } & \text { Waste Acceptance Criteria } \\ \text { Wt\% } & \text { Weight Percent } \\ & \end{array}$


WSRC-TR-2006-00063

Revision 0

This page intentionally left blank. 


\subsection{INTRODUCTION AND BACKGROUND}

The Process Science \& Engineering (PS\&E) section of the Savannah River National Laboratory (SRNL) was requested by the Defense Waste Processing Facility (DWPF) via Technical Task Request (TTR) HLW/DWPF/TTR-2004-0031 ${ }^{1}$ to evaluate the impacts on DWPF processing for streams from the Actinide Removal Process (ARP) and the Modular Caustic Side Solvent Side Extraction (CSSX) Unit (MCU). These two facilities will treat the salt currently being stored in the High Level Waste (HLW) tanks and are currently planned to begin operations during fiscal year 2007. Initial flowsheet demonstrations with the two salt streams have previously been completed. ${ }^{2,3}$ However, additional studies were required with the ARP stream due to changes in the DWPF incorporation strategy, and MCU runs were necessary to determine the partitioning of the MCU organics during processing.

In DWPF, the ARP sludge/monosodium titanate (MST) stream will be incorporated in the Sludge Receipt and Adjustment Tank (SRAT) during caustic boiling of the sludge. A blend of sludge and ARP will be targeted to match the typical solids loading seen in sludge only processing. After addition of the ARP at boiling is completed, the SRAT receipt sample will be taken so that the acid consumers in the ARP stream can be accounted for in the DWPF acid addition calculation. A slightly different strategy was used during the previous ARP testing; ARP was added to the sludge and then boiling was performed to concentrate the sludge and $\mathrm{ARP}^{3}$. Therefore, the new strategy needed to be verified in simulant flowsheet testing to ensure that all impacts were identified.

Earlier MCU testing indicated minimal impact on SRAT processing due to the incorporation of the MCU stream. ${ }^{3}$ However, the testing did identify potential issues with organic carryover to the SRAT condenser system. Therefore, additional testing was necessary with more prototypic solvent concentrations, a better organic addition system, and with improved methods for closing the organic mass balance.

A Task Technical \& Quality Assurance Plan ${ }^{4}$ was previously written outlining the activities and controls necessary to meet the objectives and requirements of the TTR. This set of testing was performed using the guidance and protocols outlined in the Task Technical Plan.

A total of five SRAT runs were performed to meet the objectives of this phase of testing. The first two runs specifically addressed the ARP addition strategy, and data was collected to assess the impacts. The other three runs utilized the incorporation strategy, but additional data was not collected. The first three runs tested $239 \mathrm{ppm}$ of solvent in the MCU stream, while the last two runs used $50 \mathrm{ppm}$ of MCU solvent. The $239 \mathrm{ppm}$ number represents the total solvent equivalent to DWPF's estimate of the maximum Isopar ${ }^{\circledR} \mathrm{L}$ that could be processed. The $50 \mathrm{ppm}$ number is closer to the design basis estimate of carry-over. The run ID and the particular parameters investigated were as follows:

SB4-18 239 mg/L MCU organic fed separately from the MCU aqueous portion

SB4-29 $\sim 239 \mathrm{mg} / \mathrm{L} \mathrm{MCU}$ organic fed with the MCU aqueous portion

SB4-30 $\sim 239 \mathrm{mg} / \mathrm{L}$ MCU organic fed with the MCU aqueous portion

SB4-31 $\sim 50 \mathrm{mg} / \mathrm{L}$ MCU organic fed with the MCU aqueous portion

SB4-33 $\sim 50 \mathrm{mg} / \mathrm{L}$ MCU organic fed with the MCU aqueous portion 
WSRC-TR-2006-00063

Revision 0

This page intentionally left blank. 


\subsection{APPROACH}

This section describes the approach that was used to perform the ARP impact testing and the MCU organic carry-over testing. It is divided into three subsections. Section 2.1 describes the simulant compositions and preparation methods. Section 2.2 describes the procedures and equipment utilized in the testing. Finally, Section 2.3 describes the analytical methods and procedures that were used in performance of the test.

\subsection{Simulant Compositions and Preparation Methods}

Since Sludge Batch 4 (SB4) simulant flowsheet studies have been and are being performed in parallel and the SB4 simulant was used in the earlier ARP and MCU runs, PS\&E used the same blended sludge composition in this testing. The SB4 composition was based on projections provided by Lilliston ${ }^{5}$ and represented the scenario where SB4 is blended with SB3 after producing 1200 equivalent canisters. This SB4 composition contained Tank 4, which is no longer a component of SB4, but allows for a more direct comparison to the other runs. The "Maximum" MCU case, where "Maximum" represents the highest dose/Cs loading case, from the Preliminary Material Balance Calculations performed by Campbell ${ }^{6}$ served as the basis for the MCU composition and volume tested. For a 6000 gallon DWPF SRAT batch, the MCU target volume was 6400 gallons. The ARP stream makeup was based upon Appendix E of X-CLC-S-00113 by Subosits ${ }^{7}$. DWPF selected the ARP case as the possible upper bound on the volume of ARP material to be processed. The ARP and MCU streams were consistent with the streams used in the earlier ARP and MCU runs. ${ }^{3}$

Run SB4-18 used left over SB4 sludge simulant from the first round of MCU testing (i.e., batch 031505), while new SB4 simulant had to be produced for the remaining runs. The target sludge simulant elemental calcined composition is given in Table 2-1, while the supernate chemistry is provided in Table 2-2. Uranium is included in the table for completeness, but was not added in the simulant. The sludge was fabricated using the generic B and C sludges that were fabricated at the Clemson Environmental Technologies Laboratory ${ }^{\mathrm{a}}$. Trim chemicals were added to the two sludge simulants to obtain the target composition.

The nominal components for the Appendix E case of the ARP stream are given in Table 2-3. In the ARP facility, the stream to be transferred to DWPF will be generated at $102.4 \mathrm{lbs} / \mathrm{hr}$; therefore, $\sim 2367$ gallons of ARP will be fed per SRAT batch according to Subosits ${ }^{7}$. The ARP simulant was made from reagent grade chemicals, dried SB4 sludge solids, and vendor supplied sodium titanate slurry. This ARP simulant was used in all of the runs in this test series.

The MCU strip effluent stream will consist of water, $\mathrm{CsNO}_{3}, \mathrm{HNO}_{3}$, and the organic solvent. The target mass balance values and nitrate concentration for the aqueous fraction of the MCU strip effluent stream is given in Table 2-4. For the first run, SB4-18, the test used MCU solvent obtained from the Chemical Science \& Technology (CS\&T) section ${ }^{\mathrm{b}}$ for the earlier MCU runs. The solvent contained the four organic components, which were $0.007 M$ BOBCalixC6, $0.75 M$ Cs-7SB modifier, $0.003 M$ tri-n-octylamine (TOA), and the diluent Isopar ${ }^{\circledR} \mathrm{L}$.

\footnotetext{
${ }^{a}$ Contract \#DE-FC09-00SR22184, Project \#DOES-006, SCUREF contract SC0183. D.H. Miller oversaw the fabrication of the sludge and D.C. Koopman provided the recipes for fabrication.

${ }^{\mathrm{b}}$ The solvent sample was from a mixture of $700 \mathrm{ml}$ of solvent, Lot \#PVB B000894-31W from P.V. Bonnesen at ORNL, and $800 \mathrm{ml}$ of modifier/Isopar mixture (0.50 M modifier), Lot \#B000894-6DM from P.V. Bonnesen at ORNL. Tom Peters performed the re-working of the mixture to obtain the latest blend ratios for the solvent.
} 
WSRC-TR-2006-00063

Revision 0

Table 2-1: Target Calcined Composition for SB4 Simulant

\begin{tabular}{|c|c|c||}
\hline Element & Wt\% & Ratio To Fe \\
\hline $\mathrm{Al}$ & 12.75 & 0.743 \\
\hline $\mathrm{Ba}$ & 0.147 & 0.009 \\
\hline $\mathrm{Ca}$ & 1.49 & 0.087 \\
\hline $\mathrm{Ce}$ & 0.172 & 0.010 \\
\hline $\mathrm{Cr}$ & 0.175 & 0.010 \\
\hline $\mathrm{Cu}$ & 0.065 & 0.004 \\
\hline $\mathrm{Fe}$ & 17.15 & 1 \\
\hline $\mathrm{K}$ & 0.987 & 0.058 \\
\hline $\mathrm{La}$ & 0.075 & 0.004 \\
\hline $\mathrm{Mg}$ & 0.964 & 0.056 \\
\hline $\mathrm{Mn}$ & 4.36 & 0.254 \\
\hline $\mathrm{Na}$ & 16.20 & 0.945 \\
\hline $\mathrm{Ni}$ & 3.22 & 0.188 \\
\hline $\mathrm{Pb}$ & 0.158 & 0.009 \\
\hline $\mathrm{Si}$ & 1.23 & 0.072 \\
\hline $\mathrm{Th}$ & 0.031 & 0.002 \\
\hline $\mathrm{Ti}$ & 0.012 & 0.001 \\
\hline $\mathrm{U}$ & 7.65 & 0.446 \\
\hline $\mathrm{Zn}$ & 0.099 & 0.006 \\
\hline $\mathrm{Zr}$ & 0.208 & 0.012 \\
\hline
\end{tabular}

*Based on projections from Lilliston ${ }^{5}$ Uranium is included in the table for completeness but was not added to the simulant.

Table 2-2: Target Supernate Chemistry and Solids Concentration for SB4 Simulant

\begin{tabular}{||l|c||}
\hline Parameter & Baseline Wash \\
\hline Density $(\mathrm{g} / \mathrm{mL})$ & 1.0542 \\
\hline $\mathrm{Na}(\mathrm{M})$ & 1.1044 \\
\hline $\mathrm{NO}_{2}(\mathrm{M})$ & 0.4620 \\
\hline $\mathrm{NO}_{3}(\mathrm{M})$ & 0.2381 \\
\hline $\mathrm{OH}(\mathrm{M})$ & 0.2668 \\
\hline $\mathrm{Cl}(\mathrm{M})$ & 0.0010 \\
\hline $\mathrm{SO}_{4}(\mathrm{M})$ & 0.0220 \\
\hline $\mathrm{F}(\mathrm{M})$ & 0.0041 \\
\hline $\mathrm{CO}_{3}(\mathrm{M})$ & 0.0496 \\
\hline $\mathrm{AlO}_{2}{ }^{-2}(\mathrm{M})$ & 0.0190 \\
\hline $\mathrm{C}_{2} \mathrm{O}_{4}{ }^{-2}(\mathrm{M})$ & 0.0074 \\
\hline $\mathrm{PO}_{4}{ }^{-3}(\mathrm{M})$ & 0.0013 \\
\hline Insoluble Solids $(\mathrm{Wt} \%)$ & 15.67 \\
\hline Total Solids $(\mathrm{Wt} \%)$ & 21.62 \\
\hline
\end{tabular}


Table 2-3: Nominal Appendix E ARP Components for DWPF Stream

\begin{tabular}{||c|c||}
\hline Component & lb/hr \\
\hline Water & 97.58 \\
\hline $\mathrm{KNO}_{3}$ & 0.0015 \\
\hline $\mathrm{NaOH}$ & 0.38 \\
\hline $\mathrm{NaNO}_{3}$ & 0.96 \\
\hline $\mathrm{NaNO}_{2}$ & 0.02 \\
\hline $\mathrm{Sr}\left(\mathrm{NO}_{3}\right)_{2}$ & $1.30 \mathrm{E}-03$ \\
\hline $\mathrm{Sludge}$ & 1.838 \\
\hline $\mathrm{MST}$ & 0.705 \\
\hline $\mathrm{NaHgOOH}$ & $9.75 \mathrm{E}-06$ \\
\hline $\mathrm{CH}_{3} \mathrm{OH}$ & $1.83 \mathrm{E}-06$ \\
\hline$\left(\mathrm{CH}_{3}\right)_{2} \mathrm{CHOH}$ & $1.32 \mathrm{E}-06$ \\
\hline $\mathrm{Na}_{2} \mathrm{C}_{2} \mathrm{O}_{4}$ & 0.594 \\
\hline
\end{tabular}

*Information is from Subosits?.

Table 2-4: MCU Aqueous Fraction Mass Balance Values for the Maximum Case

\begin{tabular}{||c|c|c||}
\hline Species & $\begin{array}{c}\text { Strip Effluent to DWPF, } \\
\mathbf{l b} / \mathbf{h r}\end{array}$ & $\begin{array}{c}\text { Additive } \\
\text { Used }\end{array}$ \\
\hline Water & 252.8 & Water \\
\hline $\mathrm{CsNO}_{3}$ & 0.0988 & $\mathrm{CsNO}_{3}$ \\
\hline $\mathrm{HNO}_{3}$ & 0.016 & $\mathrm{HNO}_{3}$ \\
\hline Total & 252.92794 & \\
\hline $\mathrm{NO}_{3}(\mathrm{M})$ & 0.003 & \\
\hline
\end{tabular}

For the other four runs, additional solvent was necessary. The CS\&T section had fabricated MCU solvent for the Strip Effluent Feed Tank (SEFT) mixing testing ${ }^{8}$, and this solvent was used in this set of testing. The CS\&T fabricated solvent did not contain BOBCalixC6 due to the limited quantity available and the cost of the material. This component was not anticipated to have an impact on SRAT processing based on earlier testing. ${ }^{3}$ Based on the SEFT testing, the lack of the BOBCalixC6 did not impact the physical properties of the solvent. ${ }^{9}$ The SEFT mixing testing also used a fluorescent dye to allow easier tracking of the solvent. This dye, Risk Reactor DFSB-K43, was used in this testing.

Mercury will be contained in the sludge to be processed at DWPF. It must be reduced below $0.45 \mathrm{wt} \%$ to meet DWPF processing criteria. Previous runs, as well as SB4 sludge-only flowsheet runs to date, have used $1 \mathrm{wt} \% \mathrm{Hg}$ based on a dried solids basis. This amount was also used in this set of runs for consistency. Noble metals at levels equivalent to previous testing were added to determine representative hydrogen generation from the inclusion of the ARP and MCU stream. Table 2-5 contains the target concentrations, which represented an upper limit based on the projected compositions for SB4.

Table 2-5: Target Levels of Noble Metals Used in Testing

\begin{tabular}{||c|c|}
\hline Noble Metal & Wt\% in Total Solids \\
\hline $\mathrm{Ag}$ & 0.00024 \\
\hline $\mathrm{Pd}$ & 0.0120 \\
\hline $\mathrm{Rh}$ & 0.0220 \\
\hline $\mathrm{Ru}$ & 0.0810 \\
\hline
\end{tabular}




\subsection{Procedures and Equipment Used in Testing}

The testing was performed at the Aiken County Technology Laboratory (ACTL) using a four-liter glass kettle to represent the SRAT and other glassware to functionally replicate the DWPF SRAT condenser system. The SRAT kettle is connected to the SRAT Condenser, the Mercury Water Wash Tank (MWWT), and the Formic Acid Vent Condenser (FAVC). A take-off line from the MWWT is used to drain condensate from the system, and it is collected in a bottle that represents the Slurry Mix Evaporator Condensate Tank (SMECT). For purposes of this report, the condensers and MWWT are referred to as the offgas components. For run SB4-18, the SRAT condenser was set to $40^{\circ} \mathrm{C}$ and the FAVC was set to $10^{\circ} \mathrm{C}$. These temperatures have been historically used in SRNL SRAT testing and were consistent with earlier MCU runs. After the first run, the temperatures were lowered to $25^{\circ} \mathrm{C}$ and $4^{\circ} \mathrm{C}$ to better match actual DWPF operating conditions.

A one-liter glass vessel with a stirring rod was used as the ARP and MCU aqueous feed tank. A Masterflex ${ }^{\circledR}$ pump with a Tygon feed line was connected to the bottom of the one-liter vessel to dispense the two streams to the SRAT at a controlled volumetric feed rate. Due to the small quantities of solvent needed in testing and the desire to feed the solvent at a constant rate, a syringe pump was used to feed the MCU solvent. In run SB4-18, the MCU solvent was fed through a Teflon line into a port in the SRAT kettle, while the MCU aqueous was fed using a separate line and port. The long lines used in this run proved problematic for feeding at a continuous rate and the equipment was modified slightly for the next run. For the other four runs, the solvent feed line was tied in to the MCU aqueous line and the feed line was shortened. A sketch of the experimental setup is given as Figure 2-1, while Figure 2-2 provides a picture of the equipment set-up.

SRAT processing parameters are summarized in Table A - 1. Each SRAT test followed a run plan specifically written for that run. ${ }^{10,11,12,13,14}$ The runs were performed in accordance with Procedure ITS-0094 ("Laboratory Scale Chemical Process Cell Simulations") of Manual L29. Slurry pH and offgas composition were measured during the experiments using in-line instrumentation. For the gas analysis, helium was introduced at a concentration of $0.5 \%$ of the total air purge as an inert tracer gas so that total amounts of generated gas and peak generation rates could be calculated. During the runs, the kettle was monitored to observe reactions that were occurring during each run to include foaming, air entrainment, rheology changes, and offgas carryover. When the dyed solvent was used, the kettle and condensers were periodically checked with a black light to determine the location of the dyed solvent. The condensers were continuously monitored to determine if any organics were collecting. Observations were recorded in laboratory notebook WSRC-NB-2005-00055 and are discussed in Section 3.0. 
Figure 2-1: Schematic of SRAT Equipment Set-Up

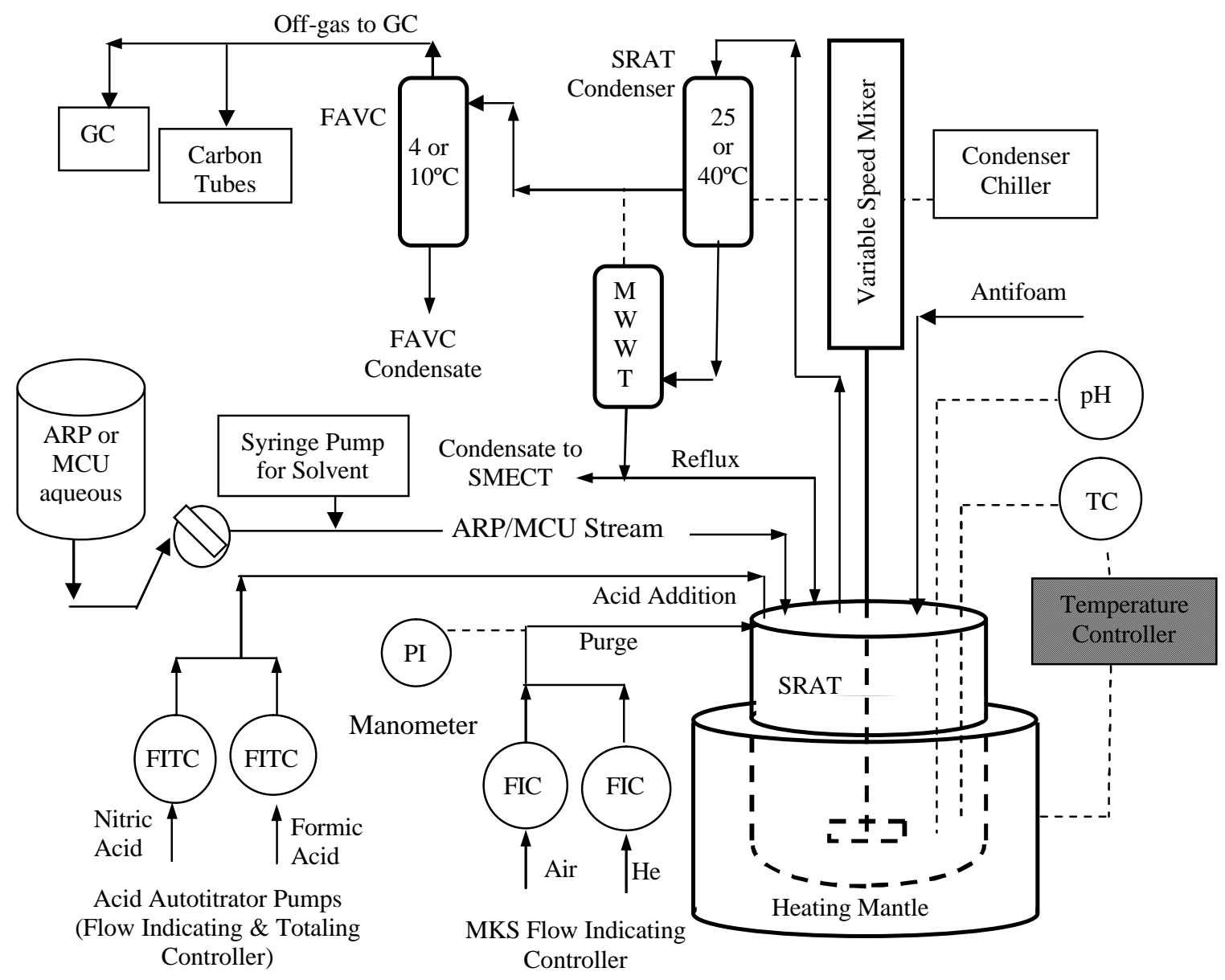


Figure 2-2: 4-L SRAT Vessel Set-up with ARP Addition

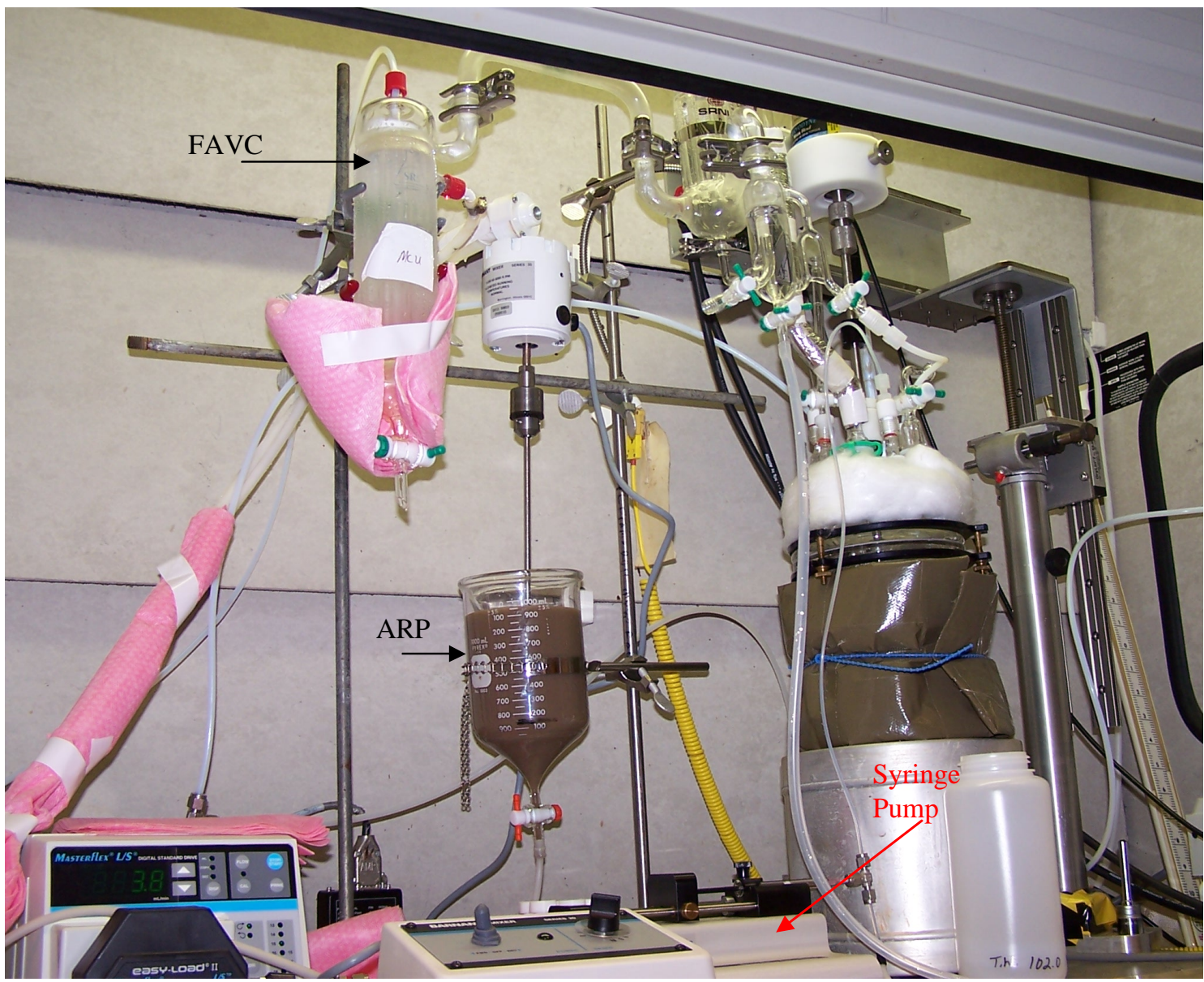

One of the primary objectives of this set of runs was to assess the revised ARP incorporation strategy. In this processing scenario, sludge is added to the SRAT at a reduced volume to accommodate the solids that will be added with the ARP stream. For the four-liter runs, approximately $95 \%$ of the nominal sludge mass was added. The sludge was added to the kettle and then the noble metals were trimmed into the kettle. Traditionally, $\mathrm{Hg}$ is also added at this point. However, this would have resulted in $\mathrm{Hg}$ being present in the sludge during caustic boiling. Due to the concern over generation of dimethyl mercury, mercury was not added until the start of the SRAT, where acidification is performed before the sludge is taken to boiling. In the DWPF, dimethyl mercury may be generated but would be generated in a contained system. DWPF would have to assess the potential impact of the material being generated. For SRNL, the toxicity is a concern and controls for working with the material have not been finalized to ensure worker safety and a proper disposal path has not been identified.

After thorough mixing of the noble metals with the sludge, the sludge was brought to boiling with $200 \mathrm{ppm}$ of IIT 747 antifoam added at $40^{\circ} \mathrm{C}$. Once the sludge temperature reached boiling $\left(\sim 101^{\circ} \mathrm{C}\right)$, ARP addition was initiated with the addition rate matching the boiling rate. Once the appropriate amount of ARP was added, the heating mantle was turned off and a SRAT receipt sample was taken. The Process Science Analytical Laboratory (PSAL), PS\&E personnel, and Analytical Development (AD) personnel performed analyses of the receipt sample and then the DWPF acid addition calculation ${ }^{15}$ was used to determine the amounts of formic and nitric acid to add. The split of the acids was determined using the redox equation currently being used in DWPF processing ${ }^{16}$ and no adjustments were made for the MCU organics. A 
program to evaluate the impact of MCU on redox will be completed before DPWF begins operations with MCU, and the impact will be verified by making glass from a SRAT run. The redox target $\left(\mathrm{Fe}^{2+} / \bullet \mathrm{Fe}\right)$ was 0.2. To account for the reactions and anion destructions that occur during processing, assumptions about nitrite destruction, formate destruction, and nitrite to nitrate conversion were made based on the data seen in previous ARP and MCU testing ${ }^{3}$. The same values were used in all runs for consistency and are provided in Section 3.0. To minimize the lag time between runs and since all of the feed used in the runs was the same after run SB4-18, the target acid additions and mass balance from the SB4-29 run were used to develop the run plans for the remaining runs. This minimized the number of samples to be analyzed and eliminated the 2 to 3 day delay in processing to analyze the SRAT receipt sample. No adjustments to the acid addition equation were performed for the addition of the MCU stream.

The ARP and sludge were heated to $93^{\circ} \mathrm{C}$ with $200 \mathrm{ppm}$ IIT 747 antifoam added at $40^{\circ} \mathrm{C}$. Concentrated nitric acid (50-wt $\%$ ) was added first and then formic acid (90-wt $\%$ ) was added to acidify the sludge and perform neutralization and reduction reactions during processing. After formic acid addition was completed, 500 ppm IIT 747 antifoam was added before going to boiling. The SRAT contents were concentrated by removing the equivalent volume of the acids, antifoam, and any flush water. After concentration, MCU addition was initiated. The goal was to add the MCU stream at the rate equivalent to the boiling rate. Therefore, continuous removal of the condensate was performed through the MWWT as the MCU was added. Once the entire MCU stream was added, heat to the kettle was removed. For runs SB4-18 and SB429 , the process air was turned off after the heat was removed, while in the other runs, the air flow continued to allow any organic vapors to be captured by the carbon tubes to try to close the material balance.

The SRAT kettle and the condensers were rinsed with methylene chloride for run SB4-18. Methylene chloride had been used in the previous testing and was believed to be effective in removing the organic residues from the SRAT surfaces. Due to poor recoveries of Isopar ${ }^{\circledR} \mathrm{L}$, the next run, SB4-29, used three rinses with methylene chloride. The rinses were submitted independently to determine the effectiveness of the rinses. Poor recoveries were still seen after the triple rinse, so an independent study with glass beads contained in a glass vessel was performed to determine the effectiveness of the rinses. This study spiked the container with a known amount of Isopar ${ }^{\circledR} \mathrm{L}$, and three different solvents (methylene chloride, hexane, and carbon disulfide) were tested to determine their effectiveness at recovering the Isopar ${ }^{\circledR} \mathrm{L}$. The results indicated that hexane appeared to provide the best recovery. The use of hexane does present a potential problem for interference during analysis, but if the appropriate column and equipment parameters are used, then the interference can be accommodated. For the last three runs, hexane was used to triple rinse the equipment and the rinses for each component were submitted as one sample.

A post leak check was performed on the SRAT equipment to determine if any of the seals had degraded or connections had become loose during SRAT processing. A reduction in the recovery from the pre-run leak check would have indicated a potential loss of organic vapor or SRAT generated gases.

\subsection{Analytical}

Analyses for this task used guidance of Analytical Study Plan (ASP), SRNL-GPD-2005-00001 ${ }^{17}$. Sample request forms were used for samples to be analyzed, and analyses followed the guidelines and means of sample control stated in the ASP for the task. A unique lab identification number was assigned to each sample for tracking purposes. Analyses were performed using approved analytical and Quality Assurance procedures.

Samples of the ARP simulant, sludge simulant, the SRAT receipt from SB4-18 and SB4-29, the SRAT products, the offgas condensate, and from the rinsing of the SRAT equipment were taken for analyses. The MCU aqueous simulant was not analyzed because of the simplicity of its make-up (see Table 2-4). Analyses 
were performed by the PSAL, the PS\&E section, and AD. The discussion of the analytical methods is subdivided into organic analyses and all other methods for analyses.

\subsubsection{Organic Analyses Methods}

Since completing the organic material balance was one of the primary objectives of this testing, a significant quantity of samples were submitted for organic analyses. This was done at the expense of the typical SRAT sampling to provide the best chance of closing the material balance. AD analyzed the SRAT product, condensate samples, and the vessel rinses to quantify the concentrations of Isopar ${ }^{\circledR} \mathrm{L}$, modifier, TOA, and BobCalixC6, when applicable.

Gas Chromatography/Mass Spectrometry (GC/MS) was used for semivolatile organic compound (SVOC) analysis. Isopar ${ }^{\circledR} \mathrm{L}$ and TOA results were reported from this method, along with any organomercurials if they were present in the mixture. Analytical separations were carried out on a Hewlett Packard 6890 gas chromatograph, equipped with a 30 meter DB-XLB column, with $0.18 \mathrm{~mm}$ diameter and 0.18 micron film thickness. Quantification was performed using a Hewlett Packard 5973 mass selective detector. The mass spectrometer tuning was confirmed within 24 hours prior to each measurement using perfluorotributylamine. When necessary, samples were prepared by extracting each sample with a known amount of methylene chloride or hexane, with the selected solvent matching that used for rinsing the SRAT equipment. If the sample was a vessel rinse that already contained methylene chloride or hexane, this additional extraction was not necessary and only a spike was performed. Isopar ${ }^{\circledR} \mathrm{L}$ quantitative analysis was performed using a mixed isotopic dilution standard of nonane- $\mathrm{d} 20$, decane- $\mathrm{d} 22$, and dodecane- $\mathrm{d} 26$. The one sigma error associated with each value was $\pm 20 \%$ for runs SB4-18, SB4-29, and SB4-30, while it was $\pm 10 \%$ for runs SB4-31 and SB4-33.

High Pressure Liquid Chromatography (HPLC) was used for modifier and BOBCalixC6 measurements. Aqueous samples were prepared for analysis by liquid/liquid extraction. Recovery studies were performed with a sample of the MCU solvent. The solvent was from Lot \# B000894-87W and contained 250,000 mg/L of modifier and $8,000 \mathrm{mg} / \mathrm{L}$ of BOBCalixC6. The recovery sample was made by spiking $0.5 \mathrm{ml}$ of solvent into $20 \mathrm{ml}$ of water. This solution was then extracted once with $5 \mathrm{ml}$ of methylene chloride. The solution was further diluted by adding $1 \mathrm{ml}$ of the methylene chloride solution to $9 \mathrm{ml}$ of hexane and $1 \mathrm{ml}$ of methylene chloride to $9 \mathrm{ml}$ of isopropanol. These solutions were then analyzed.

Table 2-6 presents the individual measurements, the average measurement and associated standard deviation, as well as the relative recovery numbers. The average recovery for a single extraction with methylene chloride of the modifier from water was $101 \%$, and the average recovery for a single extraction with methylene chloride of the extractant from water was $98 \%$. For the modifier extracts, the HPLC method used a normal-phase cyano column with $96 \%$ hexane and $4 \%$ isopropanol as the mobile phase. Table 2-7 summarizes the conditions for the modifier analysis. The analysis of the extracts for the extractant, BOBCalixC6, used a reversed-phase $\mathrm{C} 18$ column with acetonitrile as the mobile phase (see Table 2-8). The one sigma error associated with each value was $\pm 10 \%$. 
Table 2-6: Recovery Studies for HPLC Measurements

\begin{tabular}{||c|c|c||}
\hline Reported Value & Modifier & Calix \\
\hline Measurement 1 (mg/L) & 2405 & 80 \\
\hline Measurement 2 (mg/L) & 2593 & 80 \\
\hline Measurement 3 (mg/L) & 2553 & 78 \\
\hline Measurement 4 (mg/L) & 2515 & 77 \\
\hline Measurement 5 (mg/L) & 2580 & 78 \\
\hline Average Measurement (mg/L) & 2529 & 79 \\
\hline Measurement Standard Deviation (mg/L) & 76 & 1 \\
\hline \%Relative Standard Deviation & 3.0 & 2 \\
\hline Expected Value (mg/L) & 2500 & 80 \\
\hline \% recovery & $101 \pm 3 \%$ & $98 \pm 2 \%$ \\
\hline
\end{tabular}

Table 2-7: HPLC Modifier Isocratic Elution Conditions

\begin{tabular}{||c|c||}
\hline Method & Conditions \\
\hline Solvent system & Hexane/Isopropanol \\
\hline $\mathrm{t}_{\mathrm{o}}$ to $\mathrm{t}_{1}=8.0 \mathrm{~min}$ & $96 \% / 4 \%$ \\
\hline Normal Phase Cyano Column & Agilent Technologies Zorbax CN \\
\hline Oven temperature & $1 \mathrm{ml} / \mathrm{min}$ \\
\hline Flow-rate & $230 \mathrm{~nm}$ \\
\hline UV wavelength & $5 \mathrm{~mL}$ \\
\hline Injection volume & $6.3 \mathrm{~min}$ \\
\hline Retention time for Extractant & $12 \mathrm{mg} / \mathrm{L}$ to $240 \mathrm{mg} / \mathrm{L}, \mathrm{r}^{2}=0.999$ \\
\hline $\begin{array}{c}\text { Linear calibration curve } \\
\text { for Modifier }\end{array}$ & 0.73 \\
\hline R.S.D.(\%) $(\mathrm{n}=7)$ &
\end{tabular}

Table 2-8: HPLC BOBCalixC6 Isocratic Elution Conditions

\begin{tabular}{||c|c||}
\hline Method & Conditions \\
\hline Solvent system & Isopropanol \\
\hline $\mathrm{t}_{\mathrm{o}}$ to $\mathrm{t}_{1}=8.0 \mathrm{~min}$ & $100 \%$ \\
\hline Reversed-phase C18 Column & $\begin{array}{c}\text { Dychrom Chemcosorb 5 ODS-UH } \\
4.6 \mathrm{x} 150 \mathrm{~mm}, 5 \mathrm{~mm} \text { pore size }\end{array}$ \\
\hline Oven temperature & $45^{\circ} \mathrm{C}$ \\
\hline Flow-rate & $0.5 \mathrm{ml} / \mathrm{min}$ \\
\hline UV wavelength & $220 \mathrm{~nm}$ \\
\hline Injection volume & $5 \mathrm{~mL}$ \\
\hline Retention time for Extractant & $5.0 \mathrm{~min}$ \\
\hline $\begin{array}{c}\text { Linear calibration curve } \\
\text { for Extractant }\end{array}$ & $10 \mathrm{mg} / \mathrm{L}$ to $100 \mathrm{mg} / \mathrm{L}, \mathrm{r}^{2}=0.999$ \\
\hline R.S.D.(\%) $(\mathrm{n}=7)$ & 1.6 \\
\hline
\end{tabular}


The offgas from the runs was collected on activated carbon passive sampling tubes to adsorb any organics given off during the process. All carbon tubes were prepared by PS\&E personnel and then the prepared samples were analyzed by either PS\&E or AD personnel. Each activated carbon passive sampling tube consists of two activated carbon beds. The "front" bed, closest to the sampling point, is surrounded by glass wool, and the "back" bed, approximately half as much activated carbon as the "front", is between glass wool and a foam filter. First, the tubes are "cracked" by breaking the end off the tube to allow extraction of the activated carbon. Cracking involves scoring the tubes using a tungsten carbide blade to facilitate a clean break. After breaking the tube, the carbon is extracted with a combined technique. Initially, the glass wool is removed with a metal hooking device and placed into the appropriate vial. Then most of the front carbon bed will flow freely from the tube and can be poured into the appropriately labeled vial. However, in some cases, the metal hook is required to free the carbon from the glass wool previously separating the two beds. The dividing glass wool is then pulled from the tube and placed into the same preparation vial. For adsorption purposes, both sets of glass wool and the front carbon bed are all placed into the "front" vial. The remaining carbon bed and any foam filters at the back of the tube are then extracted in a similar manner and placed into the "back" vial.

After all the tubes are "cracked" and the carbon is extracted, each vial is desorbed. Desorption is necessary to remove all organics from the activated carbon into a solvent for analysis. Carbon disulfide was the solvent used for every sample analyzed in accordance with National Institute of Occupational Safety and Health (NIOSH) method 1501. Eight milliliters of carbon disulfide were added to each "front" vial, and four milliliters were added to each "back" vial. The added solvent volume for each vial was based on prescribed addition amounts for the mass of activated carbon in each bed. After adding the carbon disulfide, each vial was slightly shaken and then allowed to sit for at least thirty minutes prior to analysis (again, according to NIOSH method 1501).

To perform the analysis, an aliquot of each sample of approximately one to two milliliters is removed from the sample vial and placed into an appropriately labeled autosampler vial. The final portion of sample preparation consisted of determining the analytical sequence for the GC Mass Selective Detector. The analytical sequence is the sequence in which the samples are analyzed allowing for establishment of calibration curves to ensure analytical accuracy. The analytical sequence was as follows: standards (to establish the calibration curve), four samples, another set of standards, four samples, etc (see Table 2-9). This sequence is continued until all samples and a final set of standards are analyzed.

Table 2-9: Analytical Sequencing for Carbon Tube Analysis

\begin{tabular}{||c|c|c|c|c|c|c|c||}
\hline \hline 1 & $1 \mathrm{ppm}$ Standard & 6 & Sample 1 & 11 & $10 \mathrm{ppm}$ Standard & 16 & Sample 6 \\
\hline 2 & $10 \mathrm{ppm}$ Standard & 7 & Sample 2 & 12 & $100 \mathrm{ppm}$ Standard & 17 & Sample 7 \\
\hline 3 & $100 \mathrm{ppm}$ Standard & 8 & Sample 3 & 13 & $500 \mathrm{ppm}$ Standard & 18 & Sample 8 \\
\hline 4 & $500 \mathrm{ppm}$ Standard & 9 & Sample 4 & 14 & $1000 \mathrm{ppm}$ Standard & 19 & $1 \mathrm{ppm}$ Standard \\
\hline 5 & $1000 \mathrm{ppm}$ Standard & 10 & 1 ppm Standard & 15 & Sample 5 & 20 & etc... \\
\hline \hline
\end{tabular}

All analyses were performed using an Agilent 6890 series Gas Chromatograph and 5973n series Mass Selective Detector. The chromatography column was a 5\% diphenyl/ $95 \%$ dimethylsiloxane stationary phase column. Injection volume was set to 1.8 microliters with an autosampler and autoinjector. The Mass Selective Detector utilized the Selective Ion Monitoring (SIM) mode for detection of Isopar ${ }^{\circledR} \mathrm{L}$.

Isopar ${ }^{\circledR} \mathrm{L}$ is comprised of a multitude of aliphatic branch-chained hydrocarbon compounds that all share the sample distillation fraction point. Therefore, analysis with Gas Chromatography must take into account the total sum of all peaks resulting from the Isopar ${ }^{\circledR} \mathrm{L}$. The results for these analyses were all reported as the 
summation of the integrated peak areas of each peak within a given retention period. Figure 2-3 shows a chromatogram of Isopar ${ }^{\circledR} \mathrm{L}$, with a retention period of 8 minutes to 14 minutes (nominally).

Figure 2-3: Chromatograph of Isopar ${ }^{\circledR} \mathbf{L}$

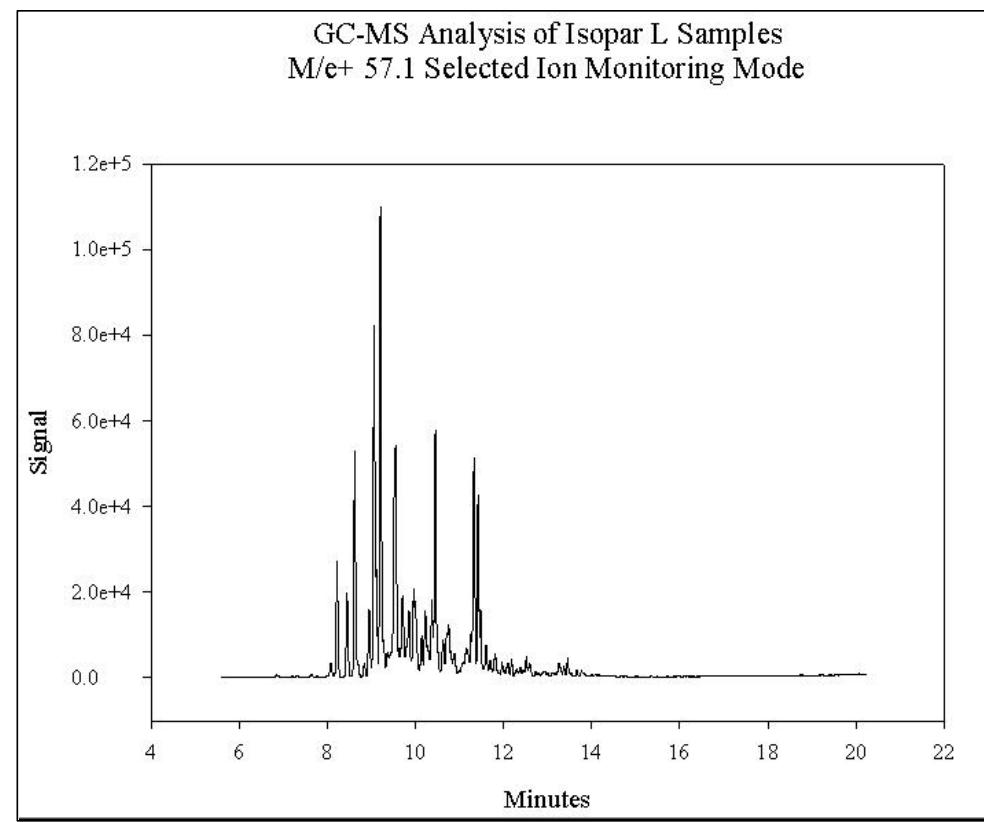

Analytical sequences typically consisted of approximately thirty to fifty samples and standards. Often drift occurred with respect to the effective sensitivity over the course of an entire analytical sequence. In effect, the results of standards dropped with time. To prevent this from affecting the results, a calibration drift curve was developed. During a given sequence, each calibration curve had a specific slope (Figure 2-4). The slope of the calibration curve is directly related to the response of each standard, such that the calibration curve slope would decrease over time when the standards response decreases over time. Therefore, the slopes of each calibration curve can be plotted over time to determine the rate of decline in effective sensitivity of the detector.

Figure 2-4: Calibration Curves for Isopar ${ }^{\circledR} \mathrm{L}$ during Analysis

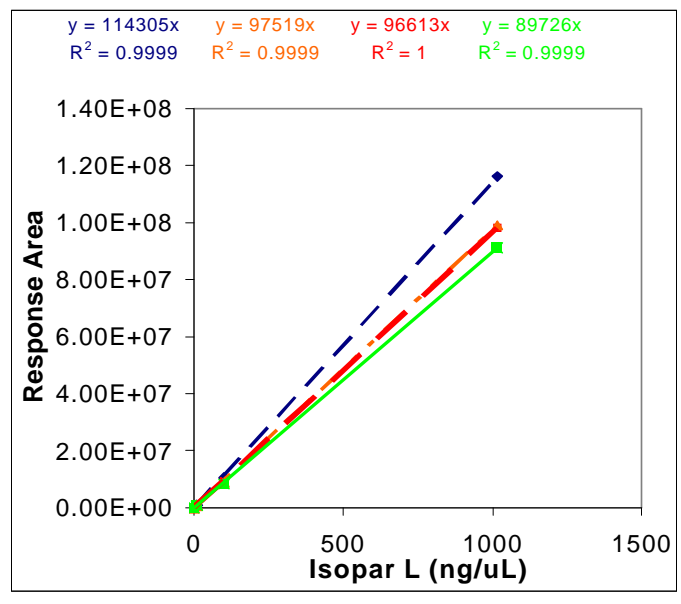

Calibration Curves for 12/02/05

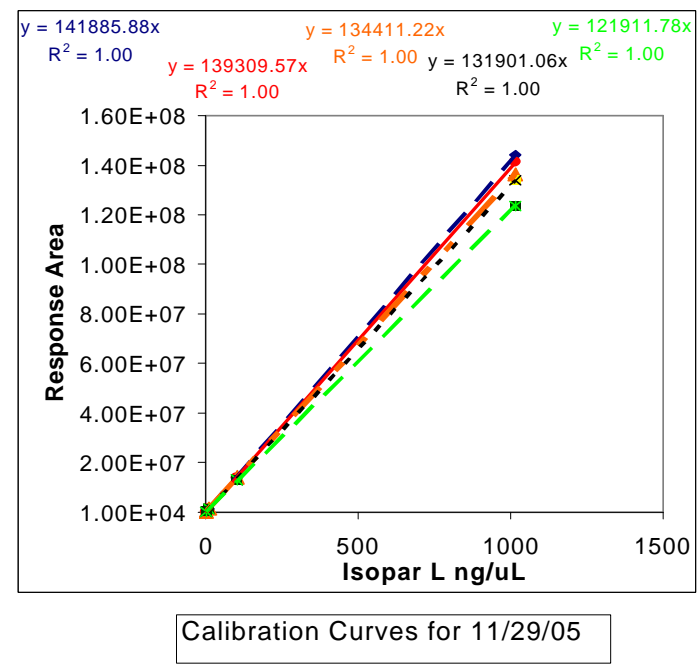


On several different analytical runs, the calibration curve slopes were tracked and plotted over time resulting in three calibration drift curves (Figure 2-5). All three drift curves were very similar in slope suggesting the decrease in effective sensitivity over time was repeatable. Thus, the drift curve can determine the decrease in sensitivity at a given time during analysis. Finally, the linear equation of the drift curve allows a factor to be applied to each sample based upon the standards analyzed that day and the time in which that sample was analyzed. This provided a more accurate result disregarding the drift in detector sensitivity.

Figure 2-5: Calibration Drift Curves

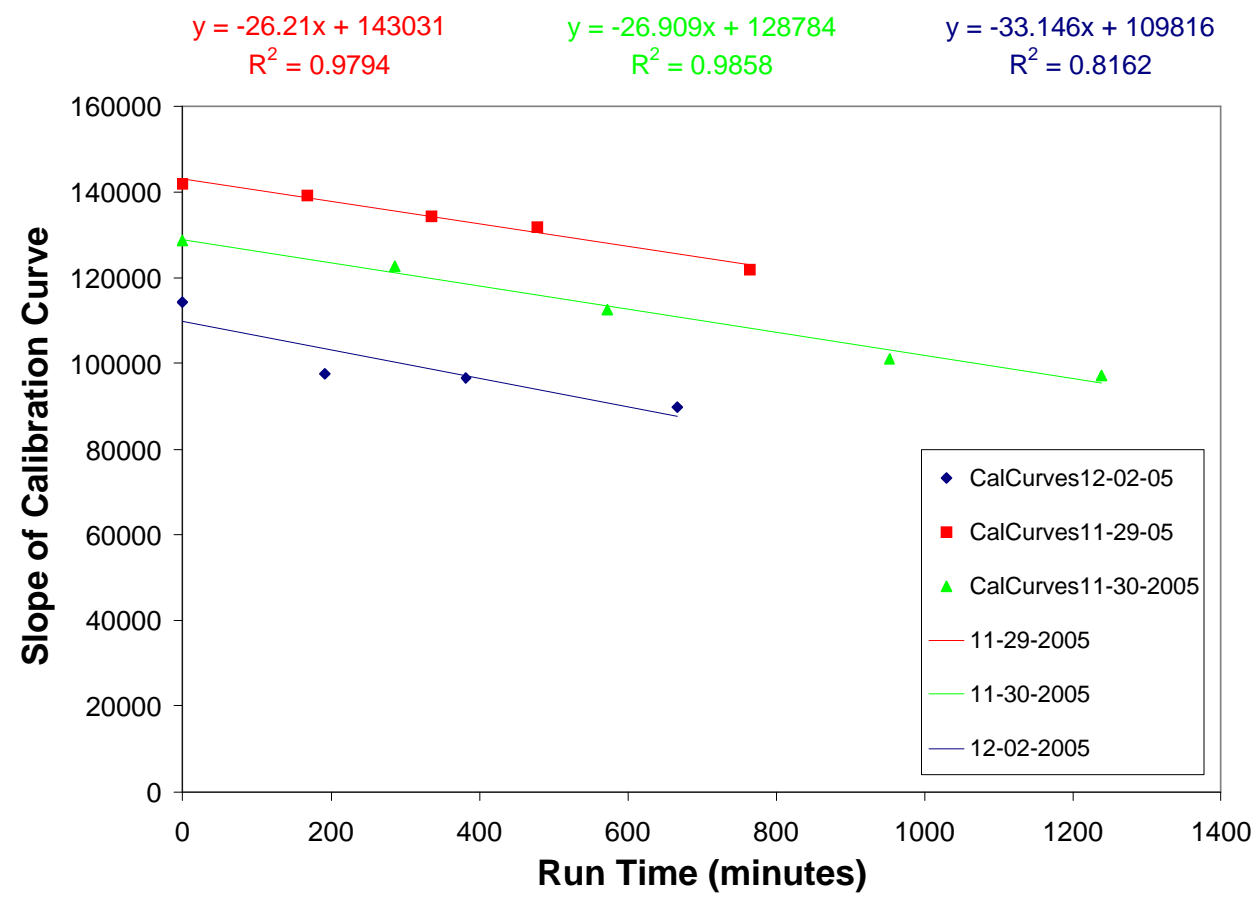

After accounting for drift, each result is back calculated to account for the initial desorption fluid volume of either eight milliliters or four milliliter of carbon disulfide. All results were reported in conjunction with the other thirty-five samples analyzed for a given process (three sets of six tubes per run, with front and back samples for each tube equals thirty-six). Finally, a sum total of all results for a given run are reported to determine the recovery of Isopar ${ }^{\circledR} \mathrm{L}$ in the offgas.

\subsubsection{Other Analytical Methods}

The sludge simulant was analyzed by the PSAL, PS\&E, and AD. The PSAL determined the chemical composition (both elemental and anions), total and dissolved solids, calcined solids, density, and $\mathrm{pH}$. To determine the elemental composition of the sludge simulant, duplicate samples of the simulant were calcined at $1100^{\circ} \mathrm{C}$ and then dissolved using $\mathrm{Na}_{2} \mathrm{O}_{2} / \mathrm{NaOH}$ and lithium metaborate fusions. The dissolved sludges were analyzed using Inductively Coupled Plasma - Atomic Emission Spectroscopy (ICP-AES) to determine the concentration of each cation. For the anion analyses, sludge preparation involved weighted dilution of the two samples before introduction into the Ion Chromatograph (IC). The total and dissolved solids were measured by the PSAL on two aliquots, and the insoluble and soluble solids fractions were calculated from the results. Due to the rapid settling problems with the sludge simulant, confirmatory total solids analyses were performed by PS\&E on each batch of sludge once it was added to the kettle. Rheology of this type of sludge simulant had been previously performed ${ }^{18}$ and, therefore, was not repeated in this series of testing. 
The PS\&E performed a manual titration using a $1 \mathrm{M} \mathrm{HNO}_{3}$ solution and 10:1 sample dilution to determine the base equivalents at $\mathrm{pH} 7$ for the sludge simulant. The calibration curve was performed in duplicate to a $\mathrm{pH}$ of $<5$, and the base equivalents at $\mathrm{pH} 7$ were calculated from the curves. AD analyzed the sludge simulant to determine the total inorganic carbon (TIC) for input to the acid addition calculation. The Immobilization Technology Section (ITS) Acid Demand TIC method was performed on three samples, with one of the samples diluted 20:1 to try to match the nominal TIC operating region.

The ARP simulant was analyzed by the PSAL and PS\&E. The PSAL determined the chemical composition (both cations and anions), total and dissolved solids, calcined solids, density, and $\mathrm{pH}$. Due to the different matrix (i.e., low solids content) of the ARP/MST slurry, an aqua regia dissolution was performed to prepare the sample for ICP-AES analysis to determine the elemental composition. The anion, solids, density, and $\mathrm{pH}$ methods were the same as those used on the sludge simulant. The PS\&E performed a manual titration to determine the base equivalents at $\mathrm{pH} 7$ using the same methods described above for the sludge simulant. No TIC or rheology analyses were performed on this simulant.

The SRAT receipt samples from runs SB4-18 and SB4-29 were analyzed by the PSAL, PS\&E, and AD. The PSAL determined the chemical composition (both elemental and anions), total and dissolved solids, calcined solids, density, and $\mathrm{pH}$ using the same methods applied to the sludge simulant. The filtered supernate from the SB4-18 SRAT receipt sample was also analyzed to determine the soluble elemental species at the start of SRAT processing. The PS\&E performed a manual titration on the samples using the methods described above for the sludge simulant, and also measured the SB4-29 receipt sample on the newly acquired autotirator. For the SB4-29 receipt sample, an average of the manual and autotitrator results was used as input to the acid addition equation. The ITS Acid Demand TIC method was performed by AD on both samples using the same methods described above for the sludge simulant. A rheology measurement was performed by PS\&E on the SB4-18 SRAT receipt sample to allow comparison to the sludge simulant only rheology and to the previously determined rheology for sludge/ARP feeds prepared with the previous incorporation strategy.

The SRAT products from runs SB4-18 and SB4-29 were analyzed by the PSAL and PS\&E. Only two of the SRAT products were analyzed, since a complete organic analysis was more important than repeating the SRAT product chemical composition analyses. A complete analysis (similar to what was done for the SRAT receipt sample) was performed on the SB4-18 product, while only anions, solids, density, and pH were determined for the SB4-29 product. Rheology measurements were performed by PS\&E on the SB4-18 SRAT product. This allowed for comparison to the sludge-only SRAT product and to the coupled feed SRAT product from earlier incorporation strategies.

PSAL analyzed the offgas condensate samples from SB4-18 to determine limited chemical composition concentrations, sample density, and sample $\mathrm{pH}$. The chemical composition was measured using ICP-AES and IC. The intent of the analyses was to identify any possible differences to sludge-only processing.

Gases were monitored during the runs using a high-speed Agilent model 3000 micro GC to provide insight into the reactions occurring during processing and to determine whether a flammable mixture could be formed in DWPF. As mentioned above, helium was used as a purge gas tracer. Two calibration standards were used to calibrate the GCs before each run to attempt to bound the quantities of the expected gases. The concentrations of these calibration standards were $0.5 \mathrm{~mol} \%$ helium, 0 and $1 \mathrm{~mol} \%$ hydrogen, 0 and $21 \%$ oxygen, 55 and $66.5 \mathrm{~mol} \%$ nitrogen, $2.5 \mathrm{~mol} \%$ nitrous oxide, $0.5 \mathrm{~mol} \%$ carbon monoxide, 20 mol\% carbon dioxide, and 0 and $10 \mathrm{~mol} \%$ nitric oxide. Calibration checks were performed before and after each run.

The GC is self-contained and is designed specifically for fast and accurate analysis. The GCs have five main components. The first is the carrier gas (argon for this testing) to transport the sample through the MolSieve 
5A PLOT (Channel A) and PLOT Q (Channel B) columns. The second is the injector, which introduces a measured amount of sample into the inlet of the analytical columns where it is separated. Injection time is 50 milliseconds for the Channel A gases (helium, hydrogen, nitrogen, oxygen, nitric oxide and carbon monoxide) and 100 milliseconds for the Channel B gases (carbon dioxide and nitrous oxide). The third component is the column, which is capillary tubing coated or packed with a chemical substance known as the stationary phase that preferentially attracts the sample components. As a result, components separate as they pass through the column based on their solubility. Since solubility is affected by temperature, column temperature is controlled during the run. The Channel A column is set at $60^{\circ} \mathrm{C}$, while the Channel B column is set at $70^{\circ} \mathrm{C}$. The fourth component is a micro-machine thermo conductivity detector. The solid state detector monitors the carrier and senses a change in its composition when a component in the sample elutes from the column. The fifth component is the data system, Cerity. Its main purpose is to generate both qualitative and quantitative data. It provides a visual recording of the detector output and an area count of the detector response. The detector response is used to identify the sample composition and measure the amount of each component by comparing the area counts of the sample to the analysis of known calibration standards. A sample was taken every 4 minutes. 


\subsection{RESULTS}

The data from the testing and any observations will be discussed in this section. This section has been divided into four subsections. Section 3.1 discusses the analyses of the sludge simulant, ARP simulant, SRAT receipt samples, and the necessary inputs for the acid calculation. Section 3.2 discusses the general observations about processing, the $\mathrm{pH}$ profiles, and the generated gas data. Section 3.3 discusses the material balance for the organics. Finally, Section 3.4 discusses the SRAT product characterization.

\subsection{Sludge Simulant, ARP Simulant, and SRAT Receipt Characterization}

As stated above, run SB4-18 used sludge simulant from previous ARP and MCU testing. The composition can be found in WSRC-TR-2005-00230 ${ }^{3}$, but is also included in this section for comparison and is denoted as Batch 031505. For the remaining runs, a fifteen liter batch of sludge simulant was fabricated using the same recipe as used in earlier testing. The SB4 simulant was identified as SB4-092705, where the number indicates the date of fabrication. The ARP simulant was fabricated for this set of testing and used the same basis as earlier testing, which was Appendix E of X-CLC-S-001137. Earlier testing fabricated the ARP simulant to take into account the concentration that would be performed in DWPF so caustic boiling would not have to be performed. As stated above and as part of the objective, the ARP simulant was fed at boiling to the sludge in the kettle before SRAT processing was initiated. After all of the ARP was fed to the system, SRAT receipt samples from SB4-18 and SB4-29 were taken and analyzed before processing was initiated. SB4-29 should be considered representative of the SRAT receipt samples for runs SB4-30, SB4-31, and SB4-33 since the same sludge simulant batch, ARP simulant, and masses were used to prepare the SRAT feed. Table 3-1 presents the analysis of the two SB4 simulants, the ARP stream simulant, and the two SRAT receipt samples.

The two simulants were similar in composition. Since uranium is not included in the simulant, the elemental compositions can not be directly compared. Instead, the simulant targets the ratio of the respective element to iron. When the ratios of the sludge simulants in Table 3-1 are compared to the target ratios given in Table $2-1$, most of the elements are slightly lower than target. The lower sodium and potassium were expected since the target assumes some of the sodium and potassium species are insoluble. The insoluble forms of these species were not added to try to match the target. It was felt that matching the supernate chemistry was more important for the SRAT testing, and any additional sodium added to try to match the target may have impacted the supernate chemistry. Some of the difference can also be attributed to the elemental iron concentration being slightly higher than targeted, which could be the result of analytical error in either the B or C sludge simulant used to fabricate the SB4 simulant. Although the elemental compositions are slightly different than the target, this should not impact the results of this testing since the data is being compared internally for the impact of ARP and MCU addition and all runs used the same simulant composition. When compared to the supernate and solids targets in Table 2-2, the anion targets were met, but the total and insoluble solids were slightly higher than targeted.

An examination of the ARP composition reveals the high concentration of sodium and titanium that is present with this stream. Based on the analyzed composition, the target ARP stream composition was met. 
Table 3-1: Sludge Simulant, ARP Simulant, and SRAT Receipt Compositions

\begin{tabular}{|c|c|c|c|c|c|}
\hline Sample ID & $\begin{array}{c}\text { Sludge Simulant } \\
\text { 031505 } \\
\text { (SB4-18 only) } \\
\end{array}$ & $\begin{array}{c}\text { Sludge } \\
\text { Simulant } \\
092705 \\
\end{array}$ & $\begin{array}{c}\text { ARP } \\
\text { Simulant }\end{array}$ & $\begin{array}{c}\text { SB4-18 } \\
\text { SRAT } \\
\text { Receipt }\end{array}$ & $\begin{array}{c}\text { SB4-29 } \\
\text { SRAT } \\
\text { Receipt }\end{array}$ \\
\hline \multicolumn{6}{|c|}{ Elemental (Wt\% in calcined solids) } \\
\hline $\mathrm{Al}$ & 14.8 & 13.9 & 3.47 & 14.9 & 14.7 \\
\hline $\mathrm{Ba}$ & 0.174 & 0.177 & N/A & 0.167 & 0.168 \\
\hline $\mathrm{Ca}$ & 2.28 & 1.90 & 1.28 & 2.08 & 2.11 \\
\hline $\mathrm{Cr}$ & 0.164 & 0.183 & 0.027 & 0.175 & 0.156 \\
\hline $\mathrm{Cu}$ & 0.076 & 0.077 & 0.034 & 0.077 & 0.071 \\
\hline $\mathrm{Fe}$ & 22.9 & 22.9 & 7.79 & 20.9 & 21.1 \\
\hline $\mathrm{K}$ & 0.818 & 0.971 & 0.290 & 0.871 & 0.829 \\
\hline $\mathrm{Mg}$ & 1.02 & 0.988 & 0.432 & 0.897 & 0.917 \\
\hline $\mathrm{Mn}$ & 6.12 & 6.20 & 3.05 & 5.66 & 5.75 \\
\hline $\mathrm{Na}$ & 11.2 & 12.5 & 31.7 & 11.8 & 13.4 \\
\hline $\mathrm{Ni}$ & 3.28 & 3.30 & 0.993 & 3.06 & 3.10 \\
\hline $\mathrm{P}$ & 0.038 & 0.046 & 0.018 & 0.050 & 0.042 \\
\hline $\mathrm{Pb}$ & 0.021 & 0.018 & 0.022 & $<0.010$ & $<0.020$ \\
\hline $\mathrm{S}$ & 0.267 & 0.284 & 0.069 & 0.250 & 0.243 \\
\hline $\mathrm{Si}$ & 1.41 & 1.44 & 0.084 & 1.28 & 1.31 \\
\hline $\mathrm{Ti}$ & 0.023 & 0.024 & 15.7 & 1.31 & 0.443 \\
\hline $\mathrm{Zn}$ & 0.124 & 0.139 & 0.001 & 0.120 & 0.132 \\
\hline $\mathrm{Zr}$ & 0.301 & 0.352 & 0.069 & 0.313 & 0.308 \\
\hline \multicolumn{6}{|c|}{ Anions ( $\mathrm{mg} / \mathrm{kg}$ in slurry) } \\
\hline $\mathrm{NO}_{2}$ & 16950 & 16400 & 294 & 16050 & 16000 \\
\hline $\mathrm{NO}_{3}$ & 12150 & 11500 & 7620 & 14250 & 14200 \\
\hline $\mathrm{SO}_{4}$ & 1365 & 1260 & $<100$ & 1325 & 1335 \\
\hline $\mathrm{C}_{2} \mathrm{O}_{4}$ & 741 & 747 & 4140 & 1540 & $<1000$ \\
\hline \multicolumn{6}{|c|}{ Physical Properties } \\
\hline Total Solids & $23.2 \%$ & $22.8 \%$ & $3.62 \%$ & $24.7 \%$ & $24.3 \%$ \\
\hline Insoluble Solids & $17.4 \%$ & $16.9 \%$ & $1.68 \%$ & $18.1 \%$ & $17.8 \%$ \\
\hline Soluble Solids & $5.79 \%$ & $5.92 \%$ & $1.94 \%$ & $6.60 \%$ & $6.49 \%$ \\
\hline Calcined Solids & $16.6 \%$ & $16.3 \%$ & $2.20 \%$ & $17.4 \%$ & $17.1 \%$ \\
\hline Density $(\mathrm{g} / \mathrm{ml})$ & 1.19 & 1.18 & 1.04 & 1.20 & 1.22 \\
\hline $\mathrm{pH}$ & 12.2 & 12.8 & 12.1 & 12.4 & 12.50 \\
\hline \multicolumn{6}{|c|}{ Other Measured Properties } \\
\hline TIC (mg/kg) & 991 & 786 & N/A & 803 & 878 \\
\hline $\begin{array}{c}\text { Base Equivalents } \\
\text { at } \mathrm{pH} 7(\mathrm{Eq} / \mathrm{L})\end{array}$ & 0.405 & 0.387 & 0.186 & 0.414 & 0.408 \\
\hline
\end{tabular}

N/A - Not analyzed

The two SRAT receipt samples reveal very slight differences in the sodium and titanium composition between the two samples. This may indicate that there was a problem obtaining a representative sample of the calcined SB4-29 material. It should be noted that while the ARP stream is being transferred to the SRAT, the stream was well mixed and the transfer line was flushed to ensure all solids were added. The other data for the two receipt samples were comparable and within analytical error, so it is believed that the feed was representative of the target sludge and ARP components supporting the conclusion that there may have been a problem obtaining a representative sample. 
The actual sludge, ARP simulant, noble metals, and Hg masses added to each SRAT run are given in Table A - 1. For runs SB4-30, SB4-31, and SB4-33, the amounts of sludge and ARP were adjusted/reduced so that the mass at the start of acid addition (i.e., the SRAT cycle) would be equivalent to the mass at the start of acid addition for run SB4-29. In run SB4-29, several SRAT receipt samples were taken since the inputs for the acid calculation were needed; whereas, only an archival sample was taken in the other runs. The inputs to the acid addition calculation are given in Table 3-2. For runs SB4-30, SB4-31, and SB4-33, the acid calculation numbers from SB4-29 were used.

Table 3-2: SRAT Receipt Measured Inputs, Assumptions for Acid Calculation, and Target Acid Addition Amounts

\begin{tabular}{||c|c|c||}
\hline Input Parameter & SB4-18 & $\begin{array}{c}\text { SB4-29 through } \\
\text { SB4-33 }\end{array}$ \\
\hline Nitrite (mg/kg) & 16050 & 16000 \\
\hline Nitrate $(\mathrm{mg} / \mathrm{kg})$ & 14250 & 14150 \\
\hline TIC (mg/kg) & 803 & 878 \\
\hline Base Eqv. (M) & 0.414 & 0.408 \\
\hline Mn (wt\% in total solids) & 3.99 & 4.45 \\
\hline Total Solids (wt\%) & 24.7 & 24.3 \\
\hline Density (g/ml) & 1.20 & 1.22 \\
\hline Calcine Factor & 0.705 & 0.702 \\
\hline Hg (\% in total Solids) & 1.0 & 1.0 \\
\hline Nitrite to Nitrate Conversion & $12 \%$ & $12 \%$ \\
\hline Formate Destruction & $20 \%$ & $20 \%$ \\
\hline SRAT Receipt Mass - Includes & 2446.8 & 2551.65 \\
\hline Sludge and ARP masses $(\mathrm{g})$ & $150 \%$ & $150 \%$ \\
\hline Acid Stoichiometry & 0.200 & 0.200 \\
\hline Redox Target & 0.9215 & 0.9208 \\
\hline Ratio of Formic to Nitric & 26.468 & 28.378 \\
\hline Nitric Acid Added (ml) & 10.53 & 10.57 \\
\hline Nitric Acid Molarity & 138.195 & 147.874 \\
\hline Formic Acid Added (ml) & 23.67 & 23.59 \\
\hline Formic Acid Molarity & 1.7402 & 1.8045 \\
\hline Acid/Liter of Slurry & 28.79 & 28.51 \\
\hline Target Solids in Product (Wt\%) & & \\
\hline & & \\
\hline
\end{tabular}

As mentioned above, a rheology sample was taken of the SB4-18 SRAT receipt material (sludge and ARP after concentration). As mentioned earlier, the SB4 simulant had previously been measured and the rheogram is given in Attachment A as Figure A - 1. The rheograms for the SRAT receipt sample are given in Attachment A as Figure A - 2. During characterization, the sludge simulant was ramped from 0 to 600 $\mathrm{sec}^{-1}$, while the SRAT receipt sample was ramped from 0 to $500 \mathrm{sec}^{-1}$. The up flow curve was above the down flow curve in all cases. The sludge simulant was fitted using a Bingham Plastic model from 40 to 600 $\mathrm{sec}^{-1}$ using the up flow curve. For the SRAT receipt samples, the Bingham Plastic model was fitted to the up flow curve between 20 to $500 \mathrm{sec}^{-1}$, and the samples were slightly thixotropic. For comparison, the rheograms for the SRAT receipt samples from the previous ARP addition strategy study are also provided in Attachment A as Figure A - 3. The samples from this set of testing had Taylor vortices at shear rates above $475 \mathrm{sec}^{-1}$. The results were fitted to the up curve for the runs because the down curve had slightly less yield 
stress but essentially the same plastic viscosity. The rheological data for these samples are summarized in Table 3-3.

All samples were visually and rheologically thin with the starting sludge simulant having the highest yield stress and plastic viscosity. The ARP addition method had a very slight impact on both the yield stress and plastic viscosity; however, the change was relatively small. The impact from ARP and MCU processing appears to be negligible based on the fact that the properties improved over the sludge simulant.

Table 3-3: Rheology Data for Sludge Simulant and SRAT Receipt for Run SB4-18

\begin{tabular}{||l|c|c||}
\hline \hline Sample & $\begin{array}{c}\text { Yield Stress } \\
\text { (dynes/cm }\end{array}$ & $\begin{array}{c}\text { Plastic Viscosity - } \\
\text { Consistency }(\mathbf{c P})\end{array}$ \\
\hline Sludge Simulant (031505) & 10.8 & 5.34 \\
\hline SB4-18 SRAT Receipt & 6.0 & 3.14 \\
\hline SB4-13 through SB4-17 SRAT Receipt* & 3.5 & 2.50 \\
\hline
\end{tabular}

*Concentrated ARP was added to the sludge so caustic boiling was not necessary and replicated ARP and sludge being boiled together to reduce the volume.

\subsection{SRAT Processing Including Offgas Data}

The runs were performed at the ACTL in a chemical hood and the parameters for the runs are given in Table A - 1. Each run was started by adding the sludge simulant to the kettle and, after the total solids were verified to be within the targeted range (i.e., $22.8 \% \pm 0.5 \%$ ), the noble metals were added. Heating was initiated and the antifoam amounts listed in Table A - 1 were added with an equal mass of water. Once the sludge was at boiling, the ARP stream was added at the same rate as the material was being removed (i.e., boil-up rate). The target rates are listed in Table A - 1, but were periodically adjusted during the run so that the addition and boil-up rate were matched as close as possible. The total time for ARP addition ranged from 3.83 to 4.42 hours due to the variation in boil up rate. Some problems were experienced with solids settling in the ARP addition line in the SB4-29 run; therefore, the MST solids were not likely added uniformly. After this run, changes were made to the feed system set-up to minimize the horizontal run, and the line was periodically purged to clear the solids. After all of the ARP simulant was added, flush water was added to the addition vessel to clear the line. The mass of condensate collected in the "SMECT" was fairly consistent from run to run when the slight changes in starting sludge mass are considered (see Table A - 1). No foaming or loss of heat transfer problems were evident during ARP boiling. A very small mass of condensate was collected in the FAVC during ARP boiling; ranging from 1.058 to $3.24 \mathrm{~g}$ for the runs.

Heat to the kettle was removed after the completion of ARP addition. In all cases, SRAT receipt samples were taken, but the total mass of samples removed was much smaller for Run SB4-30, SB4-31, and SB4-33. As stated earlier, only runs SB4-18 and SB4-29 waited for the completion of the SRAT receipt analysis before proceeding with the SRAT cycle. The remaining runs used the parameters calculated for the SB4-29 run. For runs SB4-30 and SB4-31, the ARP boiling was completed at the end of the day and then the SRAT cycle was started the next morning. For SB4-33, the SRAT was cooled to $92^{\circ} \mathrm{C}$, and then the SRAT cycle was started.

Before the SRAT cycle could be started, mercury was added to the kettle since it was not added during ARP addition due to concerns over the generation of dimethyl mercury during caustic boiling. As with the typical SRAT runs, $200 \mathrm{ppm}$ antifoam was added to the SRAT kettle before the initiation of acid addition. Nitric acid was added first and then formic acid. The acid addition requirement was slightly lower for run SB4-18 due to the slight changes in the simulant properties. For the SB4-33 run, more formic acid was added than in 
the other runs. This was due to error in reading the amount of acid to add. Both the volume and mass were listed, and the mass amount was set on the volume dispenser instead of the target volume. This resulted in 0.735 moles of additional formic acid being added to run SB4-33. This should not have an impact on the MCU solvent behavior. After the completion of acid addition, $500 \mathrm{ppm}$ antifoam was added and the vessel was ramped to boiling. Once boiling was initiated, the SRAT contents were dewatered/concentrated to bring the sludge to the target solids concentration. For run SB4-18, the MWWT was in concentration mode (instead of reflux) during acid addition since this was what was done in previous MCU testing. However, to be more prototypical of the DWPF cycle, the MWWT was put in reflux for the rest of the runs. Due to a math error during the SB4-18 run, less concentrate was removed than targeted during the initial part of the SRAT run. In order to meet the target total solids, additional concentrate was removed during MCU addition.

The MCU addition was initiated after dewatering was completed. The target solvent level was $239 \mathrm{ppm}$ $(\mathrm{mg} / \mathrm{kg}$ ) for runs SB4-18, SB4-29 and SB4-30. For runs SB4-31 and SB4-33, the target was $50 \mathrm{ppm}$ $(\mathrm{mg} / \mathrm{kg})$. As mentioned above, the MCU aqueous was in one vessel and was added with a Masterflex ${ }^{\circledR}$ pump, while the solvent was added using a syringe pump. The feed rate of the MCU aqueous was set to match the boil-up rate, while the organic addition rate was calculated and set based on the estimated time to add the aqueous. Feeding the MCU took between 10.5 - 11.67 hours. The variation in time was due to the slight differences in boiling rate during the runs since the addition was adjusted as necessary to match the obtained boil-up rates during the runs. No additional reflux period was performed.

Mixing and heating of the slurries during the SRAT cycles were not an issue. No problems with foaming or processing of the slurries were evident.

The $\mathrm{pH}$ was measured throughout the ARP addition and concentration and during the SRAT cycle. Figure 3-1 provides the $\mathrm{pH}$ plots for all the runs with the end of start of SRAT processing indicated in each run. For the ARP boiling part of the cycle, the profiles are similar with a slight shift upward in pH for run SB4-30. This run also had a longer ARP boiling time due to the low boil-up rate that was experienced, which resulted in a slight increase in the time required to obtain the equivalent condensate mass. The boil up rate for the other runs was controlled to minimize $\mathrm{pH}$ changes between the runs. The slight shift upwards in $\mathrm{pH}$ for this run remained throughout the SRAT cycle and the exact cause is not evident. The pH in run SB4-33 was significantly less than in the other runs due to the increased volume of acid that was inadvertently added.

When the $\mathrm{pH}$ plots from this set of MCU runs is compared to the previous MCU runs and to SB4 sludge only runs, the plots are very similar. Figure 3-2 shows this comparison for run SB4-13 from previous MCU/ARP testing and for run SB4-2 from the sludge only testing. Run SB4-18 had very similar behavior to the sludge only run and was closer to the same profile than the previous MCU/ARP run. Therefore, it does not appear that the salt stream addition will have a significant impact on the $\mathrm{pH}$ during SRAT processing at least at the acid addition level tested. 
WSRC-TR-2006-00063

Revision 0

Figure 3-1: pH Plots for All Runs

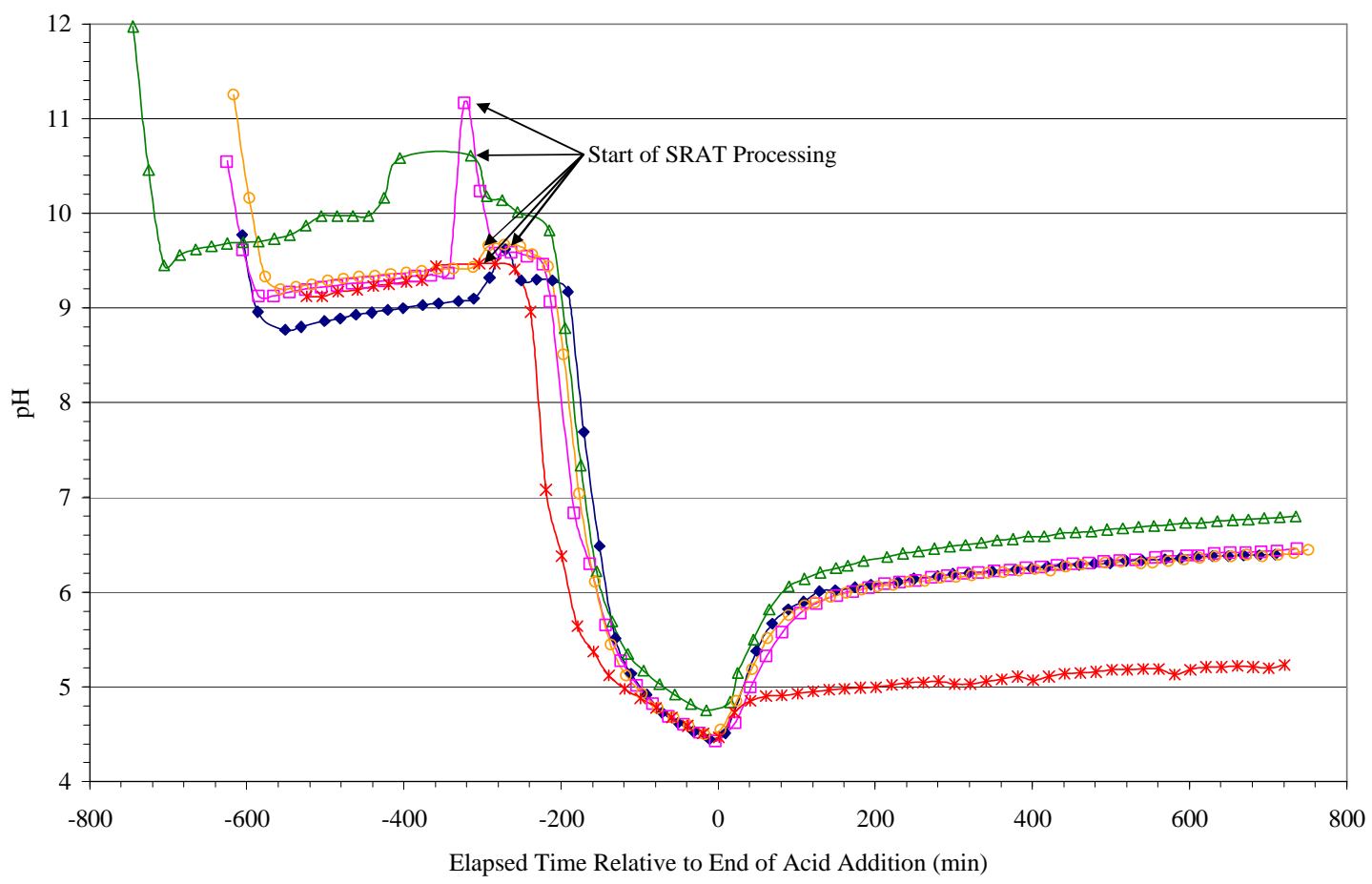

$\bullet$ SB4-18 $\square$ SB4-29 $\triangle$ SB4-30 $\circ$ SB4-31 $*$ SB4-33

Figure 3-2: pH Plot of Current MCU Run, Previous MCU Run, and Sludge Only Run

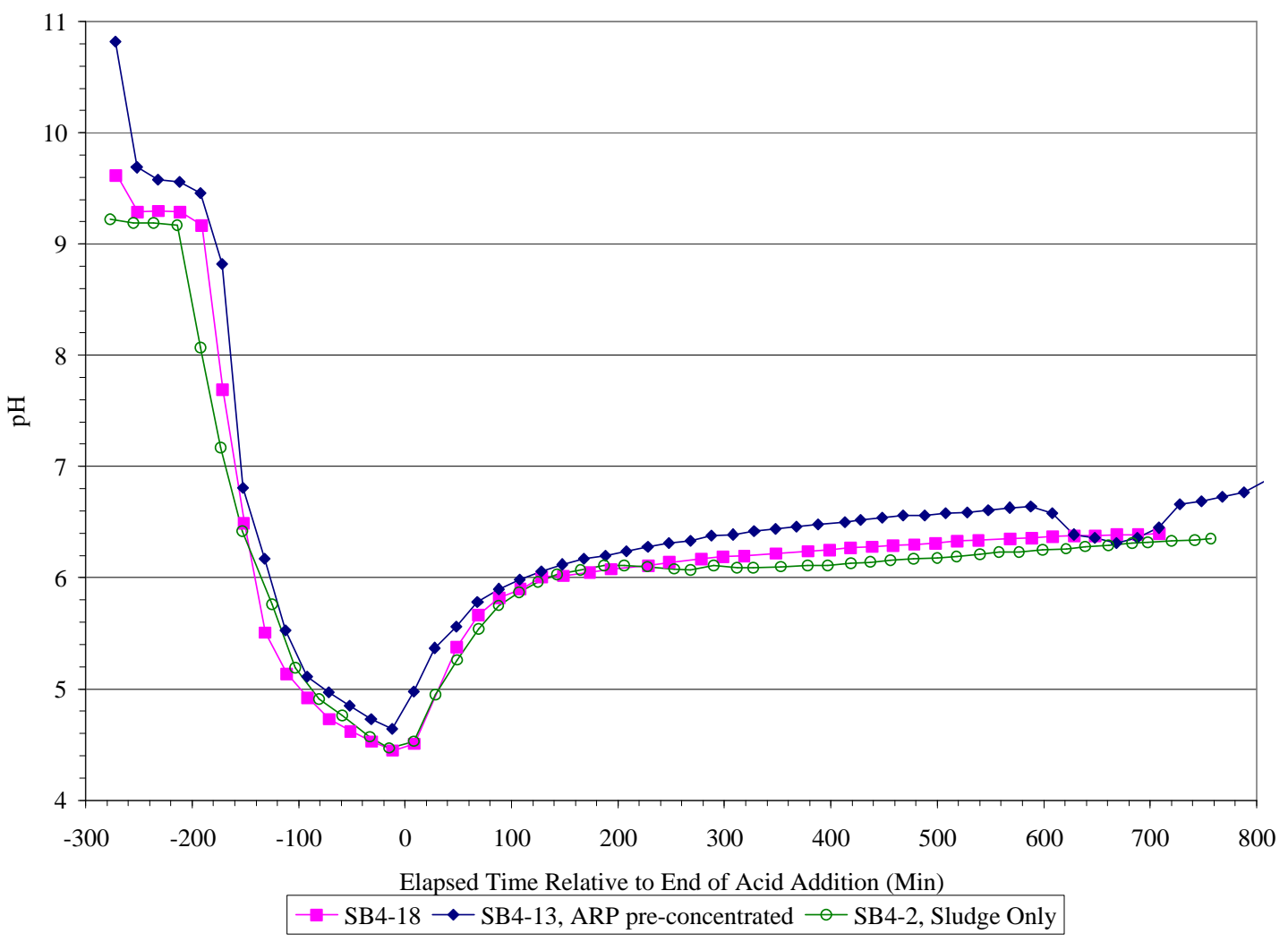


As mentioned in Section 2.2, hydrogen, oxygen, nitrogen, carbon dioxide, nitric oxide, and nitrous oxide were measured throughout the runs using GCs. Figure A - 4 through Figure A - 8 of Attachment A contain plots of the GC data from the individual runs. Generally, carbon dioxide was the first detected gas followed by the generation of nitrous oxide and/or nitric oxide. As these gases were generated, oxygen was depleted slightly. After acid addition was completed, oxygen concentration began to increase and additional peaks of carbon dioxide, nitrous oxide, and nitric oxide were detected. These peaks occurred when the SRAT contents started to boil and approximately mid-way through dewatering/concentration. Hydrogen was slightly above the detection limit for run SB4-18, but was not detected in runs SB4-29, SB4-30, and SB4-31. A slightly elevated level of hydrogen was seen in run SB4-33 due to the additional formic acid that was added. The GC data for run SB4-33 after acid addition was completed is suspect due to the low concentrations of He that were detected by the GC. The detected He was much lower than the target of 0.5 volume percent. However, the post calibration indicated no problems; therefore, the cause for the low He numbers was not clear. For the most part, little gas was generated five hours past the end of acid addition in all of the runs.

Figure 3-3 through Figure 3-5 contain plots of the carbon dioxide, nitrous oxide, and nitric oxide, respectively, from this set of runs. No significant amounts of any of any of these gases were generated during ARP boiling so that data is not included. Only a portion of the SRAT cycle data is shown since the gases are not generated throughout the run.

Figure 3-3: Measured $\mathrm{CO}_{2}$ Concentration

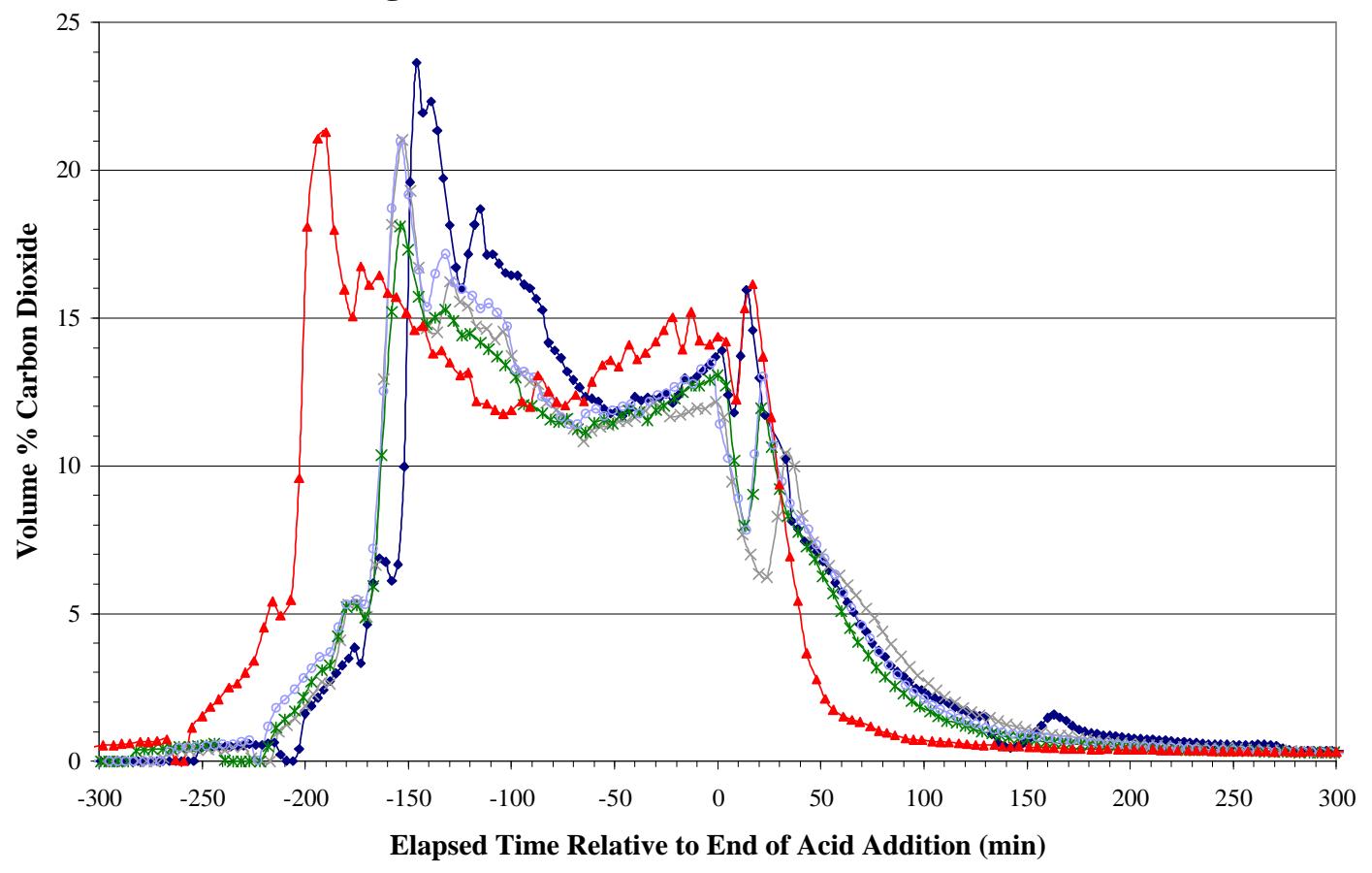

$\rightarrow$ SB4-18 $\leftarrow$ SB4-29 $*$ SB4-30 $\multimap$ SB4-31 $\leftarrow$ SB4-33 
WSRC-TR-2006-00063

Revision 0

Figure 3-4: Measured $\mathrm{N}_{2} \mathrm{O}$ Concentration

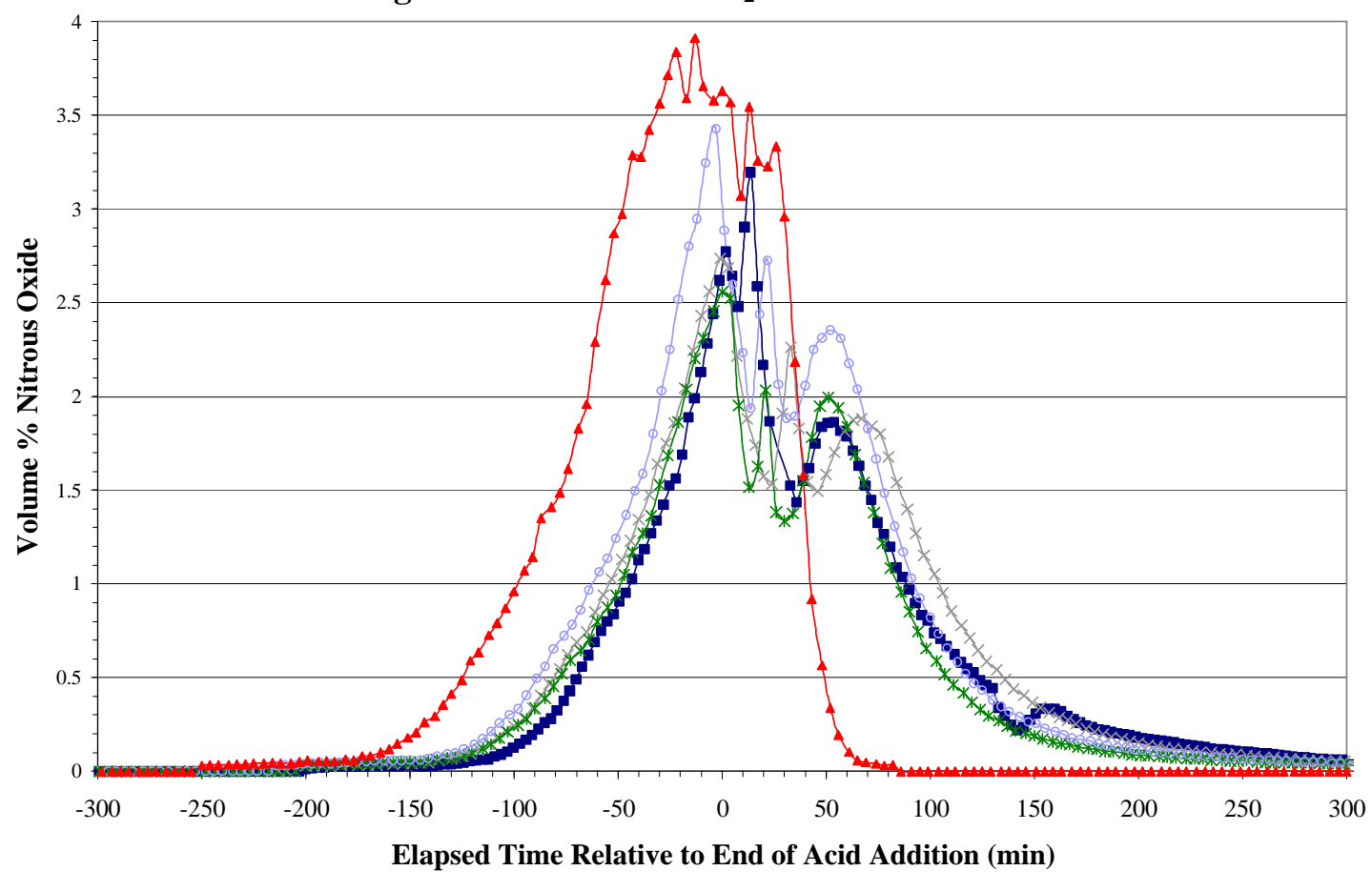

$\rightarrow-\mathrm{SB} 4-18 \rightarrow \mathrm{SB} 4-29 \rightarrow \mathrm{SB} 4-30 \div \mathrm{SB} 4-31 \rightarrow \mathrm{SB} 4-33$

Figure 3-5: Measured NO Concentration

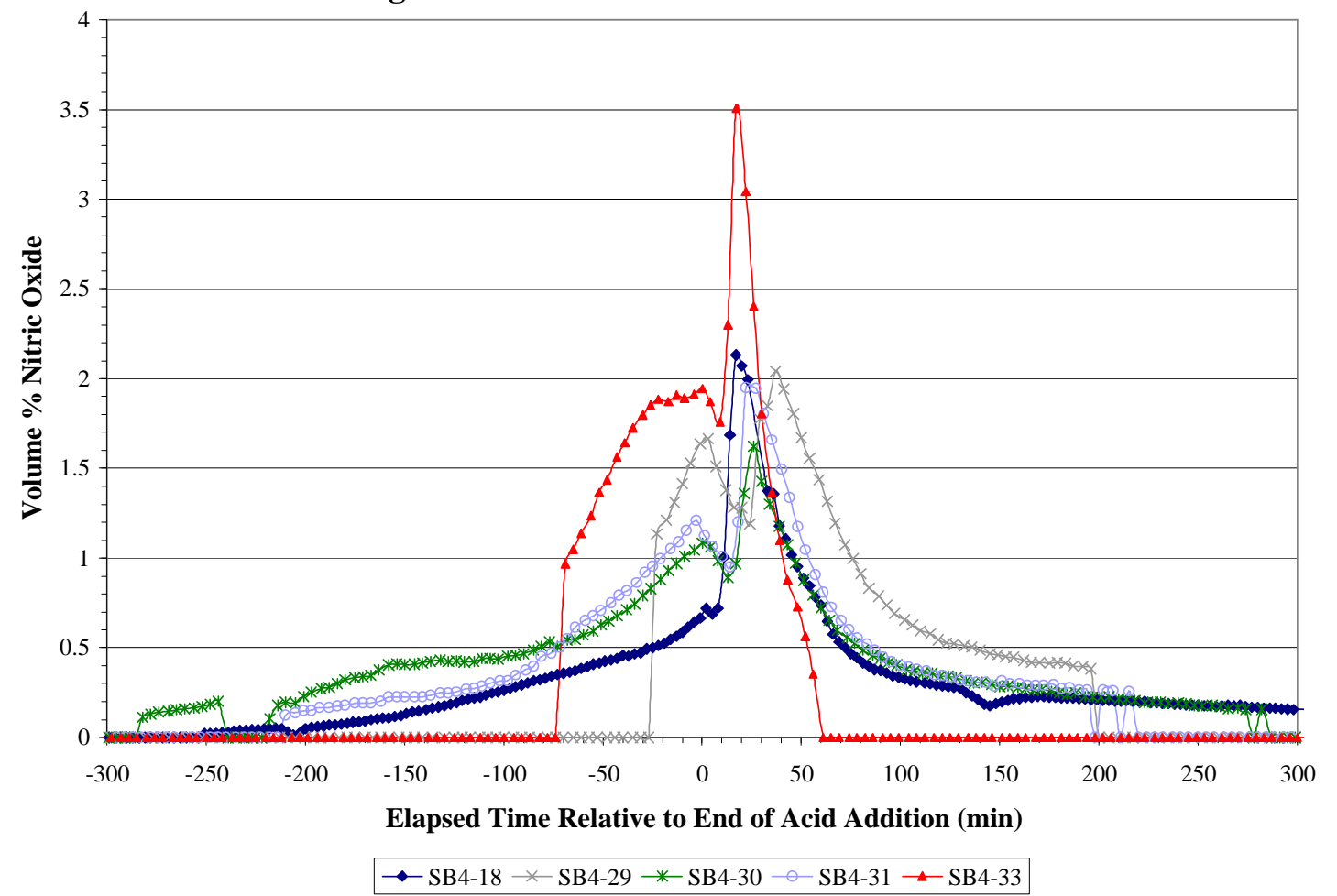


The timing and concentrations were fairly consistent from run to run with the most noticeable change occurring in run SB4-33. This change can be attributed to the higher acid amount used in the run, which resulted in a shift in the peaks to the left of 0 minutes. The first carbon dioxide peak occurred about 40 minutes into formic acid addition followed by two larger peaks during the rest of formic acid addition. A slight increase in carbon dioxide generation occurred near the end of formic acid addition and as the SRAT contents were brought to boiling. Nitrous oxide peaked near the end of acid addition, as the SRAT contents went to boiling, and shortly after dewater/concentration was initiated. All of the runs had two peaks of nitric oxide that occurred at relatively the same time, which was just before the end of acid addition and as dewatering/concentration started. The timing and relative size of the peaks were consistent with previous ARP/MCU testing ${ }^{3}$ and with SB4 sludge only testing of this simulant ${ }^{18}$.

Table 3-4 presents the observed peak off gas concentrations for each run. Slight variation was seen in the peak concentration from run to run during this set of testing. Run SB4-30 had lower peak rates than the other runs, while run SB4-33 had higher peak nitric oxide and nitrous oxide than the other runs. The exact cause for the differences is not known, but some variation is anticipated from run to run due to analytical uncertainty. In all cases, nitric oxide and nitrous oxide peak rates were higher for the MCU runs than for the SB4 sludge only runs ${ }^{18}$. If other runs that were run at higher acid stoichiometries are considered from SB4 sludge only testing ${ }^{18}$, than the peak generation rates are more consistent. Therefore, while the peak generation rates may be slightly different for processing with ARP and MCU, the rates still appear to be within the range of variation expected for the SRAT processing window for SB4.

Table 3-4: Peak Off Gas Generation Rates (Volume \%)

\begin{tabular}{||c|c|c|c|c||}
\hline \hline Run & Peak CO $\mathbf{C}_{\mathbf{2}}$ & Peak NO & Peak $\mathbf{N}_{\mathbf{2}} \mathbf{O}$ & Peak $\mathbf{H}_{\mathbf{2}}$ \\
\hline SB4-18 & 23.64 & 2.131 & 3.197 & 0.002 \\
\hline SB4-29 & 21.02 & 2.041 & 2.735 & Not Detected \\
\hline SB4-30 & 18.09 & 1.623 & 2.525 & Not Detected \\
\hline SB4-31 & 21.28 & 1.950 & 3.430 & Not Detected \\
\hline SB4-33 & 21.28 & 3.506 & 3.912 & 0.122 \\
\hline
\end{tabular}

Condensate samples from run SB4-18 were analyzed to determine any differences from sludge only processing and the anticipated species for DWPF processing. Due to the limited mass of some of the samples and the desire to attempt to close the organic material balance, only limited analyses were performed and not all analytes could be measured. The select species measured are reported in Table 3-5. The data indicated that the condensate sent to the SMECT and captured by the FAVC during ARP boiling will not be as acidic as during SRAT processing. The data further indicate that the MCU addition and concentration will also result in a slight increase in SMECT $\mathrm{pH}$. The SRAT dewater sample can be compared to the previous SB4 sludge only run with this simulant and an equivalent acid addition level. Elemental analyses were not performed on the sludge only dewater sample, but $3380 \mathrm{mg} / \mathrm{L}$ of formate and $13400 \mathrm{mg} / \mathrm{L}$ of nitrate were detected, while the measured $\mathrm{pH}$ was $0.15 .^{18}$ No comparisons can be made to the remaining samples due to the differences in processing. 
Table 3-5: Condensate Analyses from Run SB4-18

\begin{tabular}{|c|c|c|c|c|c|c|}
\hline Sample ID & $\begin{array}{l}\text { ARP Boiling } \\
\text { Concentrate }\end{array}$ & $\begin{array}{c}\text { ARP } \\
\text { Boiling } \\
\text { FAVC }\end{array}$ & $\begin{array}{c}\text { SRAT } \\
\text { Dewater }\end{array}$ & $\begin{array}{c}\text { SMECT } \\
\text { Condensate } \\
\# 1 \\
\end{array}$ & $\begin{array}{c}\text { SMECT } \\
\text { Condensate } \\
\# 2\end{array}$ & $\begin{array}{c}\text { SMECT } \\
\text { Condensate } \\
\# 3\end{array}$ \\
\hline \multicolumn{7}{|c|}{ Elemental $(\mathrm{mg} / \mathrm{L})$} \\
\hline $\mathrm{Al}$ & 0.258 & IS & 1.28 & 0.899 & 0.906 & 0.876 \\
\hline $\mathrm{Ca}$ & 0.156 & IS & 0.897 & 0.435 & 0.469 & 0.415 \\
\hline $\mathrm{Fe}$ & $<0.010$ & IS & $<0.010$ & $<0.010$ & $<0.010$ & $<0.010$ \\
\hline $\mathrm{Hg}$ & NA & NA & 2.0 & 38 & 5.0 & 4.3 \\
\hline $\mathrm{K}$ & 0.285 & IS & 2.01 & 1.70 & 1.71 & 1.73 \\
\hline $\mathrm{Mg}$ & $<0.010$ & IS & $<0.010$ & $<0.010$ & $<0.010$ & $<0.010$ \\
\hline $\mathrm{Mn}$ & $<0.010$ & IS & $<0.010$ & $<0.010$ & $<0.010$ & $<0.010$ \\
\hline $\mathrm{Na}$ & 2.24 & 6.03 & 6.80 & 2.69 & 0.203 & 0.197 \\
\hline $\mathrm{Ni}$ & $<0.010$ & IS & $<0.010$ & $<0.010$ & $<0.010$ & $<0.010$ \\
\hline$S$ & 0.218 & IS & $<0.100$ & $<0.100$ & $<0.100$ & $<0.100$ \\
\hline $\mathrm{Si}$ & NA & NA & 103 & 19.3 & 5.46 & 4.04 \\
\hline \multicolumn{7}{|l|}{ Anions $(\mathrm{mg} / \mathrm{L})$} \\
\hline Formate & $<100$ & $<100$ & 4140 & 594 & $<100$ & $<100$ \\
\hline Nitrite & $\angle 100$ & $\angle 100$ & $\angle 100$ & $\angle 100$ & $\angle 100$ & $<100$ \\
\hline Nitrate & $<100$ & $<100$ & 7205 & 3885 & 572 & 404 \\
\hline \multicolumn{7}{|c|}{ Other Measured Properties } \\
\hline $\begin{array}{c}\text { Density } \\
(\mathrm{g} / \mathrm{ml})\end{array}$ & 1.00 & 1.00 & 1.00 & 1.00 & 1.00 & 1.00 \\
\hline $\mathrm{pH}$ & 4.78 & 6.55 & 1.00 & 1.21 & 2.07 & 2.23 \\
\hline
\end{tabular}

IS - Insufficient sample; NA - Not analyzed

\subsection{Organic Data}

Given the objective of closing the material balance for the MCU organics, the results from the organic analyses were closely monitored and adjustments were made to the testing protocol with each run, as necessary, to try to gain a better material balance closure. As discussed above, the SRAT condenser temperature was changed from $40^{\circ} \mathrm{C}$ in the SB4-18 run to $25^{\circ} \mathrm{C}$ for all of the remaining runs to more closely match the DWPF operating temperature. Furthermore, the FAVC was set at $10^{\circ} \mathrm{C}$ for the SB4-18 run, but was lowered to $4^{\circ} \mathrm{C}$ for the remaining runs to match DWPF operating temperatures. Other changes to the testing protocol/equipment configuration included the following:

- Teflon lines were reduced or shortened to minimize the area available for solvent plating/coating;

- A triple rinse of each component was incorporated to ensure that all of the MCU organic was being removed/recovered instead of a single solvent rinse;

- System fittings were tightened to obtain an outlet flow within $5 \%$ of the target to minimize the potential for solvent loss;

- MCU solvent containing a fluorescent dye was used to provide a visual tracer for the solvent; and

- Post run flushing of the equipment with an air purge was initiated starting with run SB4-30 to try to capture any vaporized Isopar ${ }^{\circledR} \mathrm{L}$.

Another item that was investigated was the solvent being used to rinse the SRAT components after the testing. A limited glass and Isopar ${ }^{\circledR} \mathrm{L}$ recovery test was performed at SRNL, and hexane was selected as the optimal solvent. Initial testing (i.e., runs SB4-18 and SB4-29) used methylene chloride, but hexane appeared to be better suited for this application and was used in the remaining runs. Hexane does have potential 
interference issues during GC-MS analyses, but interference was overcome by using the proper column and equipment settings.

The organic samples can be divided into three primary groupings. The first set includes samples of the SRAT product and condensates generated during processing. The second set includes the solvent rinse solutions that were generated from rinsing the SRAT equipment to remove any organic that adhered to the equipment surfaces. The final grouping would include the carbon tubes that were installed after the FAVC to capture any organics exiting the system in a gas form.

The first set of samples includes the SRAT product, the MWWT, the condensate or SMECT samples collected during MCU addition, and the FAVC. This set of samples required extraction by AD to determine the concentration of MCU organics present. In run SB4-18, several samples of the SRAT product were taken and submitted for different analytical needs. Originally, only one sample was analyzed by AD for organic concentration; however, after no modifier or Isopar ${ }^{\circledR} \mathrm{L}$ was detected, the remaining archived SRAT product was submitted to AD for analyses. Modifier was detected in this sample; therefore, it was assumed that the concentration of modifier in this sample was equivalent to the concentration in the other samples submitted for analyses (except for the first organic AD sample). In run SB4-29, the SRAT product was split in four samples, and two were submitted to AD for organics analysis. For the remaining runs, no SRAT product samples were taken for other analyses and all samples were analyzed by AD. Analytical data from SVOC for Isopar ${ }^{\circledR} \mathrm{L}$ are contained in Table 3-6, while the HPLC data for Modifier are contained in Table 3-7.

The second set of samples or the solvent rinses did not require extractions by AD since they already contained either methylene chloride or hexane as the rinse solvent. As stated above, the initial set of data did not indicate complete recovery of the organic materials, so three independent rinses were performed on the equipment on run SB4-29 and the remaining runs. The equipment rinses were identified as follows (with an explanation of the equipment included):

1) MWWT Rinse - MWWT.

2) FAVC Rinse - the FAVC and offgas line from the SRAT condenser.

3) Post FAVC Rinse - the carbon tube holder and the offgas line from the FAVC to the GC and carbon tubes (rinse inadvertently not performed in SB4-18).

4) SRAT Condenser Rinse - SRAT condenser and off gas line from the SRAT kettle.

5) SRAT Vessel Rinse - SRAT vessel, lid, and attached glassware.

Analytical data from SVOC for Isopar ${ }^{\circledR} \mathrm{L}$ are contained in Table 3-6, while the HPLC data for Modifier are contained in Table 3-7. 
WSRC-TR-2006-00063

Revision 0

Table 3-6: Concentration of Isopar ${ }^{\circledR} \mathrm{L}$ as Measured by SVOC

\begin{tabular}{|c|c|c|c|c|c|}
\hline \multirow{2}{*}{ Sample } & \multicolumn{3}{|c|}{239 ppm Solvent Runs } & \multicolumn{2}{|c|}{50 ppm Solvent Runs } \\
\hline & SB4-18 & SB4-29 & SB4-30 & SB4-31 & SB4-33 \\
\hline MWWT & $130 \mathrm{mg} / \mathrm{L}$ & $1.1 \mathrm{mg} / \mathrm{L}$ & $<10 \mathrm{mg} / \mathrm{kg}$ & $0.18 \mathrm{mg} / \mathrm{kg}$ & $<1 \mathrm{mg} / \mathrm{L}$ \\
\hline \multirow{3}{*}{ MWWT rinse } & \multirow{3}{*}{$940 \mathrm{mg} / \mathrm{L}$} & $60 \cdot \mathrm{g} / \mathrm{g}$ & \multirow{3}{*}{$<0.3 \mathrm{mg}$} & \multirow{3}{*}{$2.7 \mathrm{mg} / \mathrm{L}$} & \multirow{3}{*}{$26 \mathrm{mg} / \mathrm{L}$} \\
\hline & & $1.5 \cdot \mathrm{g} / \mathrm{g}$ & & & \\
\hline & & $0.33 \cdot \mathrm{g} / \mathrm{g}$ & & & \\
\hline \multirow{3}{*}{ SMECT condensate } & \multirow{3}{*}{$<1 \mathrm{mg} / \mathrm{L}$} & $<0.02 \mathrm{mg} / \mathrm{L}$ & $<10 \mathrm{mg} / \mathrm{kg}$ & $<1 \mathrm{mg} / \mathrm{L}$ & $<1 \mathrm{mg} / \mathrm{L}$ \\
\hline & & $<0.02 \mathrm{mg} / \mathrm{L}$ & $<10 \mathrm{mg} / \mathrm{kg}$ & $<1 \mathrm{mg} / \mathrm{L}$ & $<1 \mathrm{mg} / \mathrm{L}$ \\
\hline & & $<0.02 \mathrm{mg} / \mathrm{L}$ & $<10 \mathrm{mg} / \mathrm{kg}$ & $<1 \mathrm{mg} / \mathrm{L}$ & $<1 \mathrm{mg} / \mathrm{L}$ \\
\hline \multirow{3}{*}{ SRAT condenser rinse } & \multirow{3}{*}{$<1 \mathrm{mg} / \mathrm{L}$} & $0.42 \cdot \mathrm{g} / \mathrm{g}$ & \multirow{3}{*}{$<0.3 \mathrm{mg}$} & \multirow{3}{*}{$<1 \mathrm{mg} / \mathrm{L}$} & \multirow{3}{*}{$<1 \mathrm{mg} / \mathrm{L}$} \\
\hline & & $0.35 \cdot \mathrm{g} / \mathrm{g}$ & & & \\
\hline & & $0.17 \cdot \mathrm{g} / \mathrm{g}$ & & & \\
\hline FAVC & $<1 \mathrm{mg} / \mathrm{L}$ & $<0.02 \mathrm{mg} / \mathrm{L}$ & $<10 \mathrm{mg} / \mathrm{kg}$ & $<1 \mathrm{mg} / \mathrm{L}$ & $<1 \mathrm{mg} / \mathrm{L}$ \\
\hline \multirow{3}{*}{ FAVC rinse } & \multirow{3}{*}{$160 \mathrm{mg} / \mathrm{L}$} & $32 \cdot \mathrm{g} / \mathrm{g}$ & \multirow{3}{*}{$<0.4 \mathrm{mg}$} & \multirow{3}{*}{$<1 \mathrm{mg} / \mathrm{L}$} & \multirow{3}{*}{$<1 \mathrm{mg} / \mathrm{L}$} \\
\hline & & $0.38 \cdot \mathrm{g} / \mathrm{g}$ & & & \\
\hline & & $0.15 \cdot \mathrm{g} / \mathrm{g}$ & & & \\
\hline \multirow{3}{*}{ Post FAVC rinse } & \multirow{3}{*}{ N/A } & $0.13 \cdot \mathrm{g} / \mathrm{g}$ & \multirow{3}{*}{$<0.2 \mathrm{mg}$} & \multirow{3}{*}{$<1 \mathrm{mg} / \mathrm{L}$} & \multirow{3}{*}{$<1 \mathrm{mg} / \mathrm{L}$} \\
\hline & & $0.29 \cdot \mathrm{g} / \mathrm{g}$ & & & \\
\hline & & $0.42 \cdot \mathrm{g} / \mathrm{g}$ & & & \\
\hline \multirow{5}{*}{ SRAT product } & \multirow{5}{*}{$<1 \mathrm{mg} / \mathrm{L}$} & \multirow{3}{*}{$<0.02 \mathrm{mg} / \mathrm{L}$} & $<10 \mathrm{mg} / \mathrm{kg}$ & $<1 \mathrm{mg} / \mathrm{L}$ & $<1 \mathrm{mg} / \mathrm{L}$ \\
\hline & & & $<10 \mathrm{mg} / \mathrm{kg}$ & $<1 \mathrm{mg} / \mathrm{L}$ & $<1 \mathrm{mg} / \mathrm{L}$ \\
\hline & & & $<10 \mathrm{mg} / \mathrm{kg}$ & $<1 \mathrm{mg} / \mathrm{L}$ & $<1 \mathrm{mg} / \mathrm{L}$ \\
\hline & & \multirow{2}{*}{$<0.02 \mathrm{mg} / \mathrm{L}$} & $<10 \mathrm{mg} / \mathrm{kg}$ & $<1 \mathrm{mg} / \mathrm{L}$ & $<1 \mathrm{mg} / \mathrm{L}$ \\
\hline & & & $<10 \mathrm{mg} / \mathrm{kg}$ & $<1 \mathrm{mg} / \mathrm{L}$ & $<1 \mathrm{mg} / \mathrm{L}$ \\
\hline \multirow{6}{*}{ SRAT vessel rinse } & \multirow{6}{*}{$<1 \mathrm{mg} / \mathrm{L}$} & $2.5 \cdot \mathrm{g} / \mathrm{g}$ & & & \\
\hline & & $0.15 \cdot \mathrm{g} / \mathrm{g}$ & $<1.4 \mathrm{mg}$ & $<1 \mathrm{mg} / \mathrm{L}$ & $<1 \mathrm{mg} / \mathrm{L}$ \\
\hline & & $0.30 \cdot \mathrm{g} / \mathrm{g}$ & & & \\
\hline & & $22 \cdot \mathrm{g} / \mathrm{g}$ & & & \\
\hline & & $0.87 \cdot \mathrm{g} / \mathrm{g}$ & $<0.6 \mathrm{mg}$ & $<1 \mathrm{mg} / \mathrm{L}$ & $0.22 \mathrm{mg} / \mathrm{kg}$ \\
\hline & & $4.8 \cdot \mathrm{g} / \mathrm{g}$ & & & \\
\hline
\end{tabular}

Notes: N/A - Sample not taken. SB4-29 used three rinses, and samples were submitted independently. For the remaining runs, triple rinses were performed but were combined for submittal. For SB4-18, the SRAT kettle and lid (with the ports and feed throughs) were washed as one sample. In the remaining runs, the rinses were split between the top and bottom of the kettle. The one sigma error associated with each value was $\pm 20 \%$ for runs SB4-18, SB4-29, and SB4-30, while it was $\pm 10 \%$ for runs SB4-31 and SB4-33. 
Table 3-7: Concentration of Modifier as Measured by HPLC

\begin{tabular}{|c|c|c|c|c|c|}
\hline \multirow{2}{*}{ Sample } & \multicolumn{3}{|c|}{239 ppm Solvent Runs } & \multicolumn{2}{|c|}{50 ppm Solvent Runs } \\
\hline & SB4-18 & SB4-29 & SB4-30 & SB4-31 & SB4-33 \\
\hline MWWT & $67 \mathrm{mg} / \mathrm{L}$ & $72 \mathrm{mg} / \mathrm{L}$ & $15 \mathrm{mg} / \mathrm{L}$ & $3 \mathrm{mg} / \mathrm{L}$ & $4 \mathrm{mg} / \mathrm{L}$ \\
\hline \multirow{3}{*}{ MWWT rinse } & \multirow{3}{*}{$476 \mathrm{mg} / \mathrm{L}$} & $815 \mathrm{mg} / \mathrm{L}$ & \multirow{3}{*}{$751 \mathrm{mg} / \mathrm{L}$} & \multirow{3}{*}{$112 \mathrm{mg} / \mathrm{L}$} & \multirow{3}{*}{$167 \mathrm{mg} / \mathrm{L}$} \\
\hline & & $30 \mathrm{mg} / \mathrm{L}$ & & & \\
\hline & & $<25 \mathrm{mg} / \mathrm{L}$ & & & \\
\hline \multirow{3}{*}{ SMECT condensate* } & $<10 \mathrm{mg} / \mathrm{L}$ & $10 \mathrm{mg} / \mathrm{L}$ & $8 \mathrm{mg} / \mathrm{L}$ & $<1 \mathrm{mg} / \mathrm{L}$ & $<1 \mathrm{mg} / \mathrm{L}$ \\
\hline & $<10 \mathrm{mg} / \mathrm{L}$ & $20 \mathrm{mg} / \mathrm{L}$ & $24 \mathrm{mg} / \mathrm{L}$ & $2 \mathrm{mg} / \mathrm{L}$ & $3 \mathrm{mg} / \mathrm{L}$ \\
\hline & $<10 \mathrm{mg} / \mathrm{L}$ & $28 \mathrm{mg} / \mathrm{L}$ & $27 \mathrm{mg} / \mathrm{L}$ & $4 \mathrm{mg} / \mathrm{L}$ & $7 \mathrm{mg} / \mathrm{L}$ \\
\hline \multirow{3}{*}{ SRAT condenser rinse } & \multirow{3}{*}{$121 \mathrm{mg} / \mathrm{L}$} & $365 \mathrm{mg} / \mathrm{L}$ & \multirow{3}{*}{$457 \mathrm{mg} / \mathrm{L}$} & \multirow{3}{*}{$93 \mathrm{mg} / \mathrm{L}$} & \multirow{3}{*}{$69 \mathrm{mg} / \mathrm{L}$} \\
\hline & & $<25 \mathrm{mg} / \mathrm{L}$ & & & \\
\hline & & $25 \mathrm{mg} / \mathrm{L}$ & & & \\
\hline FAVC & $<10 \mathrm{mg} / \mathrm{L}$ & $<4 \mathrm{mg} / \mathrm{L}$ & $<5 \mathrm{mg} / \mathrm{L}$ & $<3 \mathrm{mg} / \mathrm{L}$ & $<3 \mathrm{mg} / \mathrm{L}$ \\
\hline \multirow{3}{*}{ FAVC rinse } & \multirow{3}{*}{$<20 \mathrm{mg} / \mathrm{L}$} & $<25 \mathrm{mg} / \mathrm{L}$ & \multirow{3}{*}{$7 \mathrm{mg} / \mathrm{L}$} & \multirow{3}{*}{$<5 \mathrm{mg} / \mathrm{L}$} & \multirow{3}{*}{$<5 \mathrm{mg} / \mathrm{L}$} \\
\hline & & $<25 \mathrm{mg} / \mathrm{L}$ & & & \\
\hline & & $<25 \mathrm{mg} / \mathrm{L}$ & & & \\
\hline \multirow{3}{*}{ Post FAVC rinse } & \multirow{3}{*}{ N/A } & $<25 \mathrm{mg} / \mathrm{L}$ & \multirow{3}{*}{$18 \mathrm{mg} / \mathrm{L}$} & \multirow{3}{*}{$<5 \mathrm{mg} / \mathrm{L}$} & \multirow{3}{*}{$<5 \mathrm{mg} / \mathrm{L}$} \\
\hline & & $<25 \mathrm{mg} / \mathrm{L}$ & & & \\
\hline & & $<25 \mathrm{mg} / \mathrm{L}$ & & & \\
\hline \multirow{5}{*}{ SRAT product ${ }^{*}$} & \multirow{3}{*}{$<10 \mathrm{mg} / \mathrm{L}$} & \multirow{3}{*}{$5 \mathrm{mg} / \mathrm{L}$} & $10 \mathrm{mg} / \mathrm{L}$ & $3 \mathrm{mg} / \mathrm{L}$ & $48 \mathrm{mg} / \mathrm{L}$ \\
\hline & & & $3 \mathrm{mg} / \mathrm{L}$ & $6 \mathrm{mg} / \mathrm{L}$ & $4 \mathrm{mg} / \mathrm{L}$ \\
\hline & & & $11 \mathrm{mg} / \mathrm{L}$ & $7 \mathrm{mg} / \mathrm{L}$ & $4 \mathrm{mg} / \mathrm{L}$ \\
\hline & \multirow{2}{*}{$52 \mathrm{mg} / \mathrm{L}$} & \multirow{2}{*}{$10 \mathrm{mg} / \mathrm{L}$} & $22 \mathrm{mg} / \mathrm{L}$ & $11 \mathrm{mg} / \mathrm{L}$ & $4 \mathrm{mg} / \mathrm{L}$ \\
\hline & & & $34 \mathrm{mg} / \mathrm{L}$ & $33 \mathrm{mg} / \mathrm{L}$ & $4 \mathrm{mg} / \mathrm{L}$ \\
\hline \multirow{6}{*}{ SRAT vessel rinse ${ }^{\dagger}$} & \multirow{6}{*}{$167 \mathrm{mg} / \mathrm{L}$} & $1355 \mathrm{mg} / \mathrm{L}$ & & & \\
\hline & & $85 \mathrm{mg} / \mathrm{L}$ & $64 \mathrm{mg} / \mathrm{L}$ & $<5 \mathrm{mg} / \mathrm{L}$ & $<5 \mathrm{mg} / \mathrm{L}$ \\
\hline & & $<25 \mathrm{mg} / \mathrm{L}$ & & & \\
\hline & & $80 \mathrm{mg} / \mathrm{L}$ & & & \\
\hline & & $<25 \mathrm{mg} / \mathrm{L}$ & $73 \mathrm{mg} / \mathrm{L}$ & $<5 \mathrm{mg} / \mathrm{L}$ & $40 \mathrm{mg} / \mathrm{L}$ \\
\hline & & $<25 \mathrm{mg} / \mathrm{L}$ & & & \\
\hline
\end{tabular}

Notes: N/A - Sample not taken. The SMECT condensate is taken in three bottles and, thus, has three samples for analysis. SB4-29 used three rinses, and samples were submitted independently. For the remaining runs, triple rinses were performed but were combined for submittal. For SB4-18, the SRAT kettle and lid (with the ports and feed throughs) were washed as one sample. In the remaining runs, the rinses were split between the top and bottom of the kettle. The one sigma error associated with each value was $\pm 10 \%$.

The changes in the processing strategy implemented after run SB4-18 resulted in changes in the Isopar ${ }^{\circledR} \mathrm{L}$ concentration detected in the remaining runs. Very little to no Isopar ${ }^{\circledR} \mathrm{L}$ was detected in any of the SRAT condensers or in the SRAT product after run SB4-18. The triple rinsing performed in run SB4-29 indicated that Isopar ${ }^{\circledR} \mathrm{L}$ was still clinging to the vessel walls and condenser lines after the first rinse. The data also indicated that a more effective rinsing solvent might be necessary. The combination of the two findings led to triple rinsing and hexane being used in the remaining runs. However, as indicated earlier, the triple rinses were combined as one sample for the remaining runs instead of as independent samples for analyses. Overall, the data indicated that the rinses had greater concentrations of Isopar ${ }^{\circledR} \mathrm{L}$ than in the actual condensate or SRAT product samples.

Changes in the modifier results were also seen after implementing the processing changes. Modifier was detected in all samples or locations except for in the FAVC condensate. A very small amount of modifier was detected in the FAVC rinse and the post FAVC rinse in the SB4-30 run only. For the 239 ppm runs, the 
lower detection limit in the HPLC analysis for run SB4-30 is likely the cause of the difference. The SRAT condenser temperature change to $25^{\circ} \mathrm{C}$ appeared to result in slightly more modifier being collected in or on the SRAT condenser, MWWT and the SMECT. The concentration of modifier in the SRAT product or on the SRAT kettle varied from run to run. This variation was likely the result of the modifier being insoluble in the SRAT product. In some of the runs, the modifier was seen floating on the product surface, so the method preparing the samples had an impact on the concentration found in each sample. Therefore, the total mass of modifier found in the SRAT kettle is probably a better indication of the hold-up than the individual samples.

BOBCalixC6 was only present in the SB4-18 run since the MCU solvent used in the other runs was from the SEFT testing. When the samples from this run were analyzed, BobCalixC6 was only detected in the syringe rinse sample. Although organomercury compounds were found in previous testing ${ }^{3}$, chloromethyl mercury was only found in the FAVC sample for run SB4-18 in this set of testing. The measured concentration was 1 $\mathrm{mg} / \mathrm{L}$. No other organomercury compounds were detected in any of the samples. The presence of organomercury compounds was cited as a potential concern in previous MCU testing; however, at the concentrations tested and the process addition strategy used in this study, the formation of the compounds does not appear to be a problem.

To better estimate the actual solvent that was added to the system, the syringe pump and the feed line were also rinsed to determine the amount of solvent remaining in the syringe and in the feed line. The data from the syringe rinses is given in Table 3-8. The syringe rinses from runs SB4-18 and SB4-29 included the syringe and the feed line. For runs SB4-30 and SB4-31, the first sample included only the contents of the syringe, while the other sample included rinse material from the syringe and the feed line. In SB4-33, the sampling protocol was changed slightly with the first rinse covering only the syringe and not the feed line.

Table 3-8: Syringe Rinse Data for Isopar ${ }^{\circledR} L$ and Modifer

\begin{tabular}{|c|c|c|c|c|c|}
\hline Run ID & SB4-18 & SB4-29 & SB4-30 & SB4-31 & SB4-33 \\
\hline \multirow{3}{*}{ Isopar ${ }^{\circledR} \mathrm{L}$} & \multirow{3}{*}{$8600 \mathrm{mg} / \mathrm{L}$} & $3829 \mathrm{ug} / \mathrm{g}$ & $110000 \mathrm{mg} / \mathrm{L}$ & $680 \mathrm{mg} / \mathrm{L}$ & $650 \mathrm{mg} / \mathrm{L}$ \\
\hline & & $18 \mathrm{ug} / \mathrm{g}$ & \multirow{2}{*}{$<0.1 \mathrm{mg}$} & \multirow{2}{*}{$222 \mathrm{mg} / \mathrm{L}$} & \multirow{2}{*}{$500 \mathrm{mg} / \mathrm{L}$} \\
\hline & & $9.6 \mathrm{ug} / \mathrm{g}$ & & & \\
\hline \multirow{3}{*}{ Modifier } & \multirow{3}{*}{$3832 \mathrm{mg} / \mathrm{L}$} & $5600 \mathrm{mg} / \mathrm{L}$ & $5870 \mathrm{mg} / \mathrm{L}$ & $3431 \mathrm{mg} / \mathrm{L}$ & $2554 \mathrm{mg} / \mathrm{L}$ \\
\hline & & $35 \mathrm{mg} / \mathrm{L}$ & \multirow{2}{*}{$1094 \mathrm{mg} / \mathrm{L}$} & \multirow{2}{*}{$360 \mathrm{mg} / \mathrm{L}$} & \multirow{2}{*}{$342 \mathrm{mg} / \mathrm{L}$} \\
\hline & & $35 \mathrm{mg} / \mathrm{L}$ & & & \\
\hline
\end{tabular}

The last set of samples, the carbon tubes, was prepared as indicated in section 2.3.1. Preparation included carbon disulfide extraction of the carbon tubes. A total of 18 carbon tubes were generated in each run, with 6 tubes being used at a time to collect the offgas. The tubes were changed roughly every $4-4 \frac{1}{2}$ hours during MCU addition. In all but run SB4-29, the 18 carbon tubes were analyzed as individual tubes. For run SB429 , the carbon tubes in a set (the 6 tubes from each $\sim 4$ hour block) were combined, extracted, and then analyzed. Due to the lower initial recoveries on the carbon tubes, the affinity for the coconut shell carbon tubes to collect Isopar ${ }^{\circledR} \mathrm{L}$ was investigated with the manufacturer of the tubes. However, the manufacturer did not identify any potential issues with using the carbon tubes for this application. Based on SRNL spiking and recovery testing with the tubes, SRNL also felt that the carbon tubes were sufficient. No evidence of Isopar ${ }^{\circledR} \mathrm{L}$ carry-over to the back sides of the carbon tubes was seen, which supported the capacity of the tubes for Isopar ${ }^{\circledR}$ L. During the analysis of the carbon tubes from the SB4-30 run, it was noticed that drift in the Isopar ${ }^{\mathbb{B}} \mathrm{L}$ concentration was occurring over time. By interspersing standards throughout the run, the impact of the drift was minimized and more accurate Isopar ${ }^{\circledR} \mathrm{L}$ numbers were obtained. Table 3-9 presents the data from the analysis of the carbon tubes. Figure A - 9 through Figure A - 12 show the plots of the individual carbon tube measurements. Some variation was seen from tube to tube within a set and also from set to set. 
No consistent pattern was evident, but typically higher concentrations of Isopar ${ }^{\circledR} \mathrm{L}$ were found on the later sets of carbon tubes. Possible explanations for this finding are slightly higher organic addition rates being used towards the end of the $50 \mathrm{ppm}$ runs to meet the addition time (i.e., a matching addition rate could not be used due to the one significant figure available with the syringe pump), sufficient time being needed to completely volatilize the Isopar ${ }^{\circledR} \mathrm{L}$ so it could be captured, and the additional purging of the SRAT equipment after the run that would have been captured on the last set of tubes. The first set of carbon tubes was also analyzed by HPLC to determine the modifier concentration; however, no modifier was detected in any of the carbon tube extractions. No other carbon tubes were analyzed for modifier based on the initial analyses, coupled with the fact that very little modifier was detected in the FAVC or post FAVC samples.

Table 3-9: Isopar ${ }^{\circledR} L$ Data from Carbon Tubes

\begin{tabular}{||c|c|c|c|c|c||}
\hline In Process Sample & SB4-18 & SB4-29 & SB4-30 & SB4-31 & SB4-33 \\
\hline Tubes 1 - 6 & $8.915 \mathrm{mg}$ & $49.7 \mathrm{mg}$ & $71.29 \mathrm{mg}$ & $4.330 \mathrm{mg}$ & $0.6938 \mathrm{mg}$ \\
\hline Tubes 7 - 12 & $59.32 \mathrm{mg}$ & $32.0 \mathrm{mg}$ & $103.21 \mathrm{mg}$ & $3.805 \mathrm{mg}$ & $24.64 \mathrm{mg}$ \\
\hline Tubes $13-18$ & $84.51 \mathrm{mg}$ & $39.7 \mathrm{mg}$ & $100.64 \mathrm{mg}$ & $23.23 \mathrm{mg}$ & $39.53 \mathrm{mg}$ \\
\hline
\end{tabular}

The information from tables Table 3-6 through Table 3-9, along with the associated masses/volumes of the sample, were used to determine the material balance around the system for Isopar ${ }^{\circledR} \mathrm{L}$ and modifier for each run. The syringe rinse data was specifically used to calculate the actual amount of solvent that was added to the system. Table 3-10 presents both the mass and relative percent of Isopar ${ }^{\circledR} \mathrm{L}$ found in each sample or within each location in the SRAT system. Table 3-11 provides similar data for the modifier.

Table 3-10: Isopar $^{\circledR} \mathrm{L}$ Material Balance

\begin{tabular}{|c|c|c|c|c|c|c|c|c|c|c|}
\hline \multirow{3}{*}{ Sample } & \multicolumn{6}{|c|}{239 ppm Solvent Runs } & \multicolumn{4}{|c|}{50 ppm Solvent Runs } \\
\hline & \multicolumn{2}{|c|}{ SB4-18 } & \multicolumn{2}{|c|}{ SB4-29 } & \multicolumn{2}{|c|}{ SB4-30 } & \multicolumn{2}{|c|}{ SB4-31 } & \multicolumn{2}{|c|}{ SB4-33 } \\
\hline & $\begin{array}{c}\text { Mass } \\
(\mathrm{mg})\end{array}$ & $\begin{array}{l}\% \text { of } \\
\text { total }\end{array}$ & $\begin{array}{c}\text { Mass } \\
(\mathrm{mg})\end{array}$ & $\begin{array}{l}\% \text { of } \\
\text { total }\end{array}$ & $\begin{array}{c}\text { Mass } \\
(\mathrm{mg})\end{array}$ & $\begin{array}{l}\% \text { of } \\
\text { total }\end{array}$ & $\begin{array}{c}\text { Mass } \\
(\mathrm{mg})\end{array}$ & $\begin{array}{l}\% \text { of } \\
\text { total }\end{array}$ & $\begin{array}{c}\text { Mass } \\
(\mathrm{mg})\end{array}$ & $\begin{array}{l}\% \text { of } \\
\text { total }\end{array}$ \\
\hline Mass added & 412.6 & -- & 382.5 & -- & 372.1 & -- & 66.9 & -- & 71.1 & -- \\
\hline MWWT & 7.280 & $1.8 \%$ & 0.062 & $0.016 \%$ & ND & ND & 0.010 & $0.015 \%$ & ND & $\mathrm{ND}$ \\
\hline MWWT rinse & 17.86 & $4.3 \%$ & 1.147 & $0.457 \%$ & ND & $\mathrm{ND}$ & 0.041 & $0.061 \%$ & 0.592 & $0.832 \%$ \\
\hline SMECT condensate & ND & ND & ND & ND & ND & ND & ND & $\mathrm{ND}$ & ND & ND \\
\hline SRAT condenser rinse & $\mathrm{ND}$ & ND & 0.034 & $0.009 \%$ & ND & $\mathrm{ND}$ & ND & $\mathrm{ND}$ & $\mathrm{ND}$ & ND \\
\hline FAVC & $\mathrm{ND}$ & $\mathrm{ND}$ & ND & ND & $\mathrm{ND}$ & ND & ND & ND & $\mathrm{ND}$ & $\mathrm{ND}$ \\
\hline FAVC rinse & 3.840 & $0.93 \%$ & 1.876 & $0.491 \%$ & $\mathrm{ND}$ & ND & $\mathrm{ND}$ & ND & $\mathrm{ND}$ & $\mathrm{ND}$ \\
\hline Post FAVC rinse & N/A & N/A & 0.013 & $0.004 \%$ & ND & ND & ND & ND & ND & ND \\
\hline SRAT product & $\mathrm{ND}$ & $\mathrm{ND}$ & $\mathrm{ND}$ & ND & ND & $\mathrm{ND}$ & ND & $\mathrm{ND}$ & 0.047 & $0.066 \%$ \\
\hline SRAT vessel rinse & ND & ND & 2.678 & $0.700 \%$ & ND & ND & ND & ND & ND & ND \\
\hline Carbon tubes & 152.7 & $37.0 \%$ & 121.4 & $31.7 \%$ & 275.0 & $73.9 \%$ & 31.36 & $46.9 \%$ & 64.86 & $91.2 \%$ \\
\hline Total Recovered & 181.7 & $44.0 \%$ & 127.8 & $33.4 \%$ & 275.0 & $73.9 \%$ & 31.41 & $47.0 \%$ & 65.50 & $92.1 \%$ \\
\hline
\end{tabular}


WSRC-TR-2006-00063

Revision 0

Table 3-11: Modifier Material Balance

\begin{tabular}{|c|c|c|c|c|c|c|c|c|c|c|}
\hline \multirow{3}{*}{ Sample } & \multicolumn{6}{|c|}{239 ppm Solvent Runs } & \multicolumn{4}{|c|}{ 50 ppm Solvent Runs } \\
\hline & \multicolumn{2}{|c|}{ SB4-18 } & \multicolumn{2}{|c|}{ SB4-29 } & \multicolumn{2}{|c|}{ SB4-30 } & \multicolumn{2}{|c|}{ SB4-31 } & \multicolumn{2}{|c|}{ SB4-33 } \\
\hline & $\begin{array}{l}\text { Mass } \\
\text { (mg) }\end{array}$ & $\begin{array}{l}\% \text { of } \\
\text { total }\end{array}$ & $\begin{array}{l}\text { Mass } \\
\text { (mg) }\end{array}$ & $\begin{array}{l}\% \text { of } \\
\text { total }\end{array}$ & $\begin{array}{c}\text { Mass } \\
(\mathrm{mg})\end{array}$ & $\begin{array}{l}\% \text { of } \\
\text { total }\end{array}$ & $\begin{array}{c}\text { Mass } \\
\text { (mg) }\end{array}$ & $\begin{array}{l}\% \text { of } \\
\text { total }\end{array}$ & $\begin{array}{c}\text { Mass } \\
(\mathrm{mg})\end{array}$ & $\begin{array}{l}\% \text { of } \\
\text { total }\end{array}$ \\
\hline Mass added & 177.6 & $-\overline{-1}$ & 172.1 & -- & 157.7 & -- & 28.3 & $-\overline{-1}$ & 30.9 & $-\overline{-1}$ \\
\hline MWWT & 3.75 & $2.11 \%$ & 4.054 & $2.36 \%$ & 0.860 & $0.545 \%$ & 0.168 & $0.594 \%$ & 0.220 & $0.712 \%$ \\
\hline MWWT rinse & 9.05 & $5.09 \%$ & 18.00 & $10.5 \%$ & 24.05 & $15.3 \%$ & 1.684 & $5.96 \%$ & 3.801 & $12.3 \%$ \\
\hline SMECT condensate & ND & ND & 33.88 & $19.7 \%$ & 41.46 & $26.3 \%$ & 4.190 & $14.8 \%$ & 7.070 & $22.9 \%$ \\
\hline SRAT condenser rinse & 3.39 & $1.91 \%$ & 11.48 & $6.67 \%$ & 15.19 & $9.63 \%$ & 1.947 & $6.89 \%$ & 1.885 & $6.10 \%$ \\
\hline FAVC & ND & ND & ND & ND & ND & ND & ND & ND & ND & ND \\
\hline FAVC rinse & ND & ND & ND & ND & 0.256 & $0.162 \%$ & ND & ND & ND & ND \\
\hline Post FAVC rinse & N/A & N/A & ND & ND & 0.317 & $0.201 \%$ & ND & ND & ND & ND \\
\hline SRAT product & 52.38 & $29.5 \%$ & 14.47 & $8.41 \%$ & 32.88 & $20.9 \%$ & 17.52 & $62.0 \%$ & 14.68 & $47.6 \%$ \\
\hline SRAT vessel rinse & 6.51 & $3.67 \%$ & 74.53 & $43.3 \%$ & 12.14 & $7.70 \%$ & ND & ND & 3.445 & $11.2 \%$ \\
\hline Carbon tubes & ND & ND & N/A & N/A & N/A & N/A & N/A & N/A & N/A & N/A \\
\hline Total Recovered & 75.06 & $42.3 \%$ & 156.4 & $90.9 \%$ & 127.2 & $80.6 \%$ & 25.51 & $90.2 \%$ & 31.10 & $101 \%$ \\
\hline
\end{tabular}

ND - Concentration was below the detection limit, N/A - not measured,

Based on the mass of Isopar ${ }^{\circledR} \mathrm{L}$ and modifier actually added in each run, the solvent equivalent concentration was calculated for each run. Based on Isopar ${ }^{\circledR} \mathrm{L}$, solvent addition concentrations were $272 \mathrm{ppm}$ for run SB418, 243 ppm for run SB4-29, 237 ppm for run SB4-30, 43 ppm in run SB4-31, and 45 ppm in run SB4-33. Based on the modifier, solvent addition concentrations were were $272 \mathrm{ppm}$ for run SB4-18, 243 ppm for run SB4-29, 223 ppm for run SB4-30, 40 ppm for run SB4-31, and 44 ppm for run SB4-33.

In the case of Isopar ${ }^{\circledR} \mathrm{L}$, very little was found in the SRAT system. Typically, the rinse solutions contained higher concentrations of Isopar ${ }^{\circledR} \mathrm{L}$ than the actual condensate solutions. This indicated that the Isopar ${ }^{\circledR} \mathrm{L}$ had an affinity to collect on the SRAT equipment surfaces. The amounts of Isopar ${ }^{\circledR} \mathrm{L}$ found in the condensers was much less than what was seen in previous testing. The earlier high numbers may have been the result of slug feeding of the MCU solvent in those runs. For Run SB4-18, the amount of Isopar ${ }^{\circledR} \mathrm{L}$ found in the system was higher than the rest of the runs. This run also had a slight problem with feeding the MCU solvent since it was fed by itself through a long feed line (as opposed to being co-fed with the MCU aqueous that helped carry the solvent to the kettle). This required some adjustments during the test, which resulted in a higher concentration of solvent being transferred in while the feed problem was being corrected. Even though $100 \%$ recovery was not obtained in any run, the repeatability of the low concentrations found in the offgas samples indicates that a small concentration of Isopar ${ }^{\circledR} \mathrm{L}$ would be expected. Even if the SVOC data was a factor low due to difficulties in measuring small quantities of organics, the amounts of Isopar ${ }^{\circledR} \mathrm{L}$ retained in the system are still small.

The modifier recovery was greater than $90 \%$ in three of the runs. Therefore, the indicated partitioning should be a fairly good indicator of where the modifier will collect in the SRAT system. The data indicate that roughly half of the modifier will remain in the SRAT product. Very little is expected to collect in the FAVC or be emitted from the offgas. The rest of the modifier is likely to collect in the MWWT, the SMECT, and in the process vessel vent lines throughout the CPC equipment. Although the modifier is not a flammability concern, it has both a tendency to coat surfaces (as indicated by the amount found in the condenser rinses) and to float on liquid surfaces (as seen on the SRAT product in this run and in the SEFT mixing testing ${ }^{9}$ ). Therefore, a strategy to deal with the potential accumulation and ability to re-suspend the modifier in the condenser systems will likely be needed in DWPF. 


\subsection{SRAT Product Characterization}

Only select samples were submitted for non-organic analysis since the primary objective of this set of testing was to close the organic material balance. Complete characterization was performed on the SRAT product from run SB4-18, while limited characterization was performed on the SRAT product from run SB4-29. The limited analysis allowed for the evaluation of the impact of the ARP addition strategy. The product anion concentrations are given in Table 3-12.

Table 3-12: SRAT Product Anion Concentration (mg/kg)

\begin{tabular}{||c|c|c|c||}
\hline Run ID & Nitrite & Nitrate & Formate \\
\hline SB4-18 & 874 & 25000 & 51300 \\
\hline SB4-29 & 663 & 23750 & 47750 \\
\hline
\end{tabular}

Note: Analyses performed on weighted dilution of samples.

Results represent an average of two measurements.

The data indicate that the DWPF goal of nitrite destruction to $<1000 \mathrm{mg} / \mathrm{kg}$ was met in both runs. When potential analytical uncertainty is considered, the data was similar to the results from previous MCU/ARP testing $^{3}$ and to SB4 sludge only testing with this simulant and an equivalent acid addition level ${ }^{18}$.

Before the testing was initiated and in order to calculate the acid addition amounts, assumptions on the nitrite destruction, nitrite to nitrate conversion, and formate destruction had to be made. The values assumed in the calculations (see Table 3-2) were based on the calculated values from previous MCU/ARP testing ${ }^{3}$. After the testing was completed, the anion concentrations in Table 3-12, along with the mass balance for the runs, were used to calculate the destruction and conversion values for runs SB4-18 and SB4-29. The calculated numbers are given in Table 3-13. Formate destruction was slightly less in run SB4-18 compared to the SB429 run and the previous runs. This may have been due to the dewatering that was performed during acid addition for run SB4-18. Since that run, the operating strategy for lab-scale testing has changed to be consistent with DWPF processing. Based on the data in Table 3-13, it appears that formate destruction may be slightly impacted by the ARP/MCU incorporation.

Table 3-13: SRAT Nitrite to Nitrate Conversions and Formate Destructions

\begin{tabular}{||c|c|c|c||}
\hline Run ID & $\begin{array}{c}\text { Nitrite } \\
\text { Destruction }\end{array}$ & $\begin{array}{c}\text { Nitrite to Nitrate } \\
\text { Conversion }\end{array}$ & $\begin{array}{c}\text { Formate } \\
\text { Destruction }\end{array}$ \\
\hline SB4-18 & $94.7 \%$ & $12.9 \%$ & $17.6 \%$ \\
\hline SB4-29 & $95.9 \%$ & $10.7 \%$ & $21.6 \%$ \\
\hline Pre-Run Assumption* & $100 \%$ & $12 \%$ & $20 \%$ \\
\hline SB4 Sludge Only & $95.2 \%$ & $10.4 \%$ & $24.3 \%$ \\
\hline
\end{tabular}

*Based on SB4-13 run from previous ARP/MCU testing.

Due to the slight changes in destruction numbers realized and some variation in the actual acid addition and dewatering numbers in the runs, the acid stoichiometry and redox values changed slightly versus the targets given in Table 3-2. The acid stoichiometry for runs SB4-18, SB4-29, SB4-30, and SB4-31 was within 0.1\%, while the over-addition in run SB4-33 resulted in an acid stoichiometry closer to $178.4 \%$. The re-calculated estimated redox ratio for the SB4-18 run was 0.198, while it was slightly lower for SB4-29 at $\sim 0.191$. The extra formic acid added in run SB4-33 resulted in an estimated redox ratio of 0.253.

As mentioned in Section 2.3.2, the SB4-18 SRAT product was calcined at $1100^{\circ} \mathrm{C}$ in order to prepare the sample for cation analyses. The elements detected in the calcined solids are given in Table 3-14. When the SRAT product composition is compared with the simulant compositions given in Table 3-1, very slight 
WSRC-TR-2006-00063

Revision 0

variation is seen. However, the variation is not unreasonable given the sampling methods and analytical uncertainty.

Table 3-14: SB4-18 SRAT Product Elemental Data - Calcined Solids Wt\%

\begin{tabular}{||c|c||}
\hline Element & SB4-18 \\
\hline $\mathrm{Al}$ & 13.8 \\
\hline $\mathrm{B}$ & $<0.100$ \\
\hline $\mathrm{Ba}$ & 0.166 \\
\hline $\mathrm{Ca}$ & 1.94 \\
\hline $\mathrm{Cr}$ & 0.166 \\
\hline $\mathrm{Cu}$ & 0.074 \\
\hline $\mathrm{Fe}$ & 22.4 \\
\hline $\mathrm{K}$ & 0.893 \\
\hline $\mathrm{Li}$ & $<0.100$ \\
\hline $\mathrm{Mg}$ & 0.875 \\
\hline $\mathrm{Mn}$ & 5.91 \\
\hline $\mathrm{Na}$ & 12.2 \\
\hline $\mathrm{Ni}$ & 3.22 \\
\hline $\mathrm{Pb}$ & 0.033 \\
\hline $\mathrm{S}$ & 0.269 \\
\hline $\mathrm{Si}$ & 1.25 \\
\hline $\mathrm{Ti}$ & 0.610 \\
\hline $\mathrm{Zn}$ & 0.114 \\
\hline $\mathrm{Zr}$ & 0.324 \\
\hline
\end{tabular}

Note: Two aliquots were removed from the product sample then calcined and analyzed.

Results represent an average of the two measurements.

The total and dissolved solids were measured on the SRAT products from runs SB4-18 and SB4-29, and the insoluble and soluble solids were then calculated. As mentioned above, the calcined solids were also measured. To complete the physical property analyses, the slurry density and $\mathrm{pH}$ were measured. The results are given in Table 3-15. Slight variation is anticipated in the total solids because of the addition method for MCU. After all of the MCU is added, the SRAT cycles were stopped. If the addition and boiloff rates do not match exactly, then the solids will increase or decrease as differences in the rates change.

Table 3-15: Physical Property Data for SRAT Products

\begin{tabular}{||c|c|c|c|c|c|c||}
\hline Run ID & $\begin{array}{c}\text { Total } \\
\text { Solids } \\
(\mathbf{w t} \%)\end{array}$ & $\begin{array}{c}\text { Insoluble } \\
\text { Solids } \\
(\mathbf{w t} \%)\end{array}$ & $\begin{array}{c}\text { Soluble } \\
\text { Solids } \\
(\mathbf{w t} \%)\end{array}$ & $\begin{array}{c}\text { Calcined } \\
\text { Solids } \\
(\mathbf{w t} \%)\end{array}$ & $\begin{array}{c}\text { Slurry } \\
\text { Density } \\
(\mathbf{g} / \mathbf{m l})\end{array}$ & $\mathbf{p H}$ \\
\hline SB4-18 & 27.3 & 16.7 & 10.6 & 17.9 & 1.22 & 6.73 \\
\hline SB4-29 & 25.3 & 15.1 & 10.3 & 16.5 & 1.19 & 7.49 \\
\hline
\end{tabular}

Note: Measured on two aliquots from the same sample. Data reported is an average. Total and dissolved solids were actually measured and insoluble and soluble solids were calculated.

The SB4-18 SRAT product was also filtered to remove the supernate, so the soluble components could be determined. Relative solubility of the elements was determined by considering the amount of supernate present in the samples and the total amount of the particular element in the SRAT product. The measured supernate density was determined to be $1.11 \mathrm{~g} / \mathrm{mL}$. Table $3-16$ presents the supernate data. 
WSRC-TR-2006-00063

Revision 0

Table 3-16: SB4-18 SRAT Product Supernate Data

\begin{tabular}{||c|c|c|c|c|c|c|c|c||}
\hline Element & $\mathbf{A l}$ & $\mathbf{B a}$ & $\mathbf{C a}$ & $\mathbf{C r}$ & $\mathbf{C u}$ & $\mathbf{F e}$ & $\mathbf{K}$ & $\mathbf{M g}$ \\
\hline Supernate (mg/L) & 0.121 & 0.107 & 3850 & $<0.100$ & 0.228 & $<0.010$ & 3440 & 1685 \\
\hline Relative Solubility (\%) & 0.000 & 0.269 & 83.3 & $<0.025$ & 0.130 & 0.000 & 100 & 80.6 \\
\hline \hline Element & $\mathbf{M n}$ & $\mathbf{N a}$ & $\mathbf{N i}$ & $\mathbf{R h}$ & $\mathbf{S}$ & $\mathbf{S i}$ & $\mathbf{Z n}$ & $\mathbf{Z r}$ \\
\hline Supernate (mg/L) & 4470 & 29750 & 11.6 & 1.09 & 410 & 26.6 & 0.204 & $<0.010$ \\
\hline Relative Solubility (\%) & 31.7 & 100 & 0.151 & 0.001 & 63.8 & 0.891 & 0.075 & $<0.001$ \\
\hline
\end{tabular}

In general, the soluble species were consistent with other SRAT runs and with the anticipated SRAT chemistry. As expected, $\mathrm{K}$ and $\mathrm{Na}$ were completely soluble, while both $\mathrm{Ca}$ and $\mathrm{Mg}$ became very soluble during SRAT processing likely due to the creation of formate species. The metals $\mathrm{Ba}, \mathrm{Cr}, \mathrm{Cu}, \mathrm{Ni}, \mathrm{Zn}$, and $\mathrm{Zr}$ showed minimal solubility, which was also consistent with previous SB4 sludge only simulant testing ${ }^{18}$. One of the objectives of SRAT processing is to reduce the $\mathrm{Mn}^{+4}$ to $\mathrm{Mn}^{+2}$ during SRAT processing with a goal of $40 \%$ reduction. Mn reduction was slightly less than targeted but was consistent with the sludge only run at an equivalent acid level ${ }^{18}$. The $S$ solubility was consistent with previous MCU/ARP testing ${ }^{3}$ but was slightly less than seen in the SB4 sludge only testing. Aluminum and Fe were almost completely insoluble, which is consistent with predicted SRAT chemistry.

Mercury analysis was performed on the SB4-18 SRAT product. The measured mercury concentration was $0.167 \mathrm{wt} \%$ in the total solids. This value is below the target reduction needed for DWPF. Therefore, the addition of the MCU and ARP stream (and slightly shorter boiling time after concentration) did not appear to impact mercury reduction.

A rheology measurement was taken on the SB4-18 SRAT product. The individual rheograms for this sample are given in Attachment A as Figure A - 13. During characterization, the product samples were ramped from 0 to $500 \mathrm{sec}^{-1}$. The up flow curve was above the down flow curve and slightly thixotropic for all samples. The Bingham Plastic model was fitted to the down flow curve. For comparison, the rheograms for the SRAT product samples from the previous ARP addition strategy study are also provided in Attachment A as Figure A - 14. The samples from this set of testing had Taylor vortices at shear rates above $475 \mathrm{sec}^{-1}$. The results were fitted to the up curve for the runs because the down curve had slightly less yield stress but essentially the same plastic viscosity. A sludge only SRAT product (SB4-2) is also provided for comparison as Figure A - 15. Taylor vortices began at around $350 \mathrm{sec}^{-1}$ and the slurry is considered a Newtonian fluid based on the response of the down curve. The down curves were fitted as a Newtonian fluid from 0 to $320 \mathrm{sec}^{-1}$. The rheological data for these samples are summarized in Table 3-17. The sludge only SRAT product, SB4-2, was difficult to measure but appeared to have a lower plastic viscosity, which would be expected based on the presence of the MST solids in the other sludges.

Table 3-17: Rheology Data for SB4-18 SRAT Product

\begin{tabular}{||l|c|c||}
\hline Sample & $\begin{array}{c}\text { Yield Stress } \\
\left(\mathbf{d y n e s} / \mathbf{c m}^{2}\right)\end{array}$ & $\begin{array}{c}\text { Plastic Viscosity - } \\
\text { Consistency }(\mathbf{c P})\end{array}$ \\
\hline SB4-18 SRAT Product & 3.4 & 3.20 \\
\hline SB4-13 SRAT Product* & 1.5 & 2.43 \\
\hline SB4-2 SRAT Product - Sludge Only & Newtonian Fluid & 2.34 \\
\hline
\end{tabular}

*Previous ARP/MCU testing. 
WSRC-TR-2006-00063

Revision 0

This page intentionally left blank. 


\subsection{CONCLUSIONS}

Five lab-scale SRAT runs were completed to assess the revised ARP incorporation strategy and to determine the partitioning of the MCU solvent organics in the SRAT equipment. Changes were made to the SRAT equipment set-up and to the analytical protocol to improve the recovery of Isopar $^{\circledR} \mathrm{L}$ and modifier. Target MCU solvent concentrations of 239 and $50 \mathrm{ppm}$ were evaluated.

Very little to no Isopar ${ }^{\circledR} \mathrm{L}$ was detected in any of the SRAT condensers or in the SRAT product after run SB4-18. Typically, the rinse solutions contained higher concentrations of Isopar ${ }^{\circledR} \mathrm{L}$ than the actual condensate solutions; indicating a potential build-up problem with the solvent. The amounts of Isopar ${ }^{\circledR} \mathrm{L}$ found in the condensers was much less than what was seen in previous testing. The earlier high numbers may have been the result of slug feeding of the MCU solvent in those runs. The carbon tube data indicated that most of the Isopar ${ }^{\circledR} \mathrm{L}$ was emitted as vapor from the system. System recovery varied from 33 to $92 \%$. While the equipment changes and analytical improvements did not result in $100 \%$ closure of the material balance in every run, the data consistently showed that very little Isopar ${ }^{\circledR} \mathrm{L}$ would be expected to be captured in the SRAT condensers. Based on the runs performed after all processing changes were implemented, approximately 1 to $2 \%$ of the added Isopar ${ }^{\circledR} \mathrm{L}$ would be anticipated to collect in the condensers. Even if the SVOC data was a factor low due to difficulties in measuring small quantities of organics, the amounts of Isopar ${ }^{\circledR} \mathrm{L}$ retained in the system are still small.

The modifier was steam distilled from the SRAT and was detected in all samples or locations except for in the FAVC condensate. The concentration of modifier in the SRAT product or on the SRAT kettle varied from run to run but would be expected to be $\sim 50 \%$ based on all of the runs. This variation was likely the result of the modifier being insoluble in the SRAT product. In some of the runs, the modifier was seen floating on the product surface. The rest of the modifier is likely to collect in the MWWT, the SMECT, and in the process vessel vent lines throughout the CPC equipment. As was the case with the Isopar ${ }^{\circledR} \mathrm{L}$, modifier is also expected to coat the vessel surfaces and, in the case of the MWWT, more modifier was consistently found in the rinse than the actual MWWT sample. Recovery for the modifier was much better in this set of runs and ranged from 81 to $100 \%$ once all the equipment changes and analytical improvements were implemented.

The ARP incorporation strategy and the MCU stream did not appear to impact nitrite destruction, hydrogen generation, mercury reduction, offgas concentration, nitrite to nitrate conversion, $\mathrm{Mn}$ reduction, $\mathrm{pH}$ profiles, or foaming. Slight differences in rheology and formate destruction were observed; however, the differences at this point do not appear to have a significant impact on processing. The $\mathrm{pH}$ of the collected condensate during ARP addition and MCU incorporation will be higher than the condensate collected during sludge-only processing. This potential change in SMECT $\mathrm{pH}$ should be considered in the DWPF processing strategy for salt processing. 
WSRC-TR-2006-00063

Revision 0

This page intentionally left blank. 


\subsection{RECOMMENDATIONS/PATH FORWARD}

The updated MCU testing indicates small quantities of the MCU organics would be expected to buildup in the SRAT condenser and process vessel vent system. However, the rate of build-up or the sensitivity to build- up over time was not investigated in this set of runs. Additional bench-scale runs should be performed to attempt to quantify the build-up so it can be estimated for DWPF processing. Although the modifier is not a flammability concern, it has both a tendency to coat surfaces and to float on liquid surfaces. Therefore, a strategy to deal with the potential accumulation and ability to re-suspend the modifier in the condenser systems will likely be needed in DWPF.

Once the sludge batch for incorporation of the ARP and MCU streams is defined, a final flowsheet test should be performed to verify the acid stoichiometry necessary for ARP/MCU processing. Thus far, testing has indicated that the moles of acid per liter of slurry is consistent between sludge-only and coupled processing; whereas, the actual acid stoichiometry percentage number will be different due to the changes in the acid calculation inputs.

The presence of modifier in the SRAT product may have an impact on the glass redox ratio. A preliminary review of the original MCU data was performed by SRNL, and crucible studies were recommended to validate the expected behavior of the MCU organic (particularly modifier). Once the expected solvent carryover is finalized, these redox studies will be performed. 
WSRC-TR-2006-00063

Revision 0

This page intentionally left blank. 


\subsection{REFERENCES}

${ }^{1}$ Washburn, F.A., Sludge Batch 4 Flowsheet Studies. HLW/DWPF/TTR-2004-0031, Savannah River Site, Aiken, SC 29808 (2004).

${ }^{2}$ Baich, M.A., C.C. Herman, D.C. Koopman, D.R. Best, T.K. Snyder, and M.F. Williams, Processing Options and Impact of Incorporation of ARP in the DWPF Process Flow Sheet. WSRC-TR-2003-00326, Savannah River Site, Aiken, SC 29808 (2003).

${ }^{3}$ Baich, M.A., C.C. Herman, R.E. Eibling, M.F. Williams, and F.G. Smith, Sludge Batch 4 Simulant Flowsheet Studies with ARP and MCU: Impact of MCU Organics. WSRC-TR-2005-00230, Savannah River Site, Aiken, SC 29808 (2005).

${ }^{4}$ Baich, M.A., Task Technical \& QA Plan: Sludge Batch 4 Simulant Flowsheet Studies with MCU and ARP. WSRC-RP-2004-00881, Savannah River Site, Aiken, SC 29808 (2004).

${ }^{5}$ Lilliston, G.R., Development of Elemental Sludge Compositions for Variations of Sludge Batch 4 (SB4). CBU-PIT-2004-00011, Revision 1, Savannah River Site, Aiken, SC 29808 (2005).

${ }^{6}$ Campbell, S.G., Preliminary Material Balance for the Modular CSSX Unit. CBU-SPT-2004-00059, Revision 1, Savannah River Site, Aiken, SC 29808 (2004).

${ }^{7}$ Subosits, S.G., Actinide Removal Process (ARP) Facility. X-CLC-S-00113, Revision 0, Savannah River Site, Aiken, SC 29808 (2004).

${ }^{8}$ Adu-Wusu, K., S.L. Crump, and T.L. White, Preparation of Caustic Side Solvent Extraction (CSSX) Solvent with no BOBCalixC6 for Strip Effluent Feed Tank (SEFT) Testing - Component Amounts and Analytical Results. SRNL-WPT-2005-00118, Savannah River Site, Aiken, SC 29808 (2005).

9 Hansen, E.K., C.C. Herman, T.L. White, S.L. Crump, and T.B. Peters, $1 / 6^{\text {th }}$ Scale Strip Effluent Feed Tank - Mixing Results using MCU Solvent, WSRC-TR-2005-00552, Savannah River Site, Aiken, SC 29808 (2006).

${ }^{10}$ Herman, C.C., SB4-18 SRAT Run Plan: ARP Stream Added during Caustic Boiling and 239 ppm MCU Solvent Addition, SRNL-ITS-2005-00176, Savannah River Site, Aiken, SC 29808 (2005).

${ }^{11}$ Herman, C.C., SB4-29SRAT Run Plan: ARP Stream Addition during Caustic Boiling and 239 ppm MCU Solvent (Test \#1), SRNL-ITS-2005-00237, Savannah River Site, Aiken, SC 29808 (2005).

${ }^{12}$ Herman, C.C., SB4-30 SRAT Run Plan: ARP Stream Addition during Caustic Boiling and 239 ppm MCU Solvent (Test \#2), SRNL-ITS-2005-00265, Savannah River Site, Aiken, SC 29808 (2005).

${ }^{13}$ Herman, C.C., SB4-31 SRAT Run Plan: ARP Stream Addition during Caustic Boiling and 50 ppm MCU Solvent, SRNL-ITS-2005-00266, Savannah River Site, Aiken, SC 29808 (2005).

${ }^{14}$ Herman, C.C., SB4-33 SRAT Run Plan: ARP Stream Addition during Caustic Boiling and 50 ppm MCU Solvent, SRNL-ITS-2005-00277, Savannah River Site, Aiken, SC 29808 (2005). 
${ }^{15}$ Marek, J.C., and R.E. Eibling, Draft Calculational Algorithm for Nitric Acid Flowsheet. SRT-PTD-920050, Savannah River Site, Aiken, SC 29808 (1992).

${ }^{16}$ Jantzen, C.M., J.R. Zamecnik, D.C. Koopman, C.C. Herman, and J.B. Pickett, Electron Equivalents Model for Controlling Reduction-Oxidation (Redox) Equilibrium During High Level Waste (HLW) Vitrification. WSRC-TR-2003-00126, Savannah River Site, Aiken, SC 29808 (2003).

${ }^{17}$ Baich, M.A., Analytical Study Plan for Sludge Batch 4 with ARP and MCU Flowsheet Studies Using Simulants. SRNL-GPD-2005-00001, Savannah River Site, Aiken, SC 29808 (2005).

${ }^{18}$ Baich, M.A., C.C. Herman, D.R. Best, M.F. Williams, and E.K. Hansen, Sludge Batch 4 Simulant Flowsheet Studies: Initial Phase I SRAT Results. WSRC-TR-2005-00194, Revision 0, Savannah River Site, Aiken, SC 29808 (2005). 


\subsection{ACKNOWLEDGMENTS}

The authors would like to acknowledge the following personnel and groups for their assistance in performing the studies and analyzing the required samples:

- J.W. Duvall, D.M. Marsh, I.A. Reamer, V.J. Williams, R.J. Workman, D.P. Healy, and T.O. Burckhalter for fabricating the sludge simulants, performing the SRAT runs, and assisting with sample analysis.

- P.A. Toole for providing assistance with the analyses in the PSAL.

- J.E. Young, L.C. Johnson, and AD for providing analytical support for the simulants and receipt samples.

- J.R. Zamecnik, A.D. Cozzi, and D.P. Lambert for consultation on possible reasons for poor recovery of the organics. 
WSRC-TR-2006-00063

Revision 0

This page intentionally left blank. 
WSRC-TR-2006-00063

Revision 0

ATTACHMENT A. SRAT RUN PARAMETERS, RHEOLOGY DATA, GC, AND CARBON TUBE DATA 
WSRC-TR-2006-00063

Revision 0

Table A - 1: SRAT Run Parameters

\begin{tabular}{|c|c|c|c|c|c|}
\hline Parameter & SB4-18 & SB4-29 & SB4-30 & SB4-31 & SB4-33 \\
\hline Initial Sludge Mass (g) & 2686.8 & 2690 & 2516.0 & 2516.0 & 2516.0 \\
\hline $\mathrm{AgNO}_{3}$ Added $(\mathrm{g})$ & 0.0029 & 0.0024 & 0.0020 & 0.0022 & 0.0022 \\
\hline $\mathrm{Pd}\left(\mathrm{NO}_{3}\right)_{2} * \mathrm{H}_{2} \mathrm{O}$ Added $(\mathrm{g})-15.27 \%$ Solution & 0.4905 & 0.4898 & 0.459 & 0.4573 & 0.4587 \\
\hline $\mathrm{Rh}\left(\mathrm{NO}_{3}\right)_{3} * 2 \mathrm{H}_{2} \mathrm{O}$ Added $(\mathrm{g})-4.93 \%$ Solution & 2.7844 & 2.7874 & 2.606 & 2.6069 & 2.6090 \\
\hline $\mathrm{RuCl}_{3}$ Added (g) & 1.2109 & 1.2113 & 1.133 & 1.1354 & 1.1334 \\
\hline Rinse Water for Trim Chemicals (g) & 40.015 & 45.018 & 55.999 & 56.000 & 56.0096 \\
\hline Initial Sludge $\mathrm{pH}$ with Trim Chemicals & 10.73 & 11.45 & 12.32 & 11.63 & 12.06 \\
\hline \multicolumn{6}{|l|}{ ARP Concentration Parameters } \\
\hline Air Purge $(\mathrm{sccm})$ & 657 & 657 & 615 & 615 & 615 \\
\hline Helium Purge (sccm) & 3.3 & 3.3 & 3.1 & 3.1 & 3.1 \\
\hline Antifoam Addition (g) & 5.581 & 5.58 & 5.22 & 5.22 & 5.12 \\
\hline ARP Simulant (g) & 980.1 & 980 & 917.0 & 917.0 & 917.0 \\
\hline ARP Addition Rate (g/min) & 3.8 & 3.8 & 3.6 & 3.6 & 3.6 \\
\hline Target Boil-up Rate (g/min) & 3.8 & 3.8 & 3.6 & 3.6 & 3.6 \\
\hline ARP Flush Water $(\mathrm{g})$ & N/A & 25 & 23 & 23 & 23 \\
\hline Dewater Amount (g) & 932.5 & 950 & 882.2 & 889.5 & 891.28 \\
\hline ARP Addition Time (hr) & 4.32 & 4.42 & 3.83 & 4.5 & 4.0 \\
\hline FAVC Mass Collected (g) & 3.24 & 2.07 & 2.228 & 2.699 & 1.058 \\
\hline $\mathrm{pH}$ at End of ARP Boiling & 9.11 & 9.36 & 9.97 & 9.43 & 9.44 \\
\hline \multicolumn{6}{|l|}{ SRAT Cycle Parameters } \\
\hline $\mathrm{pH}$ at Start of SRAT & 10.81 & 11.16 & 10.58 & 9.66 & 9.47 \\
\hline Air Purge (sccm) & 582 & 582 & 598 & 598 & 598 \\
\hline Helium Purge(sccm) & 2.9 & 3.0 & 3.0 & 3.0 & 3.0 \\
\hline Hg Target (wt $\%$ in total solids) & 1.0 & 1.0 & 1.0 & 1.0 & 1.0 \\
\hline $\mathrm{HgO}$ Added $(\mathrm{g})$ & 6.5260 & 6.6949 & 6.6950 & 6.6949 & 6.6954 \\
\hline Nitric Acid Amount Added (ml) & 26.663 & 28.378 & 28.378 & 28.378 & 28.378 \\
\hline Nitric Acid Addition Rate (ml/min) & 0.67 & 0.69 & 0.69 & 0.69 & 0.69 \\
\hline Nitric Acid Moles & 0.281 & 0.300 & 0.300 & 0.300 & 0.300 \\
\hline Formic Acid Amount Added (ml) & 138.195 & 147.87 & 147.87 & 147.87 & 179.0 \\
\hline Formic Acid Addition Rate (ml/min) & 0.68 & 0.69 & 0.69 & 0.69 & 0.69 \\
\hline Formic Acid Moles & 3.271 & 3.488 & 3.488 & 3.488 & 4.223 \\
\hline $\mathrm{pH}$ at End of Acid Addition & 4.4 & 4.63 & N/A & N/A & 4.47 \\
\hline Antifoam Addition during SRAT (g) & 17.18 & 17.91 & 17.91 & 17.85 & 17.91 \\
\hline Target Boil-up Rate (g/min) & 3.4 & 3.49 & 3.49 & 3.6 & 3.63 \\
\hline Dewater Amount $(\mathrm{g})$ & 149.34 & 251.62 & 302.65 & 243.4 & 268.5 \\
\hline MCU Aqueous Addition (ml) & 2193 & 2231 & 2231 & 2231 & 2231 \\
\hline MCU Aqueous Addition Rate (g/min) & 3.4 & 3.63 & 3.49 & 3.58 & 3.58 \\
\hline MCU Solvent Addition Target (ml) & 0.615 & 0.626 & 0.626 & 0.131 & 0.131 \\
\hline Estimated MCU Solvent Addition (ml) & 0.730 & 0.638 & 0.620 & 0.130 & 0.127 \\
\hline MCU Solvent Addition Rate (ml/hr) & 0.057 & 0.063 & 0.06 & 0.012 & $0.012 / 0.030$ \\
\hline MCU Addition Time (hr) & 11.67 & 10.50 & 10.88 & 11.07 & 10.87 \\
\hline Total Condensate Removed (g) & 2215.5 & 2059.9 & 2211.5 & 2110.4 & 2197.3 \\
\hline $\begin{array}{c}\text { DWPF SRAT Scale Factor } \\
(6,000 \text { gallon basis })\end{array}$ & 11134 & 10819 & 10819 & 10819 & 10819 \\
\hline $\mathrm{pH}$ at End of SRAT (at boiling) & 6.44 & 7.44 & 6.81 & 6.42 & 5.23 \\
\hline FAVC Mass Collected during SRAT (g) & 20.6 & 14.0 & 14.75 & 13.0 & 6.19 \\
\hline Run Plan Document Number & $\begin{array}{c}\text { SRT-ITS- } \\
2005-00176\end{array}$ & $\begin{array}{c}\text { SRT-ITS- } \\
2005-00237\end{array}$ & $\begin{array}{c}\text { SRT-ITS- } \\
2005-00265\end{array}$ & $\begin{array}{c}\text { SRT-ITS- } \\
2005-00266\end{array}$ & $\begin{array}{c}\text { SRT-ITS- } \\
2005-00277\end{array}$ \\
\hline
\end{tabular}


WSRC-TR-2006-00063

Revision 0

Figure A - 1: Rheology of SB4 Simulant - Sludge Only
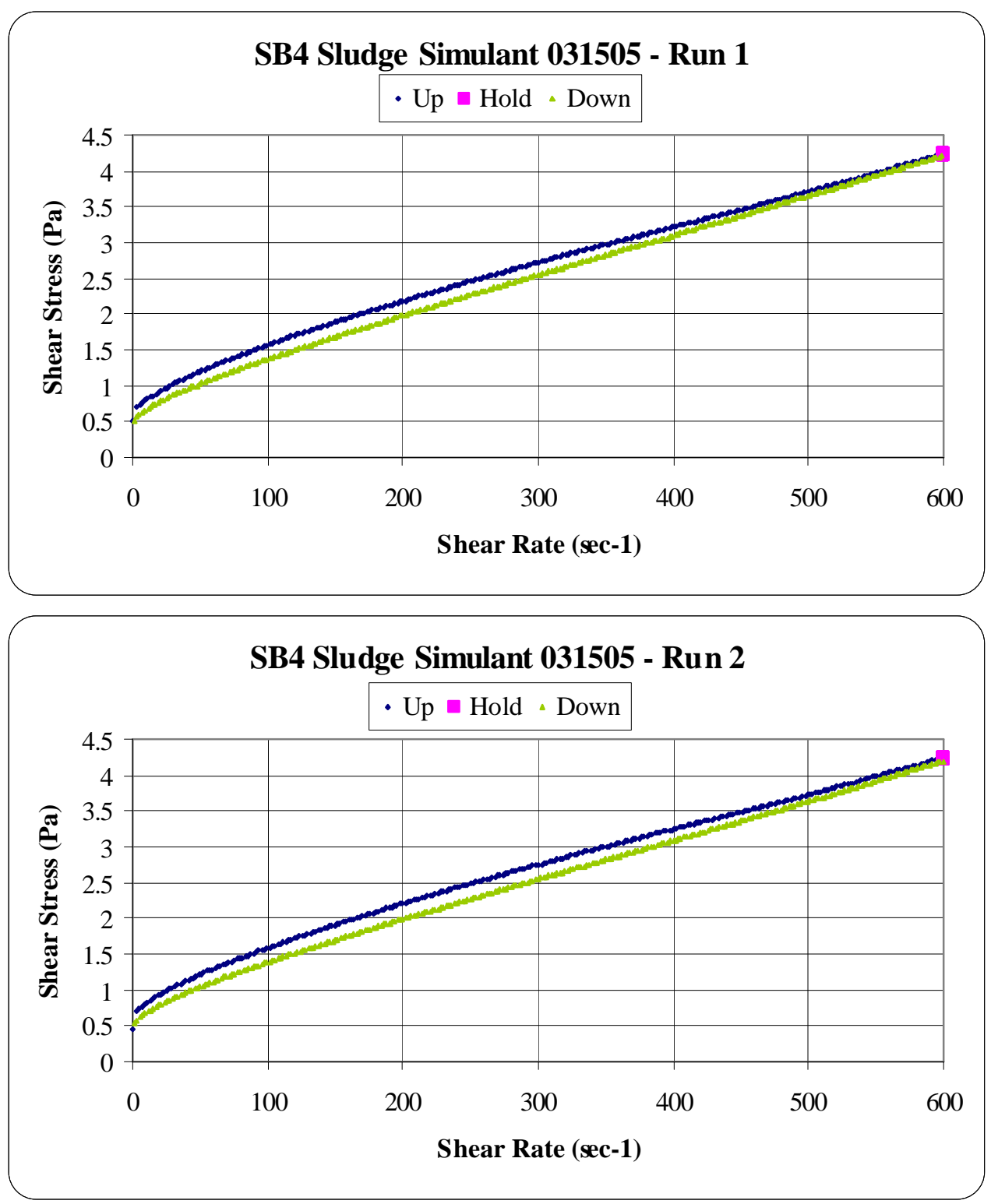

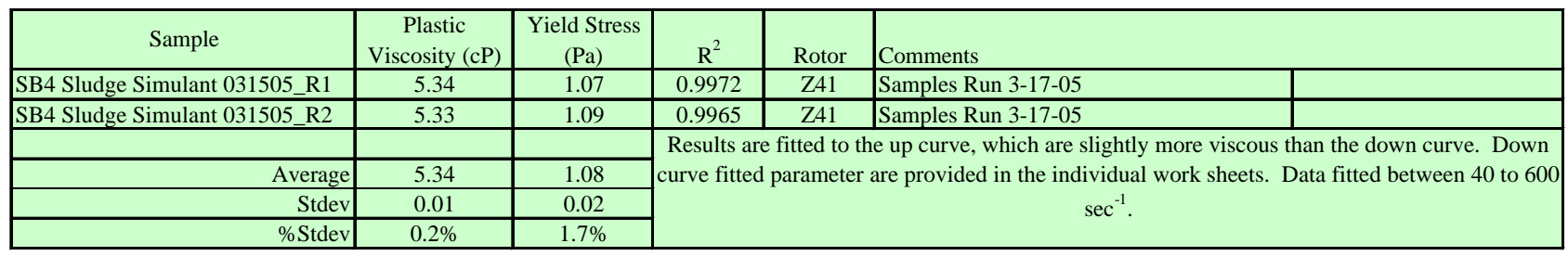


WSRC-TR-2006-00063

Revision 0

Figure A - 2: Rheology for SB4-18 SRAT Receipt Samples
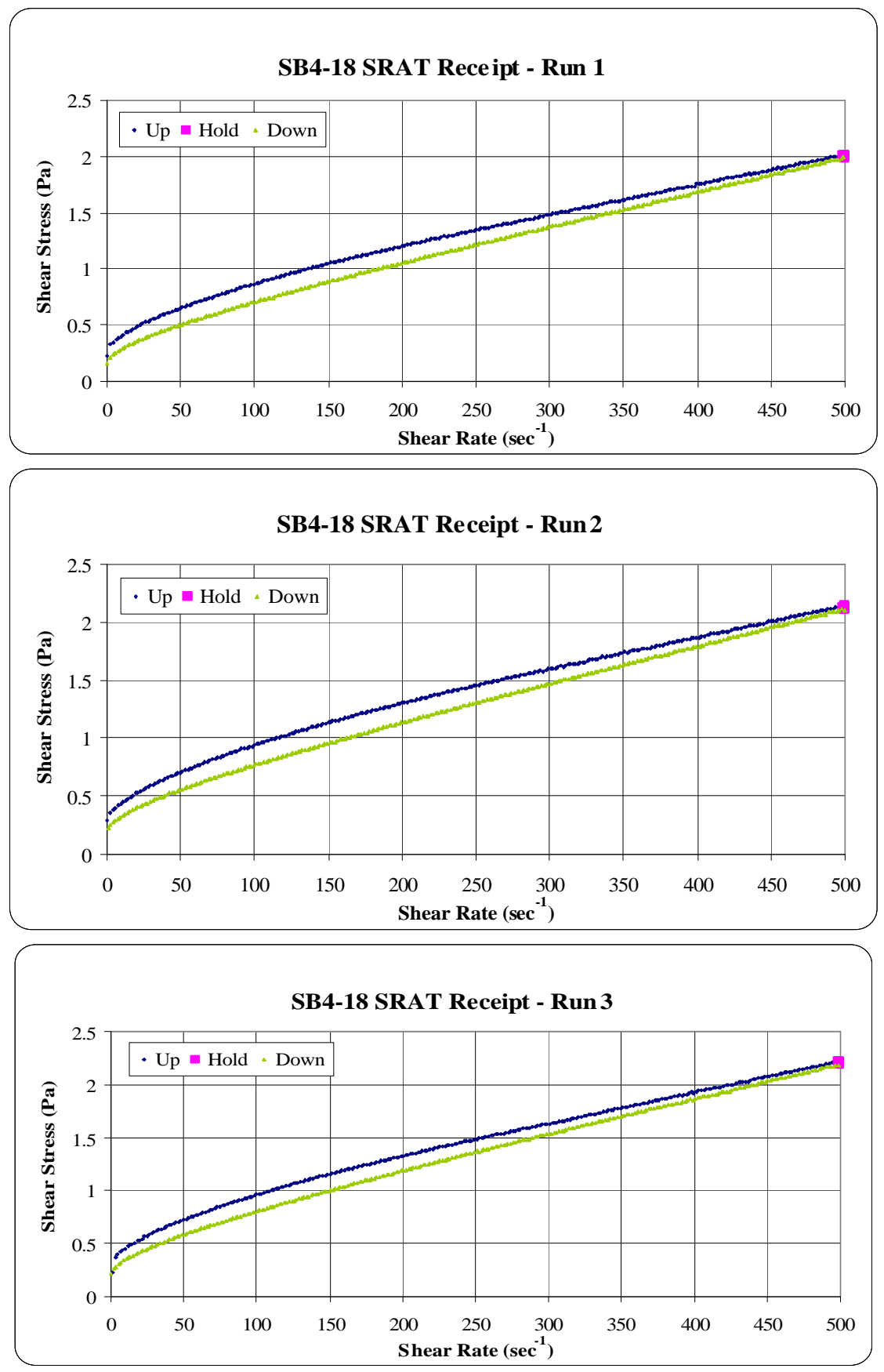

\begin{tabular}{|c|c|c|c|c|c|}
\hline Sample & $\begin{array}{c}\text { Plastic } \\
\text { Viscosity }(\mathrm{cP})\end{array}$ & $\begin{array}{c}\text { Yield Stress } \\
(\mathrm{Pa})\end{array}$ & $\mathrm{R}^{2}$ & Rotor & Comments \\
\hline SB4-18 SRAT Receipt - R1 & 3.00 & 0.56 & 0.9922 & Z41 & Samples Run 8-5-05 \\
\hline SB4-18 SRAT Receipt - R2 & 3.15 & 0.62 & 0.9900 & $\mathrm{Z} 41$ & Samples Run 8-5-05 \\
\hline Average & 3.14 & 0.60 & \multirow{2}{*}{\multicolumn{3}{|c|}{ Data fitted to up curve over from 20 to $500 \mathrm{sec}^{-1}$. Slightly thixotropic. }} \\
\hline Stdev & 0.14 & 0.04 & & & \\
\hline
\end{tabular}


Figure A - 3: Rheology from Previous Testing -Concentrated ARP Added to Sludge Simulant

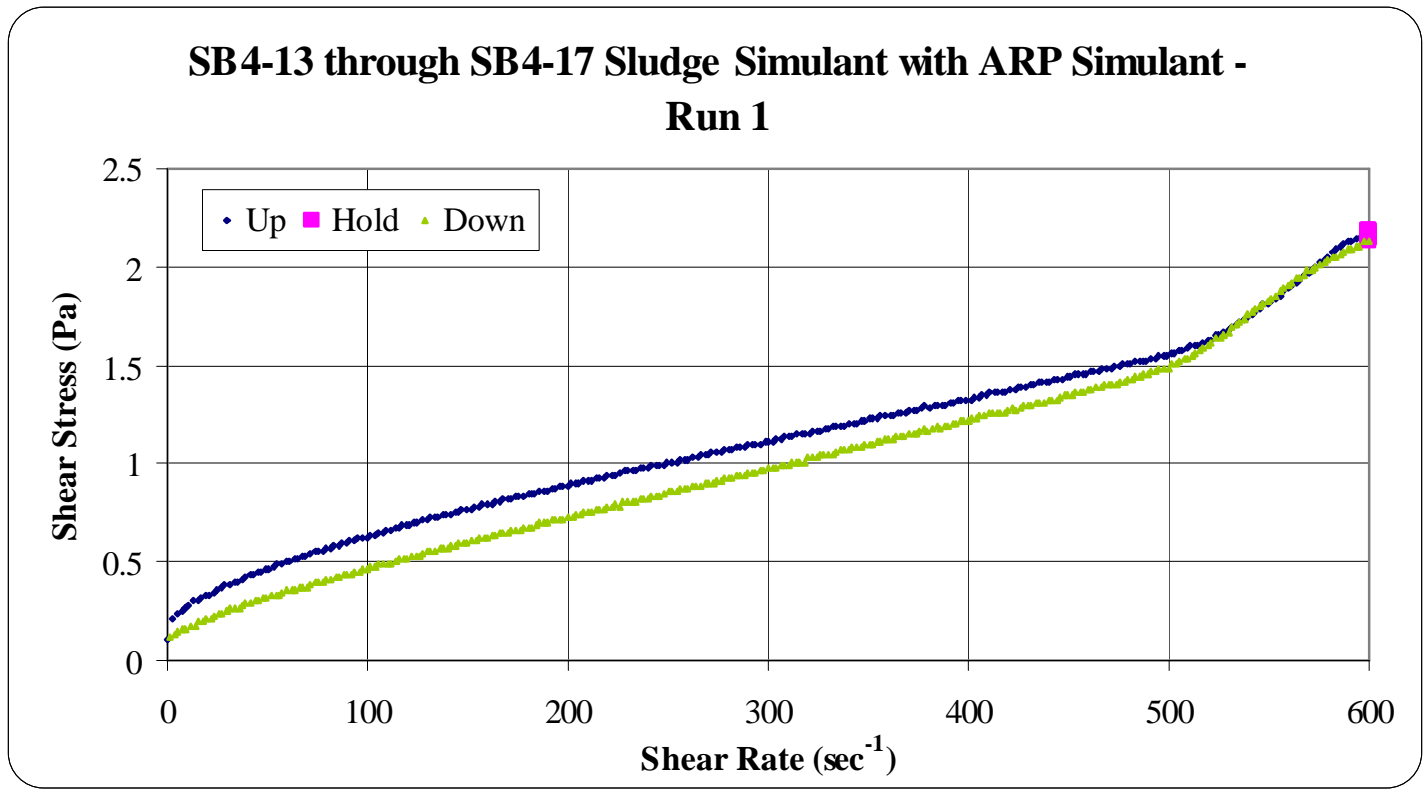

\begin{tabular}{|l|l|l|l|l|l|l|}
\hline \multicolumn{5}{|c|}{ SB4-13 through SB4-17 Sludge Simulant with ARP Simulant - } \\
Run 2 \\
\hline
\end{tabular}


WSRC-TR-2006-00063

Revision 0

Figure A - 4: SB4-18 GC Data

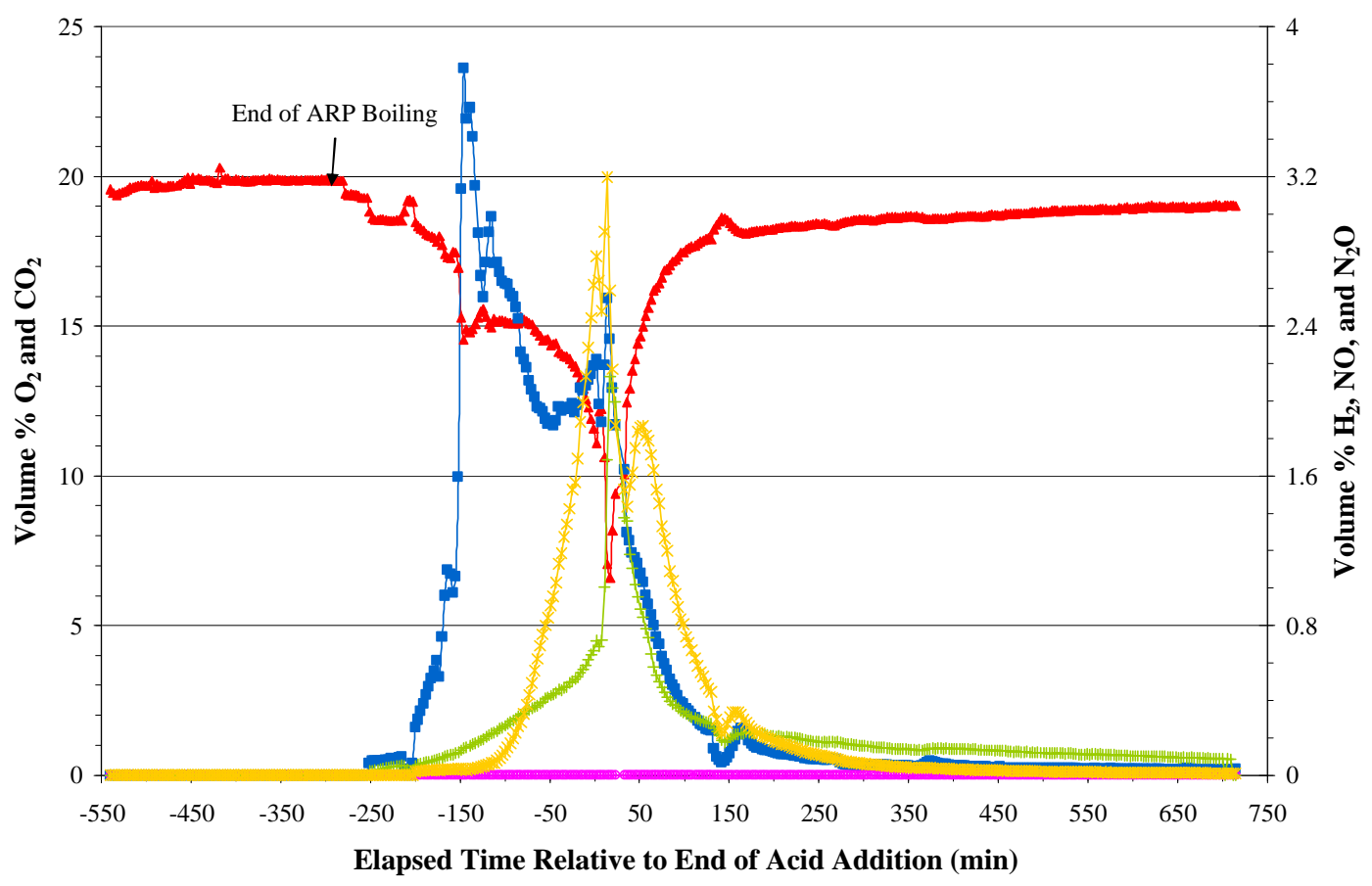

$\rightarrow \mathrm{O} 2 \rightarrow-\mathrm{CO} 2 \rightarrow \mathrm{H} 2 \multimap \mathrm{NO} \rightarrow \mathrm{N} 2 \mathrm{O}$

Figure A - 5: SB4-29 GC Data

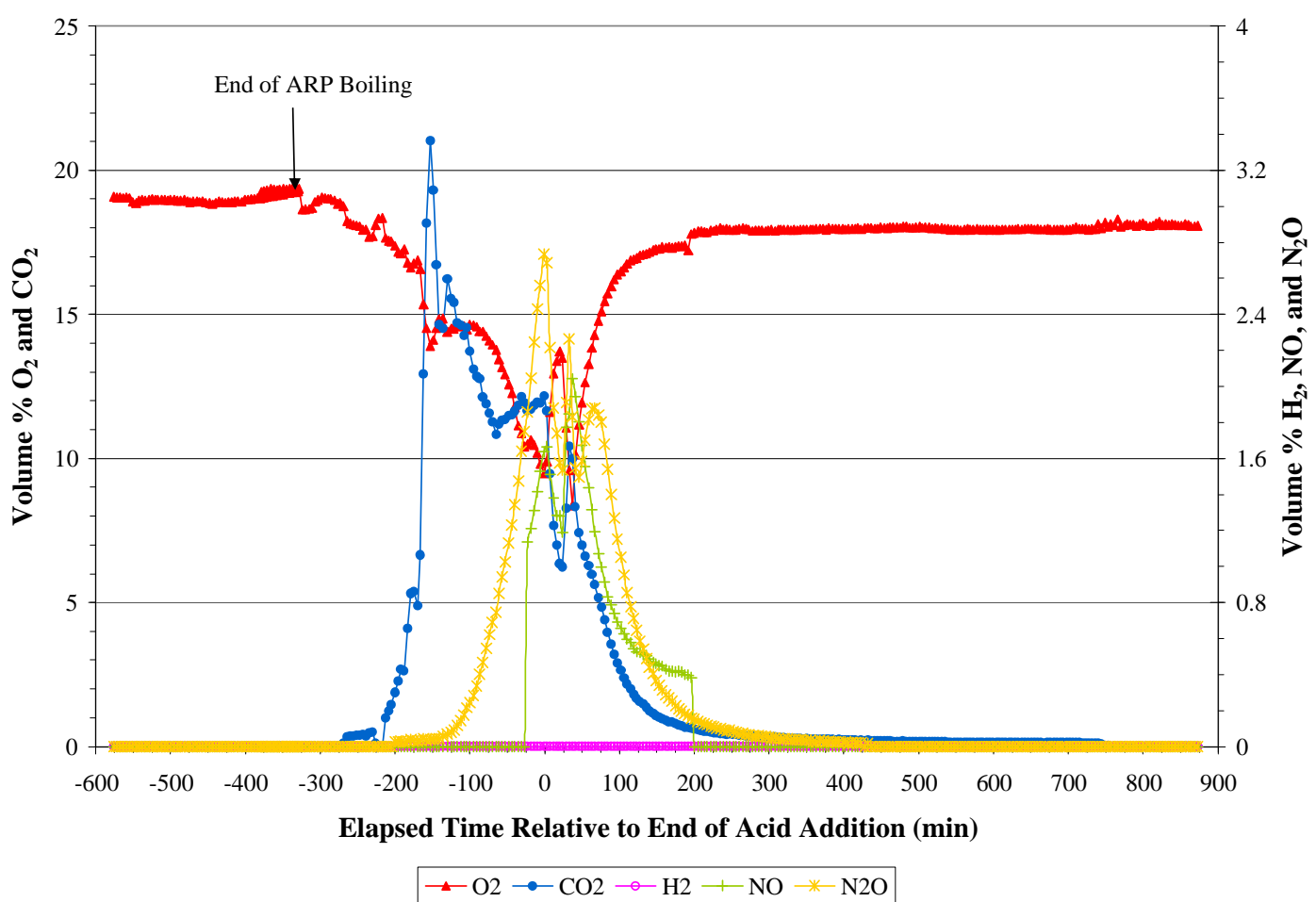


WSRC-TR-2006-00063

Revision 0

Figure A - 6: SB4-30 GC Data

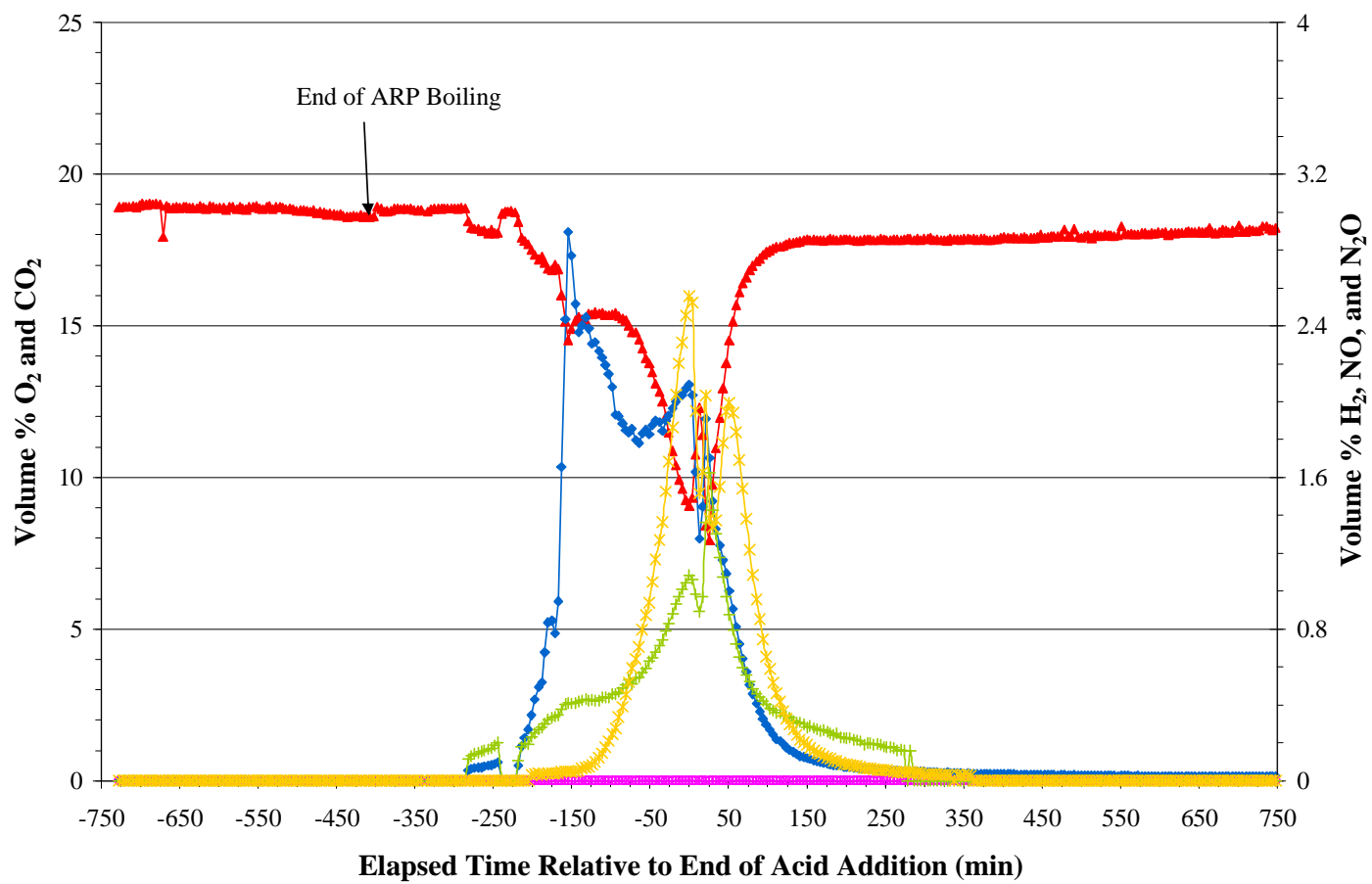

$\neg \mathrm{O} 2 \rightarrow \mathrm{CO} 2 \rightarrow \mathrm{H} 2 \rightarrow \mathrm{NO}-* \mathrm{~N} 2 \mathrm{O}$

Figure A - 7: SB4-31 GC Data

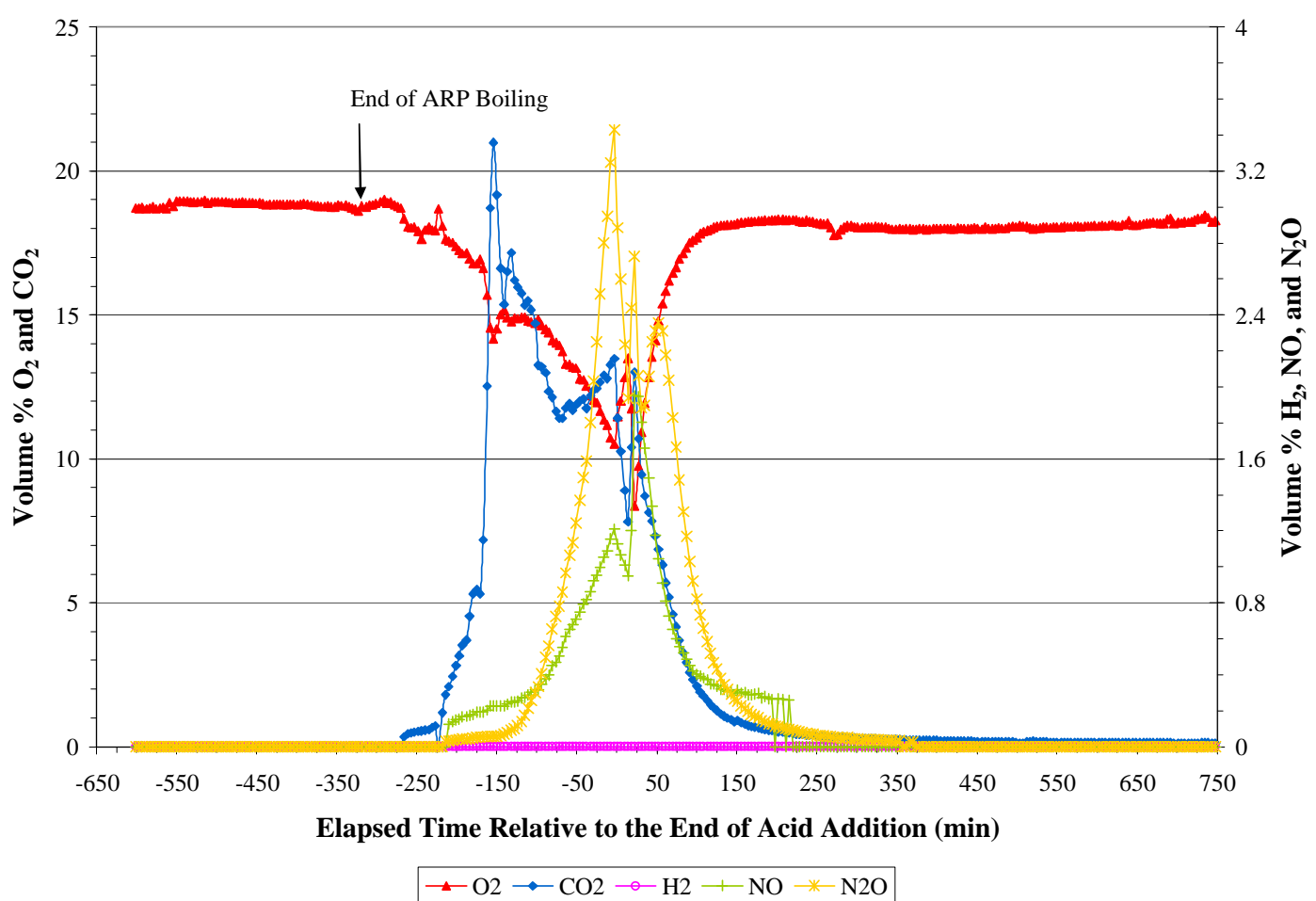


WSRC-TR-2006-00063

Revision 0

Figure A - 8: SB4-33 GC Data

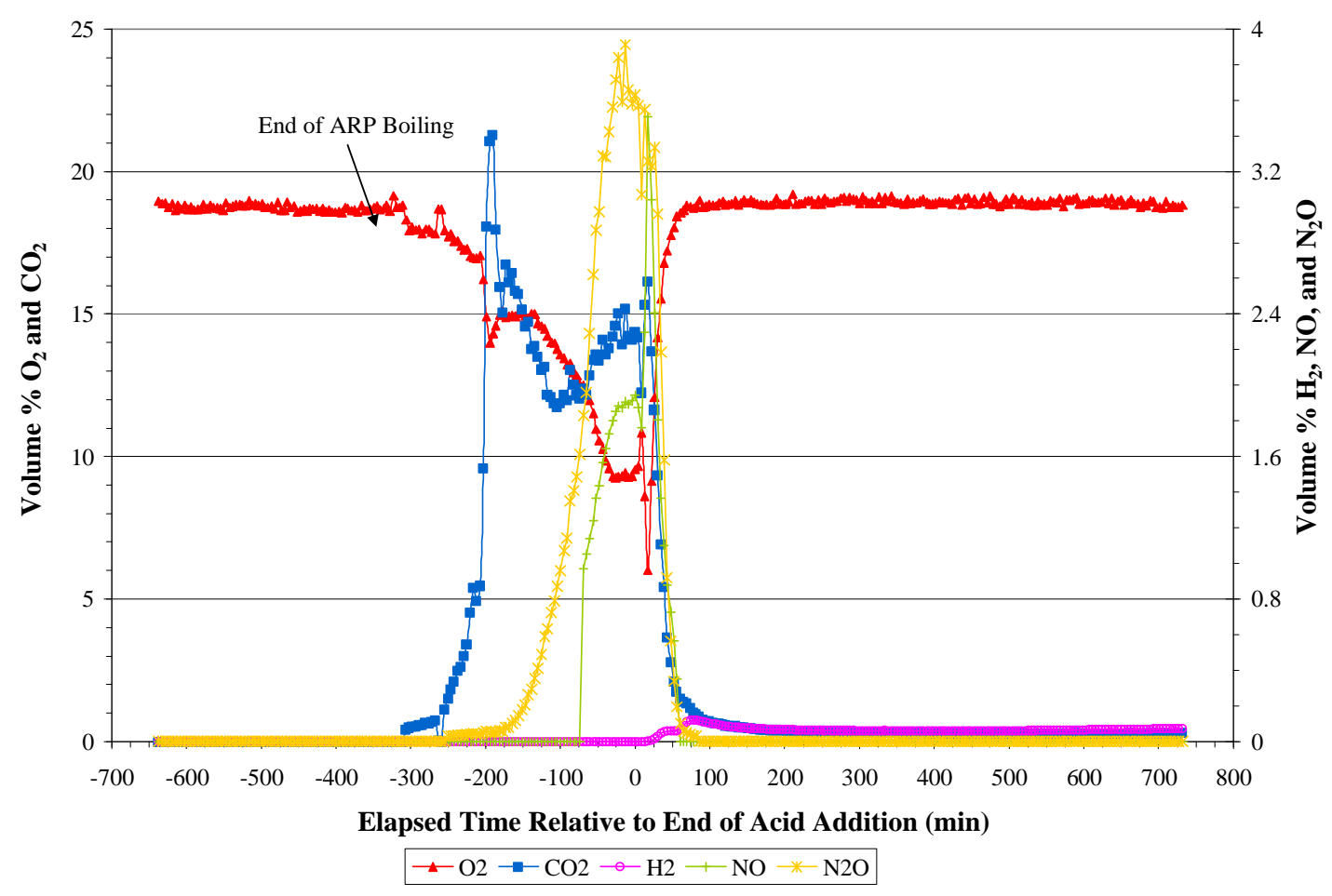

Figure A - 9: Carbon Tube Data from Run SB4-18

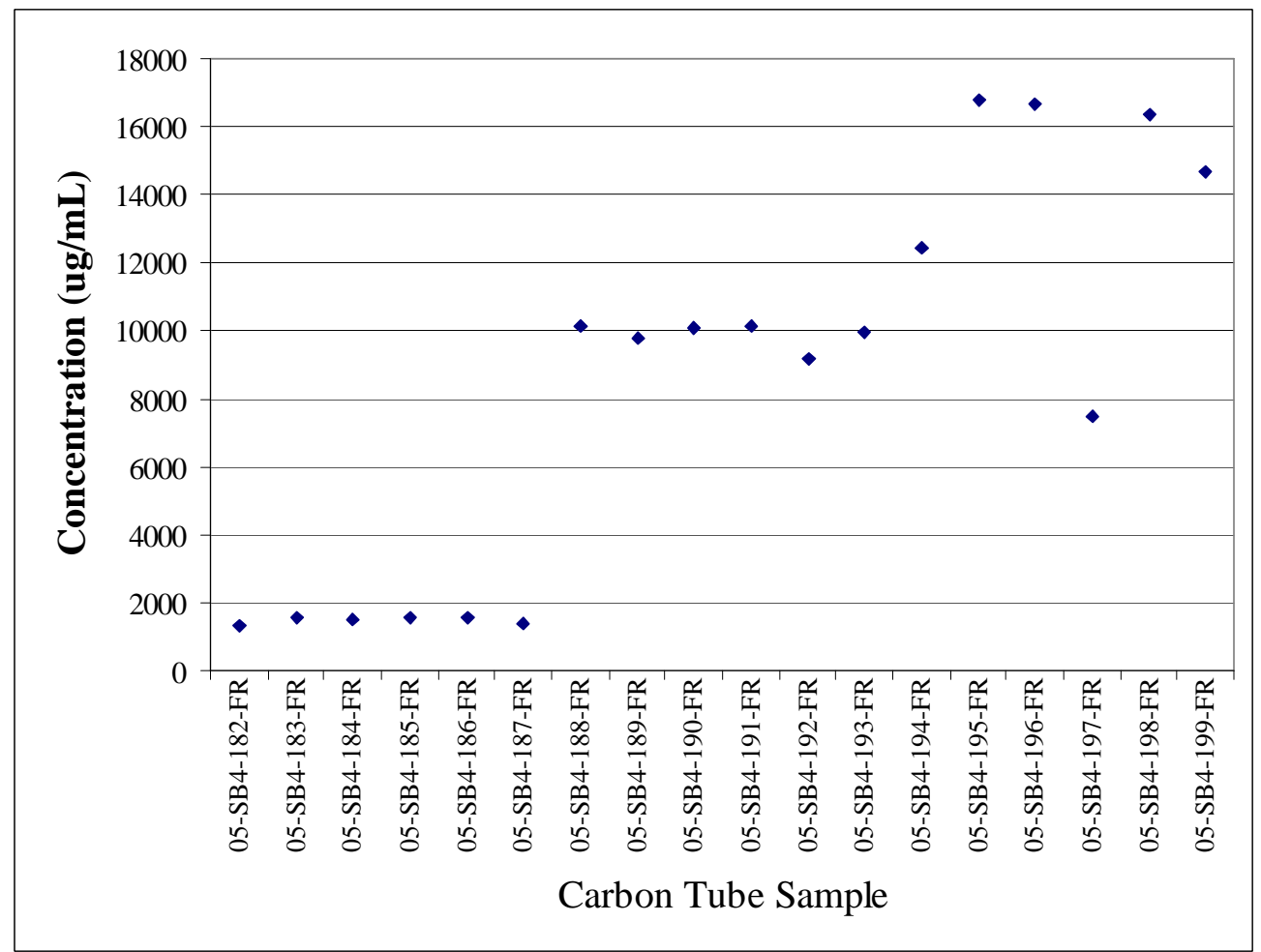


WSRC-TR-2006-00063

Revision 0

Figure A - 10: Carbon Tube Data from Run SB4-30

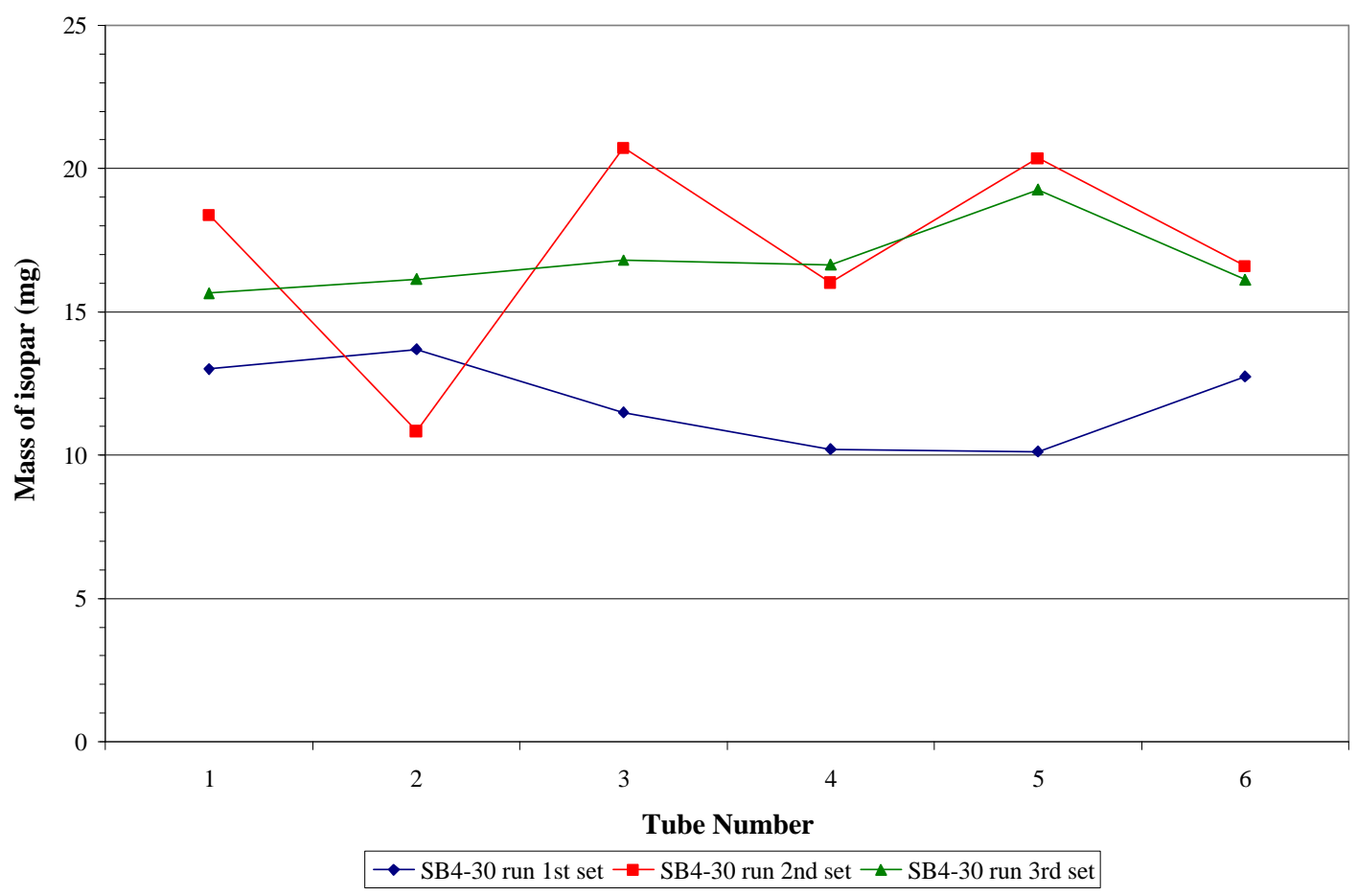

Figure A - 11: Carbon Tube Data from Run SB4-31

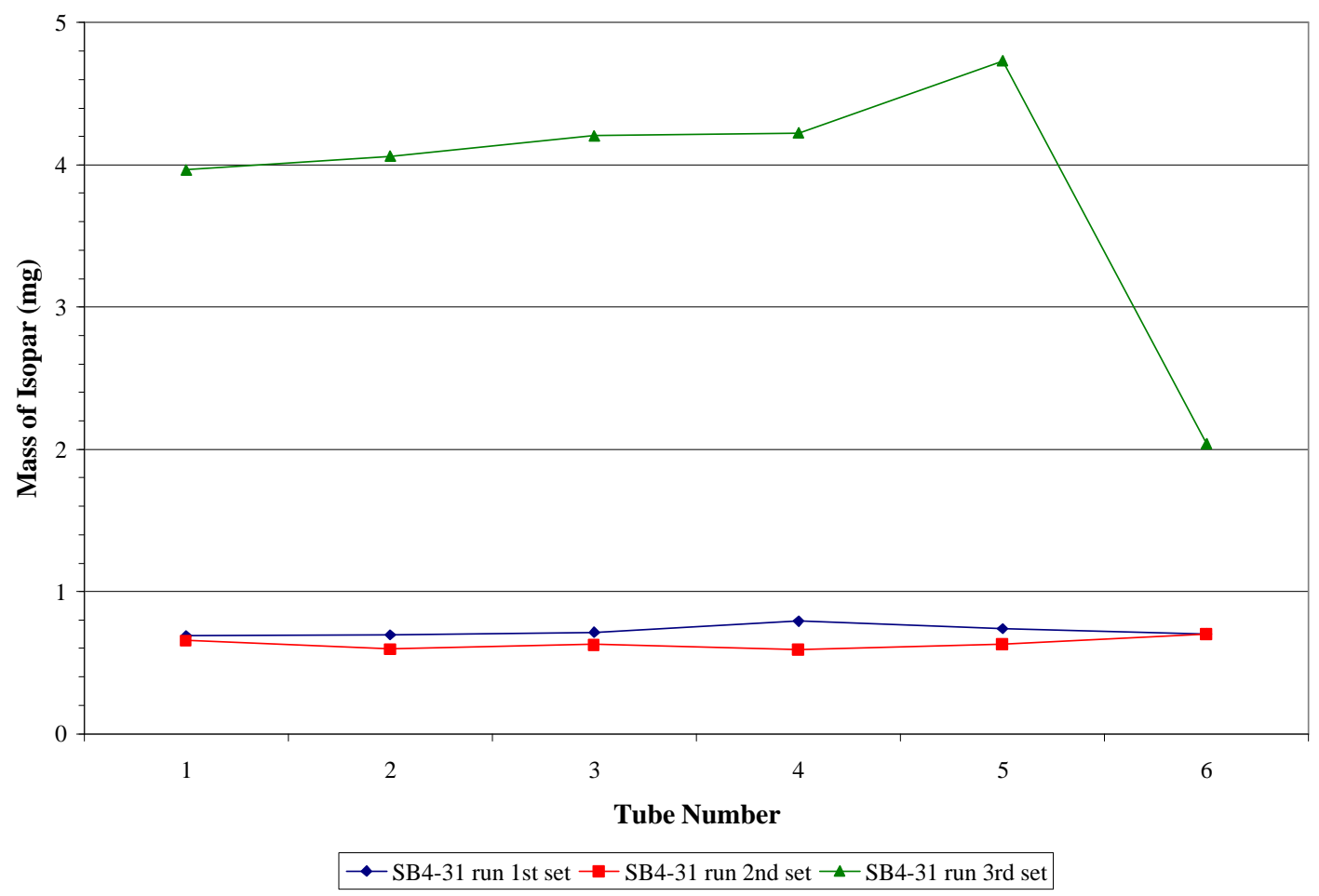


WSRC-TR-2006-00063

Revision 0

Figure A - 12: Carbon Tube Data from Run SB4-33

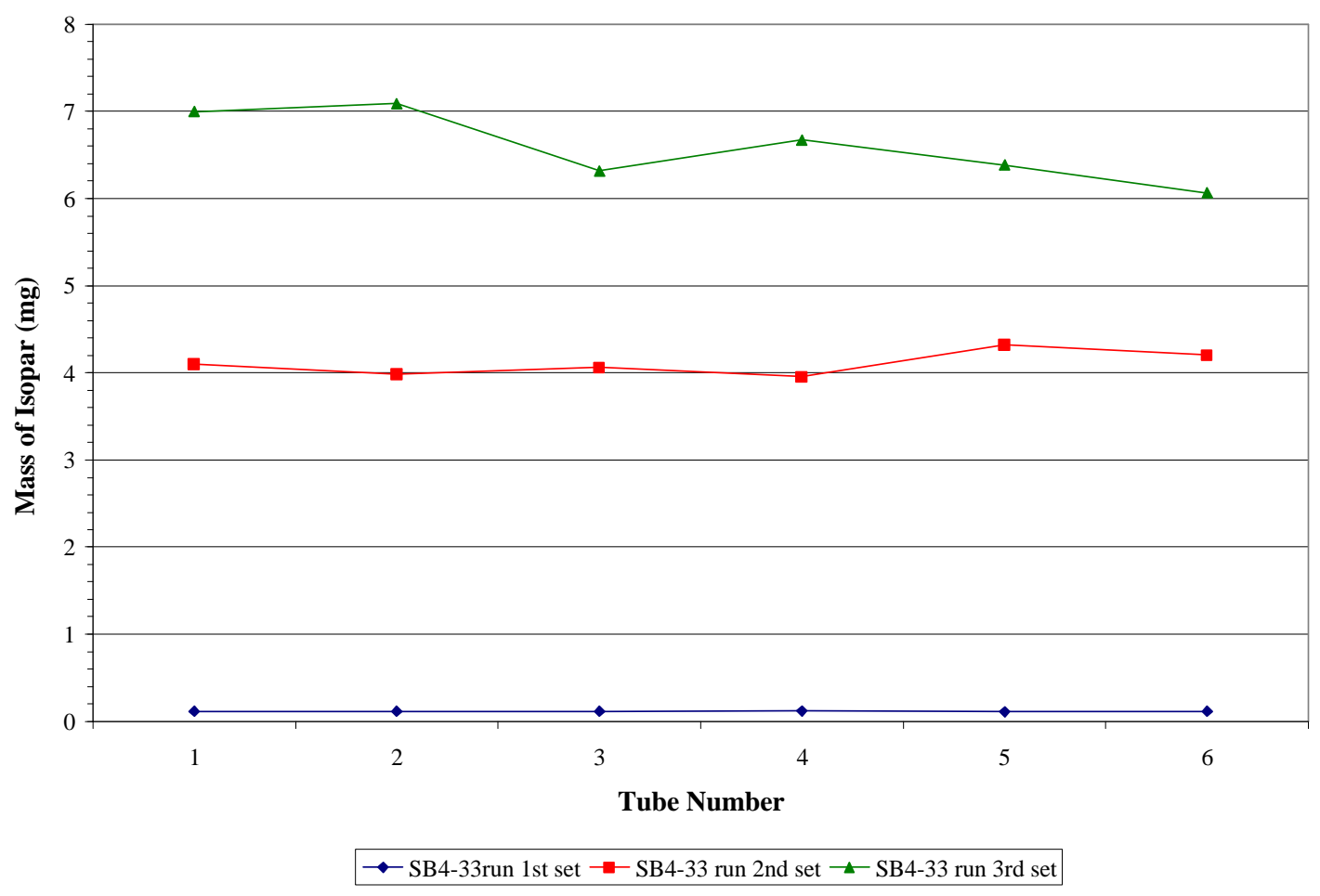


WSRC-TR-2006-00063

Revision 0

Figure A - 13: Rheology of SB4-18 SRAT Product with ARP and MCU
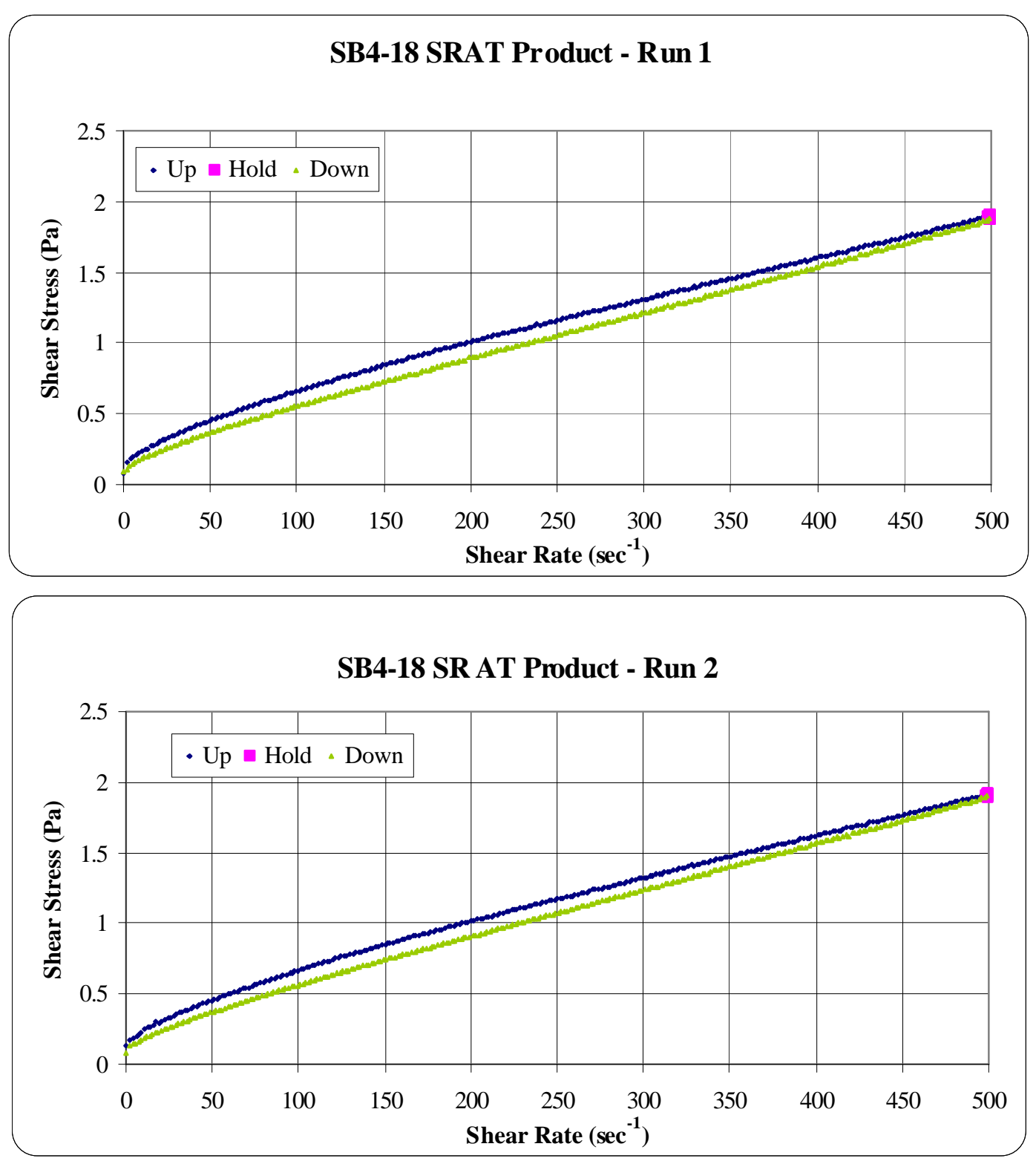

\begin{tabular}{|c|c|c|c|c|c|}
\hline Sample & $\begin{array}{c}\text { Plastic } \\
\text { Viscosity (cP) }\end{array}$ & $\begin{array}{c}\text { Yield Stress } \\
(\mathrm{Pa})\end{array}$ & $\mathrm{R}^{2}$ & Rotor & Comments \\
\hline SB4-18 SRAT Product - R1 & 3.18 & 0.34 & 0.9959 & $\mathrm{Z} 41$ & Samples Run 8-5-05 \\
\hline SB4-18 SRAT Product - R2 & 3.22 & 0.34 & 0.9962 & $\mathrm{Z} 41$ & Samples Run 8-5-05 \\
\hline Average & 3.20 & 0.34 & \multirow{3}{*}{\multicolumn{3}{|c|}{ Data fitted to up curve over from 20 to $500 \mathrm{sec}^{-1}$. Slightly thixotropic. }} \\
\hline Stdev & 0.03 & 0.00 & & & \\
\hline$\%$ Stdev & $0.8 \%$ & $0.2 \%$ & & & \\
\hline
\end{tabular}


WSRC-TR-2006-00063

Revision 0

Figure A - 14: Rheology from Previous Testing - SB4-13 SRAT Product
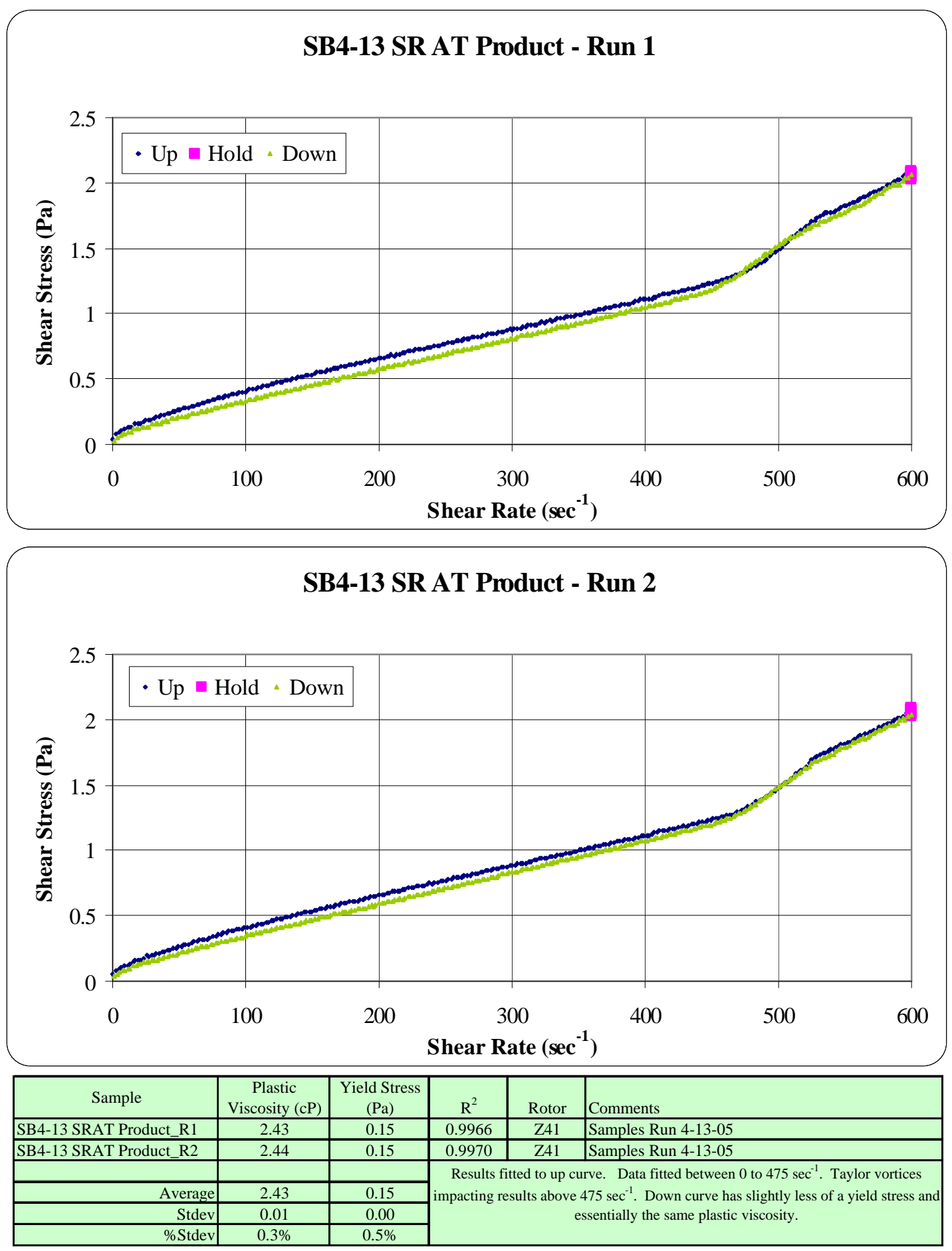
WSRC-TR-2006-00063

Revision 0

Figure A - 15: Rheology for Sludge Only SRAT Product

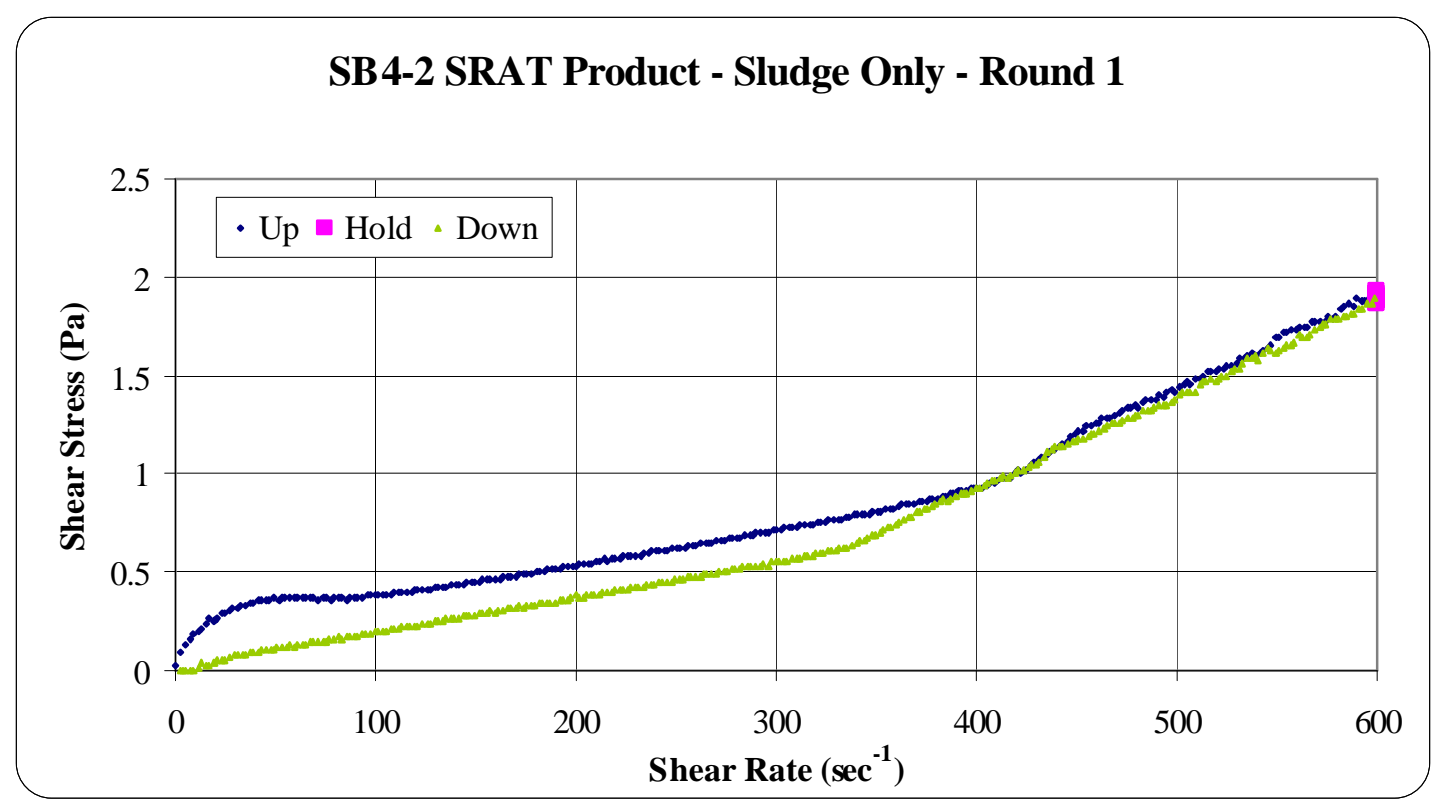

SB4-2 SR AT Product - Sludge Only - Round 2

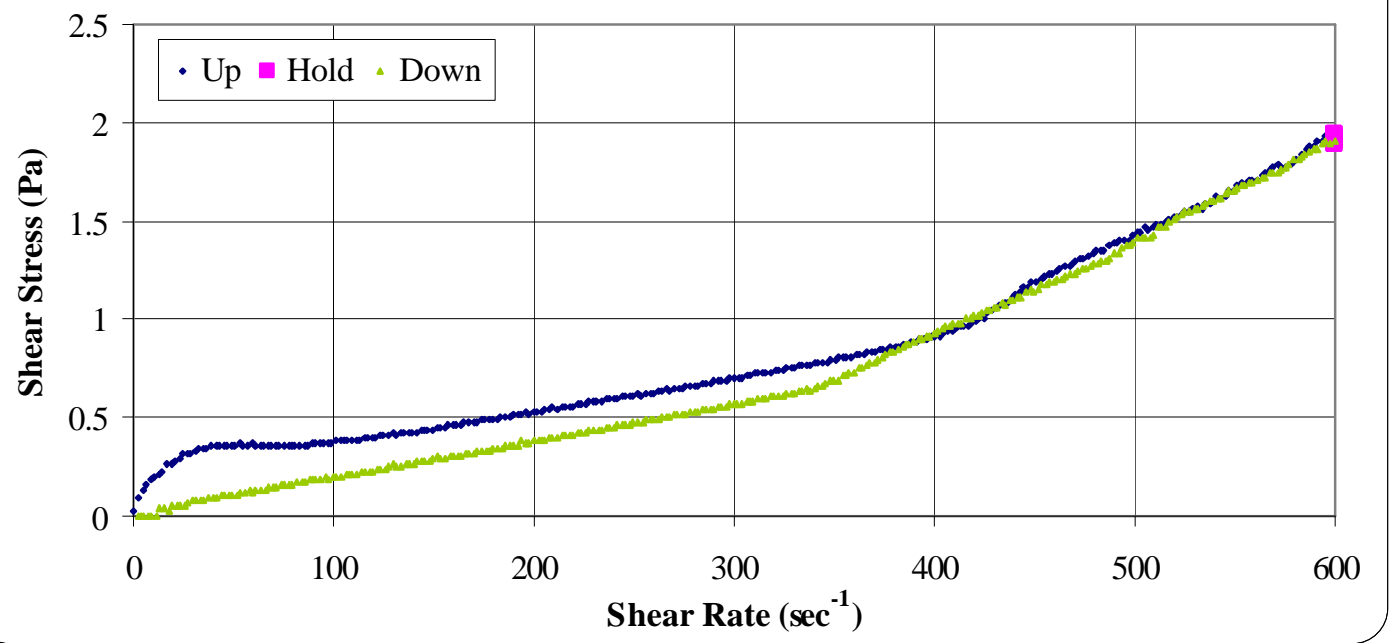

\begin{tabular}{|c|c|c|c|c|c|}
\hline Sample & Viscosity $(\mathrm{cP})$ & & $\mathrm{R}^{2}$ & Rotor & Comments \\
\hline SB4-2 SRAT Product_R1 & 2.34 & - & 0.9529 & $\mathrm{Z} 41$ & Sample Run 2-22-05, Newtonian Fluid \\
\hline SB4-2 SRAT Product_R2 & 2.33 & - & 0.9587 & Z14 & Sample Run 2-22-05, Newtonian Fluid \\
\hline & & \multirow{4}{*}{\multicolumn{4}{|c|}{ Data fitted between 0 - $320 \mathrm{sec}-1$, due to Taylor vortices. }} \\
\hline Average & 2.34 & & & & \\
\hline Stdev & 0.01 & & & & \\
\hline$\%$ Stdev & $0.3 \%$ & & & & \\
\hline
\end{tabular}




\section{Distribution:}

C. J. Bannochie, 773-42A

M. J. Barnes, 999-W

D. R. Best, 786-1A

N. E. Bibler, SRNL

E. A. Brass, 730-1B

D. B. Burns, 786-5A

T. B. Calloway, 999-W

L. M. Chandler, SRNL

D. A. Crowley, 999-W

S. L. Crump, SRNL

B. A. Davis, 704-27S

R. E. Edwards, SRNL

R. E. Eibling, 999-W

T. L. Fellinger, 704-27S

P. E. Filpus-Luyckx, SRNL

S. D. Fink, SRNL

J. M. Gillam, 766-H

J. R. Harbour, 773-42A

E. K. Hansen, 999-W

C. C. Herman, 773-42A

R. M. Hoeppel, 210-S

J. F. Iaukea, 704-30S

W. L. Isom, 766-H

C. M. Jantzen, SRNL

D. C. Koopman, 999-W

D. P. Lambert, 999-W

J. E. Marra, SRNL

S. L. Marra, SRNL

M. S. Miller, 704-S

J. E. Occhipinti, 704-S

J. M. Pareizs, SRNL

P. M. Patel, 704-27S

J. W. Ray, 704-S

M. A. Rios-Armstrong, 766-H

H. B. Shah, 766-H

A. V. Staub, 704-27S

M. E. Stone, 999-W

J. P. Schwenker, 703-H

W. B. Van-Pelt, 704-S

J. P. Vaughan, 773-41A

T. L. White, SRNL

G. G. Wicks, SRNL

M. F. Williams, 999-1W 